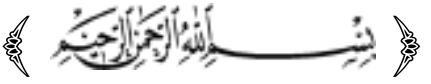

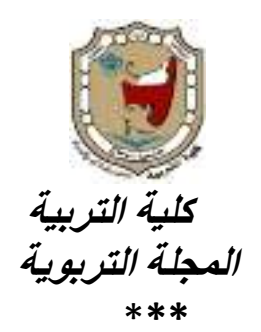

درجة هماراسة القيادات البامعية لأبعاد الإدارة الرشيقة وعلاقتها بفاعلية الأداى الوظيفي هن وجهة نظر أعضاء هيئة التدريس بجامعة الوادي البديد

$$
\begin{aligned}
& \text { إعداد } \\
& \text { د / أسماء أبو بكر صلديق عبل الله } \\
& \text { مدرس بقسم أصول التربية } \\
& \text { كلية التربية - جامعة الوادي الجديد }
\end{aligned}
$$

DOI: 10.12816/EDUSOHAG. 2020.

$$
\text { المجلة التربورية ـالعدد الثمانوز ـ ديسمبر م.r.r }
$$

Print:(ISSN 1687-2649) Online:(ISSN 2536-9091) 


\section{ملغص الدراسلة}

هدفت الاراسة الى تحديد درجة ممارسة القيادات الجامعية للإدارة الرشيقة بجامعة الوادي الجديد ، وتحديد درجة فاعلية الأداء الوظيفي لاي القيادات الجامعية بالجامعة، لإدائه والكثف عن العلاقة بين درجة ممارسة القيادات الجامعية للإدارة الرشيقة وفاعلية الأداء الوظيفي ، بالإضافة الى الكثف عن الفروق حول درجة ممارسة القيادات الجامعية للإدارة الرشيقة وفاعلية الأداء الوظيفي التي تُعزى لمتغيرات (نوع الكلية-الجنس-الارجة العلمية) واستخدمت الدراسة المنهج الوصفي التحليلي، واستعانت باستبانة مكونة من محورين:

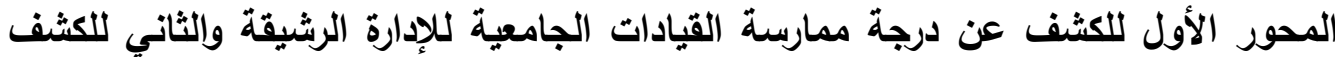

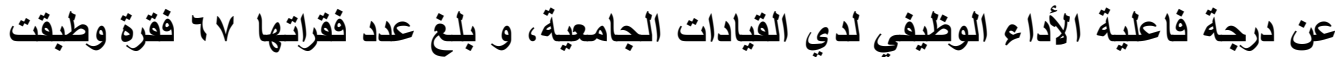
علي عينة قوامها IVV عضو هيئة تدريس من العاملين بالجامعة بنسبة هـ\%من مجتمع

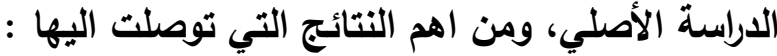

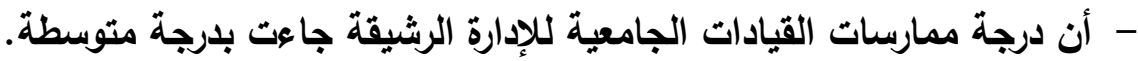

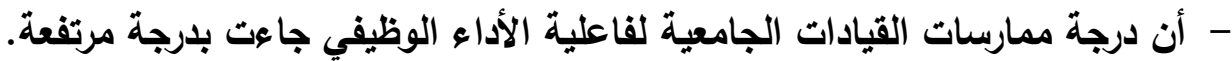

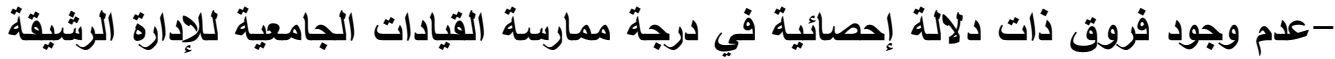
تعزي لمتغير نوع الكلية والجنس والدرجة العلمية. -عدم وجود فروق ذات دلالة إحصائية في درجة فاعلية الأداء الوظيفي لاي القيادات

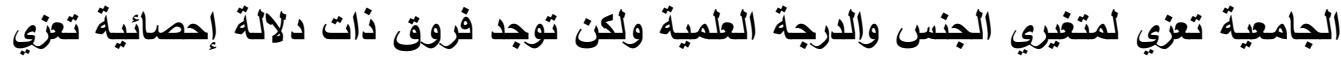
الي متغير نوع الكلية لصالح الكليات النظرية. ومن أبرز التوصيات التي أثشارت اليها الدراسة حث متخذي القرار بالجامعات

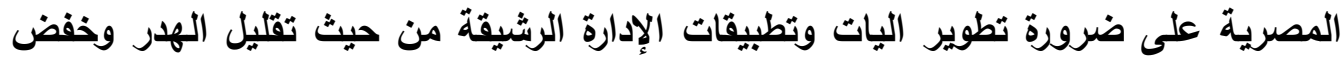
التكاليف وتعظيم الققرة التنافسية وتعزيز العمل القياسي وتطبيق مبادئ ستة سيجما بما يتناسب وقدرات وطاقات كل جامعة.

الكلمات المقتاحية: الإدارة الرشيقة-فعالية الأداء الوظيفي -القيادات الجامعية. 
The degree of practice university leaderships to the dimensions of agile Management and its relationship to Effectiveness of the job performance from the viewpoint of faculty Staffs at New Valley University

Dr. Asmaa Abdullah

Department of Foundations of Education

College of Education - New Valley University

\begin{abstract}
The study aimed to determine the degree of university leadership practice in agile management at the New Valley University, and to determine the degree of effectiveness of job performance among university leaders at the university, and to reveal the relationship between the degree of university leadership practice in agile management and the effectiveness of job performance, in addition to revealing the differences about the degree of university leadership practice in agile management And the effectiveness of the job performance that is attributed to the variables (type of college - gender academic degree) The study used the descriptive analytical approach, and it used a questionnaire consisting of two axes: the first axis to reveal the degree of university leadership practice in agile management and the second to reveal the degree of effectiveness of job performance among university leaders, and reached The number of its paragraphs is 67 , and it was applied to a sample of 127 faculty members working at the university, with $55 \%$ of the original study community. Among the most important results it reached:

- The degree of practices of university leaders in agile management came with a moderate degree.

- The degree of university leadership practices for job performance effectiveness came at a high level.

- There were no statistically significant differences in the degree of university leaders practicing agile management, due to the variable of college type, gender, and academic degree.

- There are no statistically significant differences in the degree of effectiveness of the job performance of university leaders due to the variables of gender and academic degree, but there are statistically significant differences attributed to the variable of the college type in favor of theoretical colleges.

Among the most prominent recommendations indicated by the study is the urging of decision-makers in the Egyptian universities on the need to develop agile management mechanisms and applications in terms of reducing waste, reducing costs, maximizing competitiveness and enhancing standard work and applying the principles of six sigmas in proportion to the capabilities and capacities of each university.
\end{abstract}

Key words: Agile management - Effectiveness of Job Performance University Leaders. 


\section{مقدمة}

باتت الإدارة ضرورة ملحة بل وواجبة التطبيق بثنى مناحي الحياة، كما ارتبط تقدم الدول والمجتمعات بتقام أنظمتها الإدارية القادرة على تحقيق أهدافها التنموية الاقتصادية والاجتماعية، بل لا يمكن لأي انسان ان يستظتي غنها في إدارة حياته.

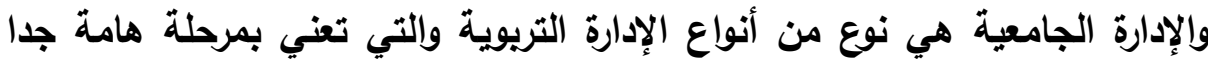
وهي مرحلة التعليم الجامعي، والتي تتميز بأنها المسؤولة عن تطوير نظام التعليم بالجامعة، فإن لم تكن هناك إدارة جامعية واعية ومستوعبة لأليات العصر وتقنياته ومجابهة المتغيرات وتطوير المجتمع فستكون عقبة أمام أي تطور جوهري، ويالتالي فإن إدارة جامعية ناجحة ومبدعة تغني مجتمع ناجح ومتطور . كما أنه لكي تتحقق أهداف التعليم الجامعي لابد من وجود نظام اداري فعال يستطيع

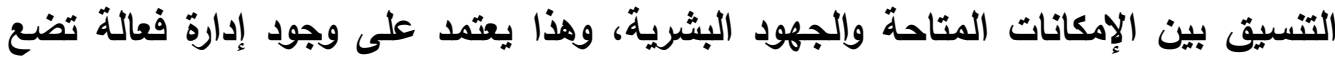
هذه الأهداف نصب أعينها، مما يستلزم الحاجة الي قيادة إدارية واعية منطلقة من تكامل النظرة الي المسؤولية والوعي المشروطين بالكفاءة والفاعلية. فالقيادة هي القلب النابض للعملية الادارية بالجامعة وجوهر نجاحها، فالجامعات تستطيع قياس مدى نجاحها وكفاءتها من خلال معاملة القيادة الإدارية للأفراد العاملين بها، فكلما كانت القيادة كفء وجيذة وتتعامل بشكل جيد مع مروئوسيها ينعكس ذلكت بشكل إيجابي على الجامعة ككل وتستطيع أن تحقق أهدافها. والجامعات اليوم مثلها مثل بقية المنظمات المجتمعية تواجه تحديات وتهايدات خارجية كثيرة بالغة الخطورة ناشئة عن المتغيرات المتسارعة في التقتية وما صاحبها من التهات انفجار معرفي ومعلوماتي وانفتاح إعلامي وتوجه نحو التخصيص وحرية اتصال، وزيادة وعي المستقيدين بحقوقهم مما شكل ضغوطات على هذه الجامعات لتحسين جودة منتجاتها وخرجيها وعملياتها الادارية، ورفع مستوي أدائها الوظيفي. واذا كانت القيادة الجيدة للجامعات تأتي ضمن العوامل المساعدة على التصدي لمثل هذه التحديات، فلا بد لهذه القيادة أن تكون جاهزة للتغير وقادرة على تكييفه والتكيف معه، وأن تكون قيادة واعية لديها القدرة على التفكير والتنظيم والقدرة على إدارة المعرفة المتدفقة

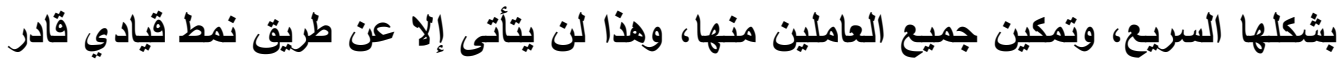


على التعامل مع كل هذه المتغيرات ليس بشكل فردي، بل عن طريق العمل الجماعي والثقة المتبادلة بين القائد ومرؤوسيه، وذلك عن طريق تحفيزهم على إنجاز أعمال لم يكن من المتوقع أن يعملوها أصلا بلون وجود هؤلاء القادة. والمستطلع للواقع الحالي للجامعات المصرية يجد أن وزارة التعليم العالي المصرية بذلت العديد من الجهود لرفع مستوي الأداء الوظيفي لقياداتها الجامعية تمثلت في تقديم برامج لتدريب القيادات في إطار الدورات التدريبية التي يقدمها مشروع تنمية قدرات أعضاء هيئة التدريس، والذي هدف الي تنمية وتحديث القدرات والمهارات الإدارية للقيادات الاكاديمية والكادر الإداري بما يمكنهم من احداث التغيير المستهذف بنجاح، وتطوير الخبرات الأتية في مجال الإدارة الجامعية لمؤسسات التعليم العالي التي تحقق استمرارية عملية التطوير(وزارة

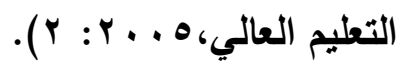
إلا ان العديد من الدراسات اشارت الي العديد من أوجه القصور بدورات تنمية قدرات أعضاء هيئة التدريس بالجامعات المصرية فيما يتعلق بالقيادات الجامعية منها دراسة (علا

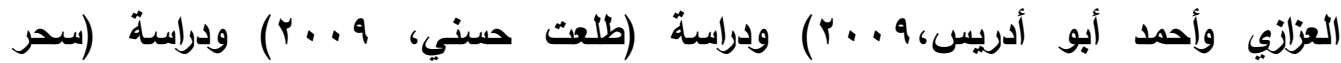

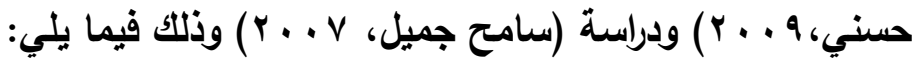
ا - يوجد نقص في عدد الدورات التدريبية التي تنفذ لفئة القيـادات الجامعية مقارنة بياقي الفئات المستهدفة. r- نمطية البرامج وعدم التركيز على المستحدث في الإدارة والقيادة الجامعية وتدريبهم على كيفية ممارسة مهامهم المستقبلية بالقيادة بما يتلاءم والتطور المنشود. r- تركز البرامج على الجانب النظري، لذا تقتصر طرق التدريب المستخدمة على المحاضرة والمناقشة، كما يقتصر الجانب العملي إن وجد على ورش العمل فقط.

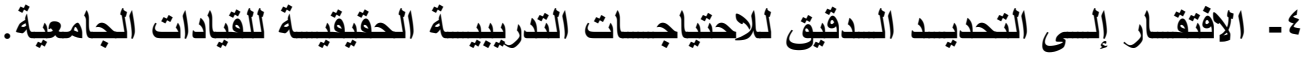
ويالنظر الي الجهود العالمية والعربية في ذلك المجال نجد أن معظم الجامعات العالمية والعربية ركزت على تدريب وتهيئة هؤلاء القادة الجامعيين وإتحداث أنماط ونظريات إدارية جليدة، لأن ذلك أصبح جزعاً لا يتجزأ من عملية التطوير والتنمية التي يقع على عاقتها إيجاد أجهزة إدارية صالحة للعمل تحت قيادة تتمتع بالكفاءة والقدرة على الإنتاجية العالية، فتنمية الأفراد العاملين في الجامعات وتدريبهم، وتحسين قراتهم ومهاراتهم وسلوكهم يعتبر أمراً 
ضرورياً للنهوض بالجامعة والأفراد على السواء والتي تتطلب مستوى عال من الكفاءة والقدرة والتي لا يمكن توفرها بالاعتماد على القدرات الطبيعية والاستعدادات الفطرية وحدها، أو عن طريق اكتساب خبرات بشكل فردي، وإنما عن طريق التدريب المنظم والبرامج المعدة إعداداً

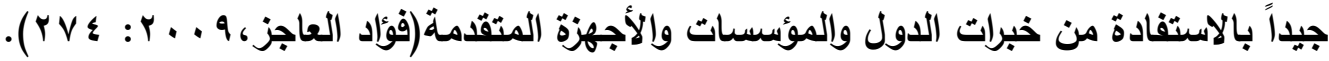
ولقد ظهرت في الآونة الأخيرة العديد من العلوم والمفاهيم الجديدة المرتبطة بعلم القيادة والإدارة وإلتي كان لها الدور الأكبر في توجيه التنافس في مراحل التحول المذكورة، والتي كان من أبرزها مفهوم الإدارة الرشيقة، والتي ترتكز على مرونة الأداء والعمل على تقليل التكاليف تهاتي تهن وتخفيض الهار، ويناء مجتمع معياري قياسي يحقى الموائمة بين رغبة الإنسان بالعمل ورغبته في تحقيق هدف أخر يجسد له التحكم والسيطرة، كما في هدف استقطاب الطاقات البشرية وتوظيفها وتدريبها (إبراهيم باداود، • Y • r). ويمراجعة التظور التاريخي لمفهوم الإدارة الرشيقة يجد ان الظهور الحقيقي له كان مع بداية التسعينات من القرن الماضي عندما ظهر مفهوم الإنتاج الرثيق والذي يسعي إلي إعادة دراسة كامل مسار العملية الإنتاجية، والتخلص من كل نشاط لا يضيف قيمة للمستفيدين، ثم ما لبثت فكرة الإنتاج الرشيق أن تحولت إلى فكر شامل يطبق في كافة المجالات وأنشطة الأعمال كالمجالات الخدمية الطبية والتعليمية حاملاً نفس المضمون، وتحقيق أفضل أداء من خلال أفضل مخرجات لينشأ مفهوم ثقافة القيمة المضافة فتشكل مفهوم الإدارة الرشيقة، وهي فلسفة إدارية حديثة تقوم على أساس تحقيق القيمة القصوى للمستفيد من خلال الحد من الهار والنفايات والانتظار(عبدالقادر مسلم وشذا أبو

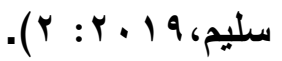

ومصطلح الإدارة الرشيقة "Lean management" يعني أن المنظمات التي تريد الاستدامة والاستمرارية والبقاء طويلا تعتمد على مدى رشاقتها؛ والرشاقة هنا تعني القدرة والبقاء والازدهار في بيئة تنافسية متغيرة والتفاعل بسرعة مع الأسواق المتغيرة وإنتاج خدمات ومنتجات جديدة غير متوقعة والاستفادة من خبراتها في اقتناص الفرص التسويقية، وتجنب التهديدات لتكون الأساس للنجاح المنشود، والاستدامة، وتعزيز وإعادة تحديد القيمة من عملياتها وأنشطتها ومنتجاتها وخدماتها مقارنة بالمنافسين (Sherehiy,2008 ). 
ولقد طبق مفهوم الإدارة الرشيقة في البداية على أنظمة الإنتاج في شركات السيارات Toyota production system" "International motor ويالتحديد شركة تويوتا " vehicle program" "ثم انتقل الي مجال الإدارة وحقق نجاحا فيها ثم الي تكنولوجيا المعلومات والاتصالات ثم القطاع الصحي ومجال التعليم ومنه الي مجال التعليم الجامعي (رزق رزقي ومحمد قريشي، 9 ـ ب : r ). وحاليا الإدارة الرشيقة علم مطبق في كل دول العالم المتقدمة، وتتفذه معظم الشركات الكبيرة في العالم، وتقوم فلسفته على القضاء على الهدر باستمرار في جميع العمليات الادارية، من خلال التحسين الصغير والمستمر والتدريجي، وتحسين الجودة وتقليل العيوب في العملية الإنتاجية والمخرجات والتركيز المستمر على تحقيق رضا العملاء، وهو يتطلب تحولا في القيادة بشكل أساسي، وإدارة قوية ومنظمة وفعالة لتقوية مبادئه، وتقديم الإرشادات، وضمان استخدام أسلوب الإدارة الجديد لتحسين النظام التظيمي بأكمله، فكأن الجانب الأكثر صعوية وأهمية في التحول الي استخدام منهج الإدارة الرشيقة هو تغير أسلوب الادارة والسلوكيات وطرائق تفكير الناس والثقافات التنظيمية بدلا من التغيير في الأدوات والعمليات والأنظمة (Nylund 2013: 7) ). ويذلك فقد جسد مفهوم الإدارة الرشيقة أحد أبرز أدوات الجودة في تقديم الخدمة

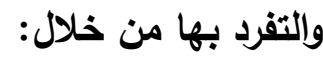
أولا: الجمع بين تعاليم المكان الجامد وتطوير العمل المتسم بالمرونة، ثم من خلال اعتماد

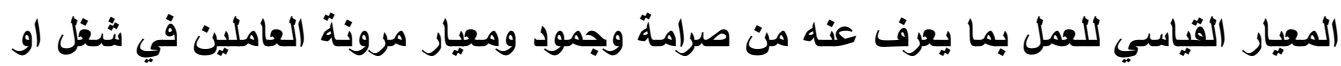
اكتساب مهارة أكثر من عمل في آن واحد. ثانيا: الولوج في قطاعات كاتت تعتبر خطوطا حمراء على مفاهيم التنافس التجاري، الا وهي

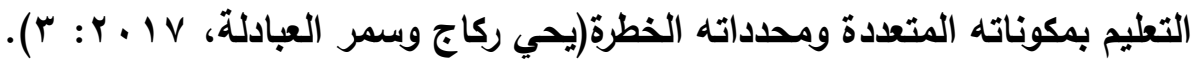
ويما أن النمط القيادي السائد داخل أي مؤسسة ومنها الجامعات سواء واء أكان إداريا او أكاديميا يؤثر بشكل فعال في السلوك الإنساني وأداء العاملين، ويساعد على تحفيز الموظفين وزيادة فاعليتهم وتحقيق اعلي مستويات الإنتاجية ورفع مستوي الأداء الوظيفي

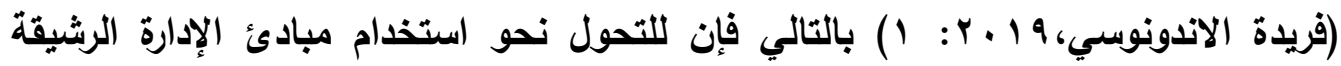


داخل الجامعات سيكون له إثر كبير في رفع وتحسين مستوي الأداء الوظيفي للعاملين بالجامعة.

في ضوء ما سبق تحاول الدراسة الحالية التعرف على مفهوم الإدارة الرشيقة واليات تطيقها، ثم التعرف على الواقع الحالي لممارسة القيادات الجامعية بإحدى الجامعات المصرية وهي جامعة الوادي الجديد للإدارة الرشيقة من وجهة نظر أعضاء هيئة التدريس وعلاقتها بفعالية الأداء الوظيفي، ووضع مجموعة من التوصيات للعمل بهذا النظام الإداري الحديث بالجامعات المصرية.

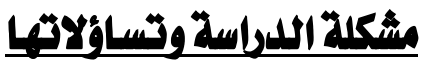

يتميز النظام العالمي الجديد بحركته السريعة لكي يلاحق التغيرات والتقتيات والتحولات والتكنولوجيا المتغيرة مما يتطلب من المنظمات المجتمعية بكافة أشكالها ومنها الجامعات ضرورة التغير لضمان تميز أدائها واستمرارية تنافسيتها. وتعتبر القيادات المحرك الأساسي والعمود الهام الذي ترتكز عليه مختلف النشاطات في أي منظمة، ومن ثم يجب علي تلك القيادات أن تكون علي مستوي التحديات التي وضعت أمامها، فهي مطالبة في ظل هذه البيئة التنافسية أن تعيد النظر في أساليب القيادة التقليدية، وإعطاء المفاهيم الإدارية الحديثة التي تحث علي الابتكار والتجديد اهتماما أكبر بحيث تكون

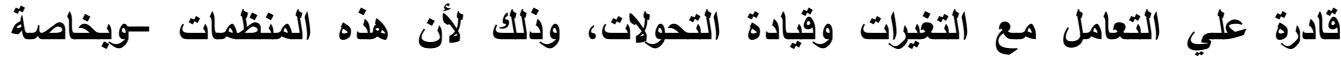

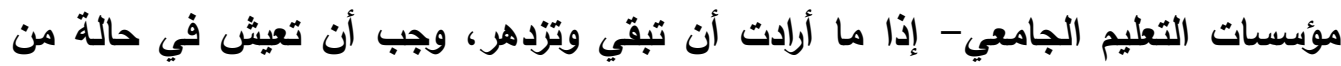
الديناميكية والتطور السريع في وقت أصبح فيه التغير المتسارع والتعقيد المتزايد صفتان متلازمتان لمنظمات القرن الجديد.

وتعد القيادات الجامعية من أبرز أعضاء المنظومة الإدارية الجامعية ومن اهم عناصرها حيث تتسم القيادات الجامعية في المؤسسة الجامعية ممثلة بمختلف كلياتها

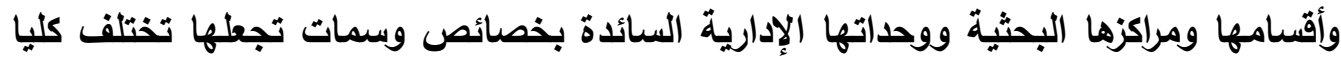
عن القيادات لمؤسسات إنتاجية أو خدمية اخري الامر الذي يظهر تأثيره على معايير وأليات

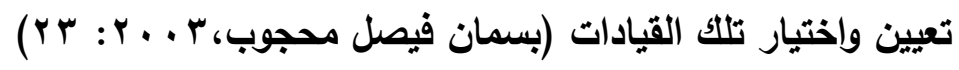

الا أن المتطلع للواقع الحالي للجامعات المصرية يجد أنها مثلها مثل باقي الجامعات في الدول النامية تواجه العديد من أوجه القصور وخاصة فيما يتعلق بالنواحي الإدارية 
والقيادية، وأن هُنَك العديد من العوامل التي أدَّت إلى ضَعف أداء القيادات الجامعية الأكاديمية

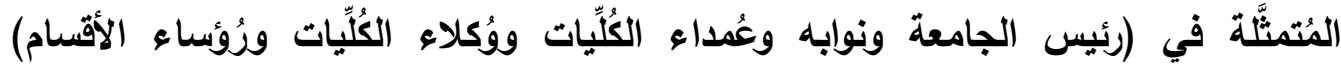
والقيادات الإدارية المتمثلة في (أمين الجامعة ومديري الإدارات المختلفة) وذلك في النواحي التالية التي أثنارت اليها العديد من الدراسات منها: 1. قصور الإعداد الإداري للقيادات الجامعية. r. ت تأكيد العمل القردي أكثر من الميل إلى جهود الفريق.

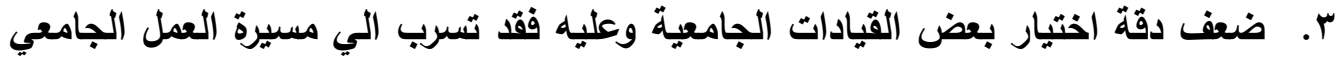
قيادات تغيب عنها المصداقية وتحاول الاحتفاظ بمواقعها بكل الأساليب عملا بميثاق الغاية تبرر الوسيلة ومن هنا تجئ شدة التمكك بالمنصب على حساب المصلحة العامة وجدية الأداء.

؛. آلية اختيار القيادات الاكاديمية والإدارية تعتمد مبدأ الثطارة بدلا من مبدأ الجدارة.

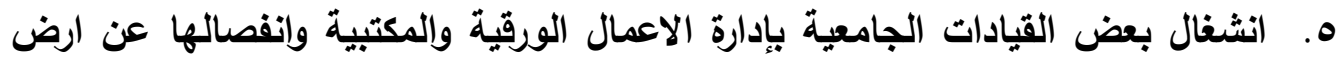
الواقع ووقوعها فريسة للذاع المؤسسي الذي يبدأ من القاعدة والمقربين (محمد عبد

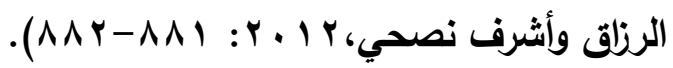
I. التداخل الوظيفي الناتج عن غياب التوصيف الوظيفي وعدم وضوح الاختصاصات (عادل

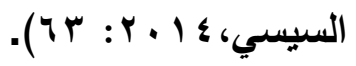

V. ضعف قررة القيادات الجامعية في المستويات الجامعية المختلفة على المبادرة نحو التغيير والتطوير عند الاقتضاء واتباعهم لتوجيهات السلطة الأعلى دون الاهتمام بالنتائج المراد تحقيقها، ويالتالي مسايرة الأوضاع القائمة والإبقاء على حالئة الجاءئل الجمود

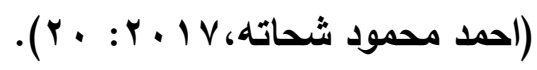

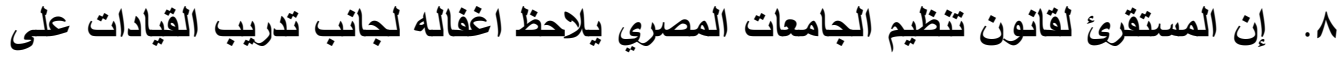

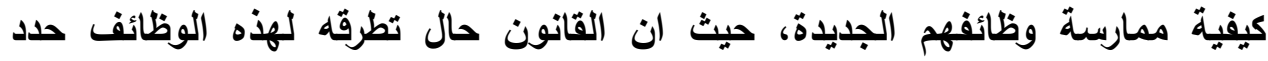
مهامها ولم يحدد ما تستجويه من تأهيل وما تحتاجه من مهارات (سامح جميل عبد الفاند

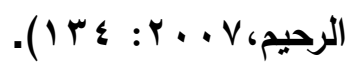


9. قصور عمليات التقويم للقادة التريويين وتقويم البرامج التأهيلية، حيث يتم الاكتفاء بحضور البرنامج في اغلب الأحيان وينعدم التقويم المستمر لهؤلاء القادة (اميل فهمي

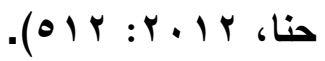

• 1 . وجود فجوة متكررة في الرؤي بين القيادات من هيئة التدريس والقيادات من الإداريين

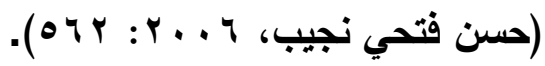

11. قصور إدارات الجامعات فما زال بعض منها يمارس بعض السلوكيات التي تعوق تطبيق إدارة الجودة الثاملة ومنها عدم اشراك المرؤوسين في اتخاذ القرارات والتسلط والاندفاع والاهتمام بالمصالح الفردية.

r ا. القيادة الجزئية والتي تظهر في تركيز قيادات الجامعة على الموضوعات الخارجية أكثر من تركيزها على الموضوعات الداخلية والذي يكون له تأثير غير مرغوب على ايه عملية

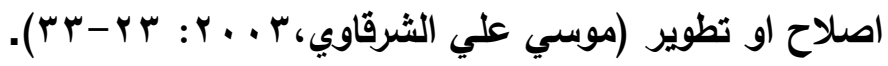

rا.تسيطر المركزية على أداء القيادات الاكاديمية والادارية مما يسلبها حرية المبادرة والتطوير

ع ا. عدم استقرار الهياكل التظيمية مع الظلل في العلاقات الوظيفية نتيجة للصراع على

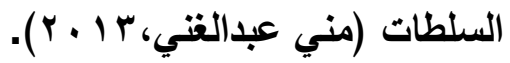

ويسبب تعدد أوجه النقص والقصور التي تعاني منها القيادات الجامعية فإن نتائج العديد من الدراسات أوصت بضرورة الاهتمام بتحديث الأساليب الإدارية بالجامعات ورفع الجدارة المهنية للقيادات المختلفة مثل الجدارة القيادية والإدارية والقنية(امل علي العدية

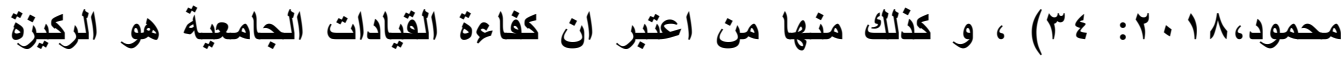
الأساسية للنمو والتقلم والتظور بمؤسسات التعليم العالي، وهذا يتطلب منهم مجموعة من المهارات والقدرات والمعارف المتطورة والمتجددة والتي تتناسب مع المتغيرات المعاصرة، والذي

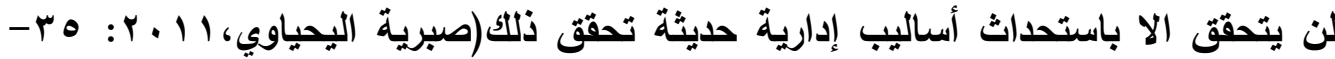
هـ) ، ومنها من اكد علي ضرورة استخدام أساليب إدارية حديثة لضمان اعلي مستوي من

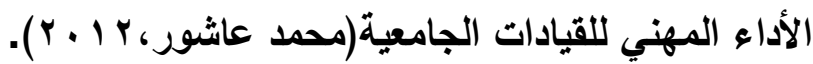
ويالتالي تكمن مشكلة الدراسة الحالية بأنه في ضوء الاتجاهات الادارية المعاصرة لم تعد الإدارة عملاً مكتبيا فقط ولم يعد القيادات الجامعية اصحاب السلطة والتسلط 
والمتواجدين في مكاتبهم يعقدون الاجتماعات ويقروئون التقارير المرفوعة إليهم بل أصبح على القيادات ان يعايشوا مرؤوسهم بالحوار والاتصال المباشر معهم والمتابعة الفعلية لما يقومون به ، وهذا ما يمكن تحقيقه من خلال اساليب واليات ادارية حديثة من خلال التواجد في المواقع التفيذية، والتعرف على المشكلات وكيفية التعامل معها والاهتمام بمفاهيم فريق العمل ونشر ثقافة منع الإهدار وتقليل الضائع والتالف في استخدام الموارد من خلال الأنشطة المختلفة للعمل، بحيث تعمل علي رفع مستوي فاعلية الأداء الوظيفي لمرؤوسيها ، وهو ما تصبو إليه الحاجه في هذه الاراسة من خلال التعرف علي مدي ممارسة الإدارة الرشيقة لدي

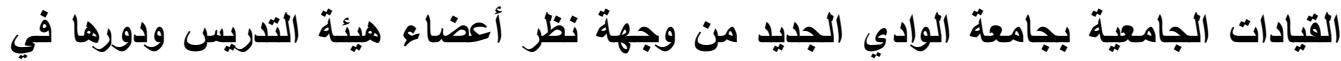
رفع مستوي فاعلية الأداء الوظيفي محاولة التوصل الي مجموعة من التوصيات لتطبيق مفاهيم الإدارة الرشيقة بما يرفع جودة الأداء بالجامعة.

في ضوء ما سبق تحاول الاراسة الحالية الإجابة عن التساؤل الرئيس التالي:

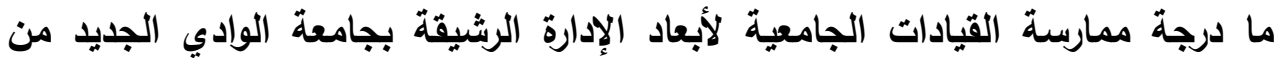
وجهة نظر أعضاء هيئة التدريس بها؟ وما علاقة هذه الممارسة بفاعلية الأداء الوظيفي فيها؟ ويتفرع من هذا التساؤل الرئيس، الأسئلة الفرعية التالية: - ما الإطار الفكري لأبعاد الإدارة الرشيقة؟ وما علاقتها بفاعلية الأداء الوظيفي بالجامعات؟ - ما واقع ممارسة القادة الجامعيين للإدارة الرشيقة بجامعة الوادي الجديد من وجهة نظر أعضاء هيئة التّريس؟ مهمب - ما واقع فاعلية الأداء الوظيفي لاي القادة الجامعيين بجامعة الوادي الجديد من وجهه نظر أعضاء هيئة التدريس؟ -هل توجد فروق ذات دلالة إحصائية حول درجة ممارسة القادة الجامعيين للإدارة الرشيقة من وجهه نظر أعضاء هيئة التدريس بجامعة الوادي الجديد وفقا لمتغيرات الدراسة؟ -هل توجد فروق ذات دلالة إحصائية حول درجة ممارسة القادة الجامعيين لفاعلية الأداء الوظيفي من وجهه نظر أعضاء هيئة التدريس بجامعة الوادي الجديد وفقا لمتغيرات الدراسة؟ 
- هل توجد علاقة ارتباط موجبة ذات دلالة إحصائية بين " درجة ممارسة الإدارة الرشيقة وفاعلية الأداء الوظيفي لدي القادة الجامعيين بجامعة الوادي الجديد من وجهه نظر لونه أعضاء هيئة التذريس وفقا لمتغيرات الدراسة - ما السبل المقترحة لتفعيل أسلوب الإدارة الرشيقة لاي القيادات الجامعية بجامعة الوادي الجديد من وجهة نظر أعضاء هيئة التدريس بما يعمل على تحقيق فاعلية الأداء الوظيفي للقيادات الجامعية؟

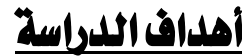

تهذف الاراسة الحالية الي التعرف على درجة ممارسة القيادات الجامعية للإدارة الرشيقة وعلاقتها بفاعلية الأداء الوظيفي من وجهه نظر أعضاء هيئة التدريس بجامعة الوادي الجديد كما تسعي الي تحقيق الأهداف التالية: 1. تقديم إطار نظري تعريفي لمفهومي الإدارة الرشيقة وفاعلية الأداء الوظيفي والعلاقة بينهما. r. التعرف على درجة ممارسة القيادات الجامعية بجامعة الوادي الجديد للإدارة الرشيقة من وجهة نظر أعضاء هيئة التدريس. r. التعرف على واقع فاعلية الأداء الوظيفي لاي القيادات الجامعية بجامعة الوادي الجديد من وجهاه نظر أعضاء هيئة التدريس. ؛. . التعرف على الفرق بين استجابات عينة الدراسة حول متغيرات الدراسة تعزي للعوامل (نوع الكلية، الجنس، الارجة العلمية). ه. التعرف على ما إذا كانت هناك علاقة ارتباطية موجبة بين درجة ممارسة الإدارة الرشيقة وفاعلية الأداء الوظيفي. مان. צ. التوصل الي مجموعة من التوصيات والمقترحات التي من شأنها تفعيل الإدارة الرشيقة

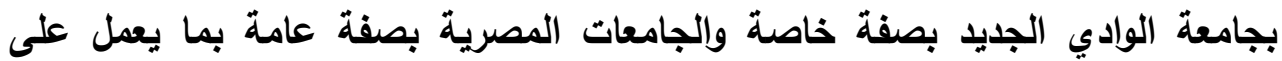
تحقيق فاعلية الأداء الوظيفي للقيادات الجامعية. 


\section{أهمية اللدراسة}

تتبع أهمية الدراسة الحالية في تناولها لموضوع من الموضوعات الحديثة وهو الإدارة

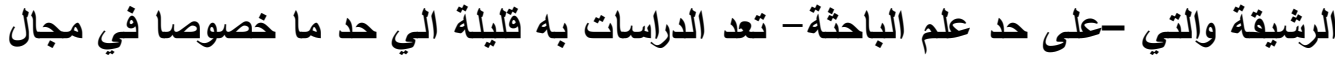
التعليم الجامعي، ويالتالي محاولة اثراء الدارات التي التيات أجريت في ذلك المجال، كما تبرز

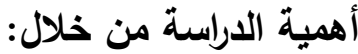
ا قد تسهم في توجيه انظار الباحثين لإجراء المزيد من الدراسات التطبيقية في هذا المجال. r قد تساهم من خلال النتائج والتوصيات في تعزيز وتحسين الخدمات التي تقدمها القيادات الجامعية بالجامعات المختلفة.

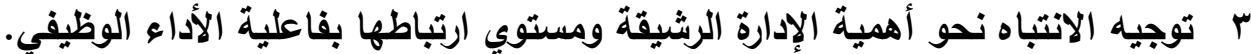
؛ الاطلاع على واقع الإدارة الرشيقة بجامعة الوادي الجديد-ورصد جوانب القوة والضعفوتطبيقاتها بداخل الجامعة.

ه تقليم توصيات تساعد على تطبيق مبادئ الإدارة الرشيقة بالجامعات المصرية. 7 إدارية حديثة ترفع من مستوي جودة أداء القيادات الجامعية بالتعليم الجامعي.

\section{اللداسات السابقة:}

سوف يتم تقسيم الدراسات السابقة الي محورين، الأول يتناول الدراسات السابقة المرتبطة بالإدارة الرشيقة، والثاني يتناول الداراسات السابقة المرتبطة بفاعلية الأداء الوظيفي

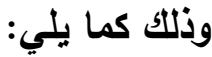

\section{أولا : اللدراسات التي تناولت الإدارة الرثيقة}

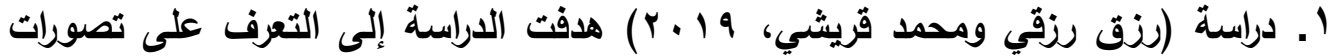
عينة الدراسة حول مستوى توفر الإدارة الرشيقة بالمؤسسة الاستثفائية المتخصصة و اثر ذلك على أدائها وتكون مجتمع الدراسة من جميع الموظفين بالمؤسسات السابقة البالغ عددهم (10) وتم التطبيق علي عينة عشوائية حجمها (•0) موظف وتم استخام الاستبيان كأداة للاراسة من اعداد الباحث، وخلصت الدراسة إلى عدة توصيات ينبغي الاهتمام بها حتي تلعم تطبيق مبادئ الإدارة الرشيقة وتؤدي الي نجاحها منها

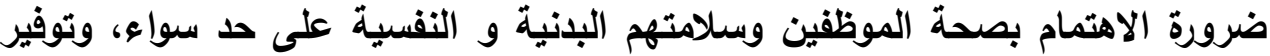


نظام معلومات شامل ،بسيط وفعال متاح نسبيا لكافة الموظفين وحثهم على تبادل و مشاركة المعلومات بما يخدم المصلحة العامة وعدم عرقلتها، وتظوير إمكانيات الموظفين من خلال إقامة برامج تدريب متنوعة تمس كل التخصصات و منحهم فرص عديدة وعادلة للحصول على تكوين أو التدريب اللازم.

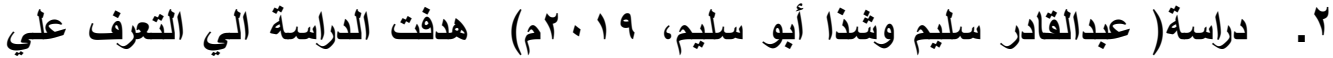
دور الإدارة الرشيقة في تحقيق الابداع وييان مدي توافر أدوات الإدارة الرشيقة ، وتحديد

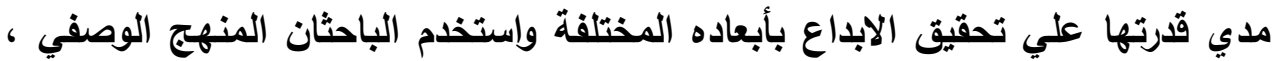
وطبقت الاراسة علي شركة جوال بقطاع غزة، والبالغ عددهم ه1 موظف، واستخدمت الاستبانة كأداة للاراسة ، وخلصت الي مجموعة من النتائج أهمها يوجد اثز لأدوات الإدارة الرشيقة وعناصر الابداع في شركة جوال ويوصي الباحثان بعدد من التوصيات أهمها إعطاء شركة جوال اهتمام اكبر في تطبيق أدوات الإدارة الرشيقة وخاصة التحسين المستمر ، وكذلك توافر العاملين متعددي الوظائف .

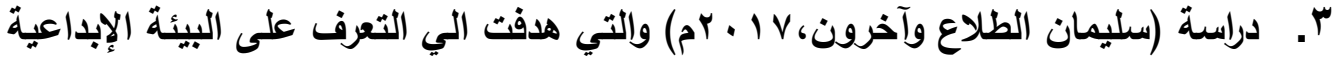
وعلاقتها بالإدارة الرشيقة في الكليات التقتية بفلسطين، وقد تم استخدام المنهج الوصفي التحليلي، من خلال استبانة تم توزيعها علي عينة مكونة من 9 ×^من العاملين بالكليات التقنية بفلسطين، واظهرت النتائج وجود نسبة مرتفعة من مناخ تطبيق البيئة الإبداعية بتلك الكليات كذلك وجود مستوي مرتفع من تطبيق الإدارة الرشيقة.

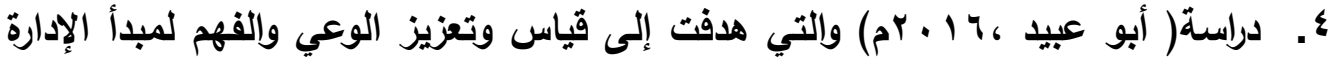
الرشيقة في صناعة الانشاءات الفلسطينية، واعتمدت الدارسة بشكل أساسي على المنهج الوصفي التحليلي وأسلوب الدارسة الميدانية، حيث تم تصميم استبيان تم تطبيقه علي شركات المقاولات في الضفة الغربية ، وتوزيعه علي عينة مكونة من سه ا شركة للمقاولات، ومن أهم النتائج التي توصلت اليها ان هناك مجموعة من العوامل تدعم نجاح الإدارة الرشيقة تخص الموارد البشرية مثل سلوك الموظف الإيجابي والخبرات والمعلومات بالإضافة الي عوامل خاصة بالمؤسسة مثل ثقافة المؤسسة والتدريب والتتسيق والاتصال وفي نهاية الدراسة تم ريط كل هذه العوامل بإطار عمل يوضحها ويوضح اثرها علي نجاح تطبيق الإدارة الرشيقة. 
•. دراسة (بن وارث وجابة، 17 • Yم) والتي هدفت الي تسليط الضوء علي مفهوم الإدارة الرشيقة، واستعرضت مختلف اشكال الهـر التي يمكن أن تواجه المؤسسات خلال العمليات الإنتاجية ، واستخدمت المنهج الوصفي التحليلي، وتم استخدام الاستبيان كأداة للاراسة والذي طبق علي المؤسسات الصيدلانية الجزائرية ومن أهم النتائج التي توصلت لها ان الإمكانات الأساسية المتوفرة بجميع تلك المؤسسات تدعم وتشجع استخدام الإدارة الرشيقة كذلك السياسة التدريبية، الا ان العائق الأكبر يتمثل في غياب روح التعاون بين الإدارة والعمال في تطبيق هذه الإدارة.

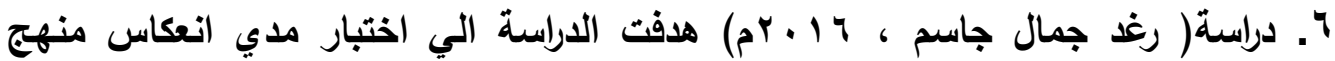
الإدارة الرشيقة علي ممارسات إدارة الموارد البشرية في اثثين من أهم شركات الاتصال العاملة في العراق هما زين -اسيا سيل وقد استعملت الاستبانة أداة رئيسة للحصول علي البيانات والمعلومات فضلا عن المشاهدات من خلال الزيارات الميدانية لموقع الثركتين، إذ وزعت علي عينة عشوائية مكونة من · ه فردا من العاملين في قسمي الموارد البشرية وخدمة العملاء في الشركتين محل الدراسة ولقد توصل الباحثان الي مجموعة من النتائج أهمها ان النتائج الإحصائية لجميع علاقات الارتباط والتأثير بين أدوات الإدارة الرشيقة وممارسات إدارة الموارد البشرية كانت موجبة وذات دلالة معنوية ولا توجد فروق معنوية بين الشركتين محل الاراسة في مجال تطبيق أدوات الإدارة الرشيقة وممارسات الموارد البشرية. V. دراسة (Anne-Caroline Golard,2015) هدفت الباحثة من الاراسة الي الإجابة عن مجموعة من الأسئلة هي ماذا يعني احترام الموظفين في شركة تطبق الإدارة الرشيقةكيف يتم فهم هذه المقارية الموضوعية-ما هي جوانب الاحترام التي يمكن بلورتها من خلال أبعاد العدالة التظيمية، وتوصلت الباحثة الي ان احترام الموظفين في منظمة تطبق الإدارة الرشيقة يمكن تحليله من خلال الابعاد الأربعة للعدالة التظظيمية لان جميع الجهات الفاعلة تشير علي الأقل مرة واحدة للعدالة، وخلصت في النهاية الي انه من الجيد

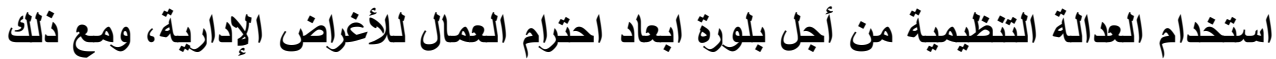
فقد اكلت أن اطار التحليل هذا لا يكفي لأنه لا يسمح بتوحيد كل التصورات من حيث مفهوم الاحترام. 
^. دراسة (Niccolo Curatolo , 2014 ) استهدفت الدراسة التعرف على مدي تأثير تطبيق معايير الإدارة الرشيقة علي أداء الممارسين الطبين والاداريين ويالتالي الي تحسن العمليات وتوفير الوقت والموارد كطريقة جيدة للاستثمار داخل المؤسسات الطبية ، والذي توصلت الاراسة من خلال الي وجود علاقة مرتفعة فيما بينهر. 9 9. دراسة(Sparrow \& Otaye, 2014) هدفت الدراسة الي تحديد العلاقة بين التفكير الرشيق ودور إدارة الموارد البشرية في تحقيق الاستدامة الرشيقة والتي قد تؤدي الي لئي تغيرات في رأس المال الفكري المحيط بالتفكير الرشيق والخبرات الأساسية الجيديدة، واستندت الدراسة الي 11 مقابلة مع كبار المديرين المسئولين عن نثاط الإدارة الرشيقة واستراتيجية الموارد البشرية في ץ 1 منظمة بالاعتماد علي أسلوب دراسة الحالة للوصول

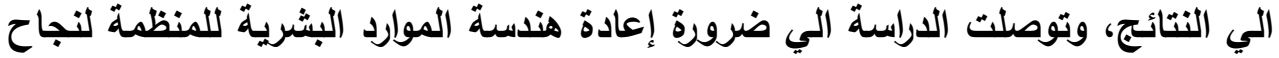
تنفيذ الإدارة الرشيقة من خلال اجراء تغييرات في مهارات وسلوكيات وكفاءات الموارد البشرية وكذلك تغييرات في ممارسات الموارد البشرية. • ا. دراسة ( Damrath,2012)هدفت الدراسة الي وضع اطار عام من الممكن استعماله كبديل مفاهيمي لتتفيذ مفهوم الإدارة الرشيقة في قطاع الخدمات، وكانت منهجية الدارسة وصفية أجريت لوصف مبادرات الإدارة الرشيقة في قطاع الخدمات مستخدمة الاستبانة

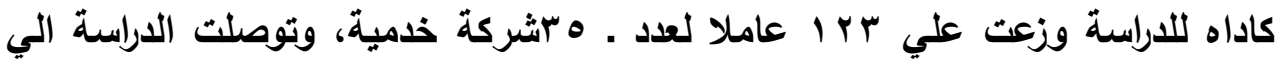
مجموعة من الاستتاجات أهمها إمكانية تطبيق الإدارة الرشيقة في قطاع الخدمات بالاعتماد علي عدد من الأدوات الرشيقة.

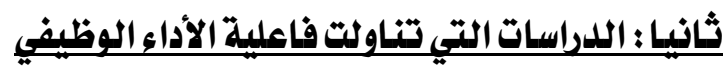

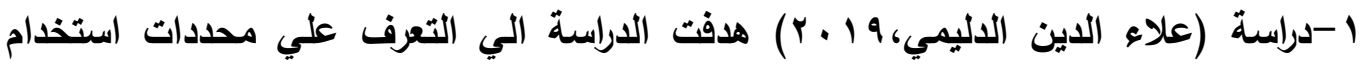
العاملين في المؤسسات الإعلامية الأردنية للتسويق المعرفي واثره علي فاعلية الأداء وفق النظرية الموحدة، وقد استخدمت الدارسة المنهج الوصفي الكمي الاستكثافي، وقد استخدم الأدئ

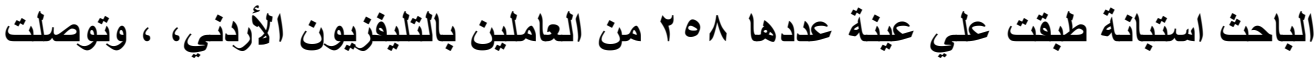

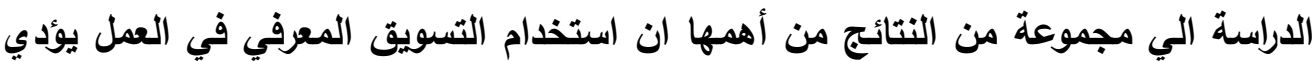

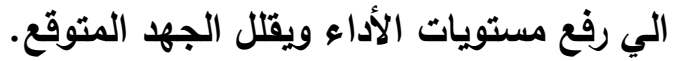




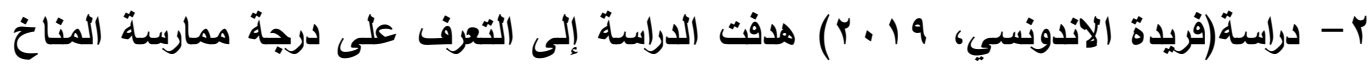

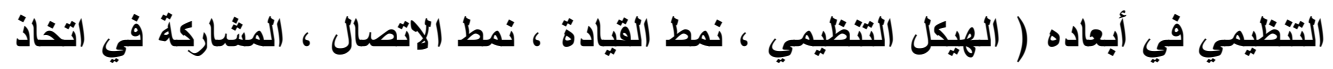

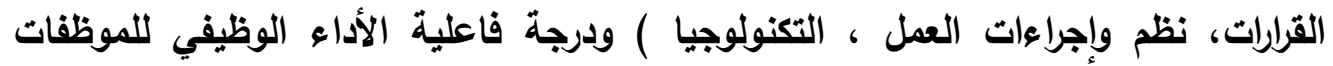

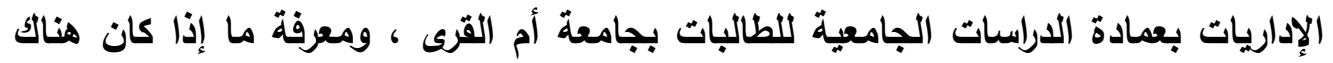

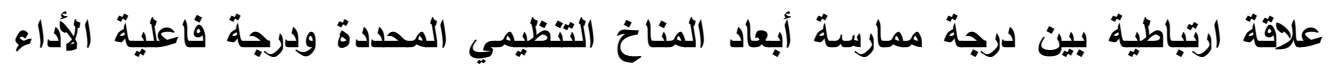

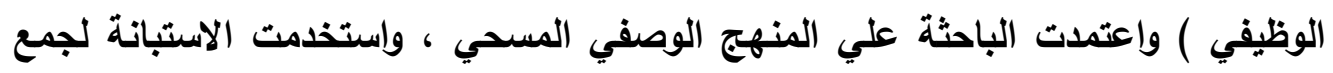

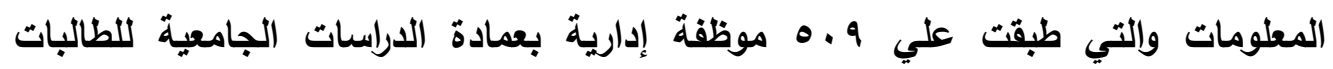

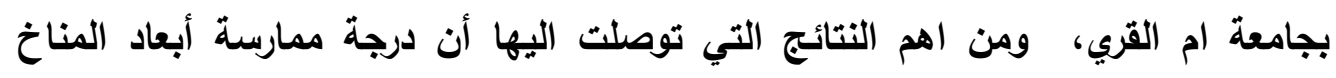
التظيمي جاءت بدرجة "متوسطة ".

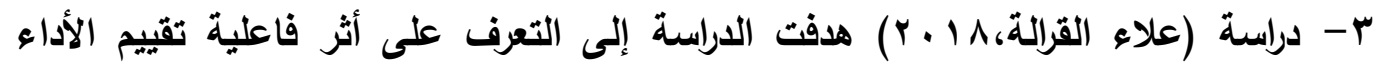

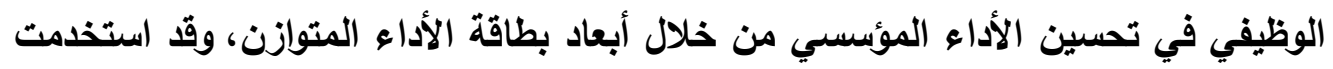
الدراسة الاستبيان كأداة لها والتي طبقت على عينة عددها بـ ؟ ؛ من العاملين بوزارة العدل

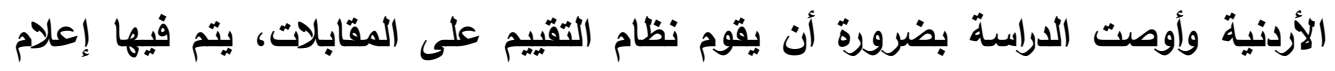

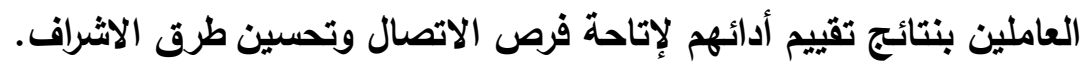

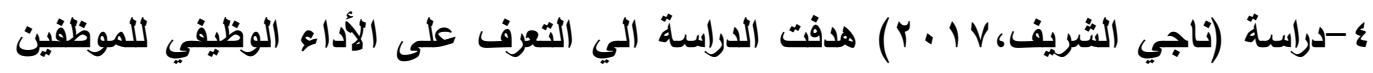

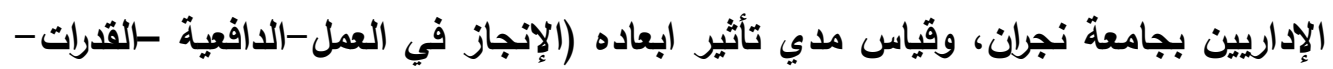

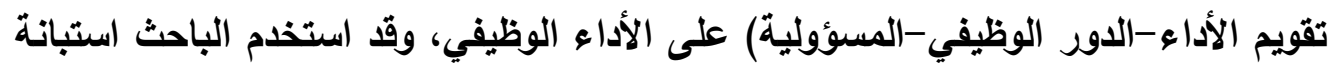

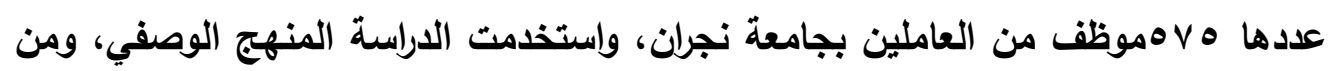
الهم النتائج التي توصلت اليها ان الأداء الوظيفي لاي العاملين بجامعة نجران جاء مرتفعا.

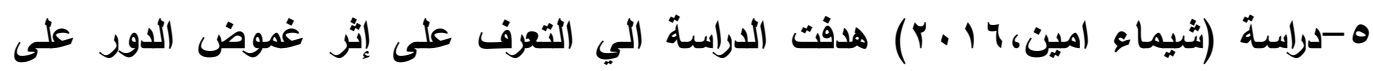

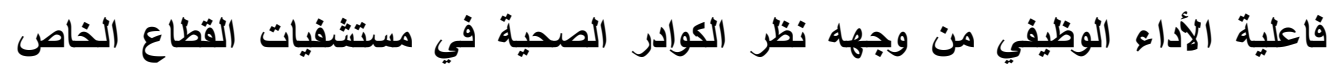

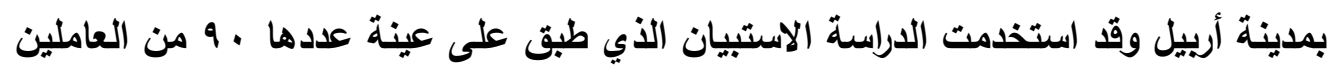
بالقطاع الصحي الخاص، واستخدمت الدراسة المنهج الوصفي ومن اهم النتائج التي توصلت

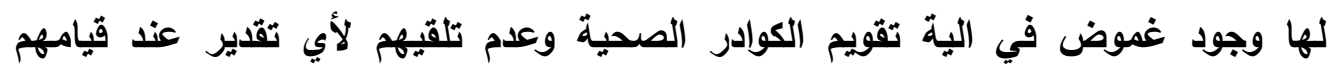

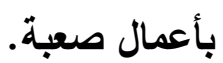




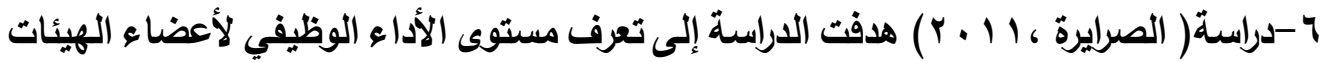
التدريسية في الجامعات الأردنية الرسمية من وجهة نظر رؤساء الأقسام فيها، واستخدم الباحث الاستبانة كأداة للاراسة طبقت على عينة مكونة من (VV) رئيس قسم أكاديمي ومن اهم التتائج التي توصلت اليها الدراسة أن مستوى الأداء الوظيفي لأعضاء الهيئات التدريسية كاتت مرتفعة، ودلَّت النتائج على عدم وجود فروق ذات دلالة تعود للمتغيرات (نوع الكلية ،النوع الاجتماعي، الرتبة الأكاديمية، سنوات الخبرة، مكان الحصول على الدكتوراه، الجامعة التي يعمل بها)، وأوصى الباحث بأن تقوم الجامعات بتعزيز الأداء الوظيفي لأعضاء الهيئات التدريسية فيها، وأن تتعرف إلى حاجاتهم ورغباتهم لتحقيق الممكن منها وإثباعها، وأن توفر نظام حوافز تثجيعية، مادية ومعنوية، لما لها من أثر إيجابي في المحافظة على مستوى الأداء الوظيفي المرتفع. V-دراسة (Fleming,2010)هدفت الدراسة الي الكشف عن تصورات أعضاء هيئة التدريس في مجموعة من الجامعات في الولايـات المتحدة الأمريكية نحو الأداء الوظيفي لرؤسـاء

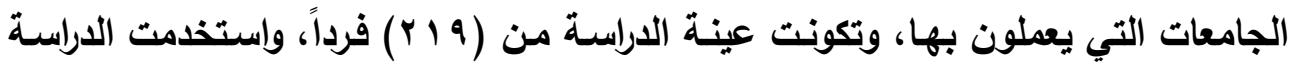
الاستبانة والمقابلة في عملية جمـع البيانات، وأثـارت نتائج الدراسـة أن توقعات أعضـاء هيئة التدريس كانت متوسطة نحو الأداء، كما أن أداء الرؤسـاء يؤثثر على أداء أعضـاء هيئة التدريس في الجامعات، وأن الأداء الوظيفي لأعضاء هيئة التدريس مرتبط بتوقعاتهم نحو الحوافز التي يمكن أن يحصل عليها الموظف إن كان أداءه الوظيفي جيدا. ^-دراسة (Hallinger,2010) هدفت الدراسة الي الكشف عن الأداء الوظيفي لأعضاء هيئة

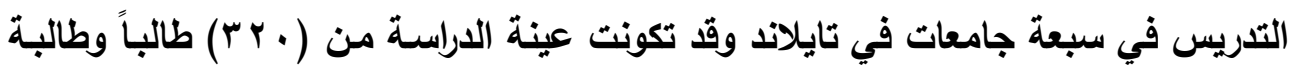
في الجامعات، واستخدمت الاراسـة تحليل محتوى تقييم الطلبة لأعضاء هيئة التدريس، وأثـارت النتائج إلى أن مستوى الأداء الوظيفي لدى أعضاء هيئة التدريس كان مرتفعاً حسب تقييم الطلبة لهم. 9-دراسة (Yum Hamis \& ljad,2009) هدفت الدراسة الي تقيبم الأداء الوظيفي لأعضاء هيئة التدريس في الجامعات الماليزية، وتكونت عينة الدراسة من (9 ( ا Y) فرداً تم اختيارهم عشوائيا، وقد استخدمت الاراسـة الاستبانة المبنية على بطاقة الأداء المتوازن والمقابلات وتحليل المحتوى في جمع البيانات، وأثـارت نتائج الدراسـة بأن هناك علاقة ارتباطيه بين 
الأهداف التظيمية في الجامعات ويبين مستوى الأداء الوظيفي لأعضاء هيئة التدريس، وأظهرت النتائج أن معاملات الارتباط بين العدالة التنظيمية والأداء الوظيفي كاتت موجبة.

\section{التعقبيب على اللدراسات السيابقة}

من خلال عرض الاراسات السابقة، يمكن استخلاص النقاط الآتية: ا تأكيد التأثير الإيجابي للإدارة الرشيقة في تطوير مستوي العمل وتحسين جودة الاداء وقا أكد ذلك دراسة كل من (عبد القادر سليم وشذا أبو سليم، 9 ا.بم) ودراسة (بن وارث وجابة، 7 1 • بم) ودراسة (Anne-Caroline Golard,2015). r أن الإدارة الرشيقة تعتبر منهج اداري يسعي للتركيز على القيم، والعمل على تحقيق الكمال في المؤسسات من خلال عمل الفريق وحسن استخدام الحقائق والبيانات وسرعة الاستجابة للتحديات والفرص من أجل تحقيق أفضل مخرجات وتقليل الهار وخفض التكاليف وتحسين الخدمات والاستجابة لمتطلبات العملاء وقد أكد ذلك دراسة (أبو عبيد

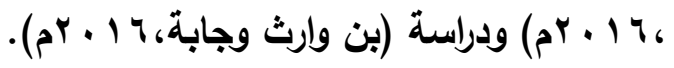

r أن الإدارة الرشيقة أضحت مسارا لمعظم الشركات الكبيرة حول العالم، كونها تحقق الاستخدام الأمثل للموارد داخل المؤسسة، سواء مادية أو بشرية أو مالية، فضلا عن حسن تعاملها مع عنصر الوقت الأي يعد من العناصر الأساسية في وظيفة الإنتاج، وأكد

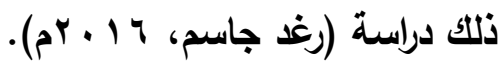

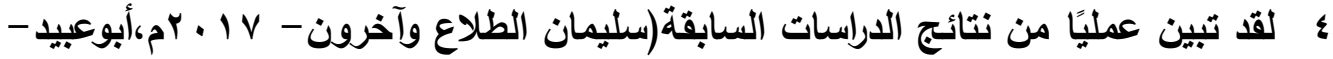

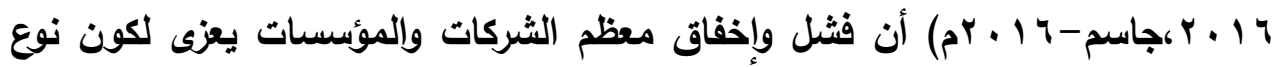
الإدارة التي تمارس (إدارة ثقيلة) مترهلة والتي وصلت جذورها البيروقراطية السلبية وإنتشرت في مفاصلها حتى أصبحت جزيًا من خصوصيتها وشخصيتها وقيمها وتقاليدها، ولم تعد تملك القدرة على محاريتها أو التخلص منها، وأصبحت منغلقة على نفسها متمسكة بأساليب وطرق ووسائل تقليدية لم يعد لها في عالم التقتية والمعلومات والعولمة مكان، وأصبح من أبرز سماتها التفرد والهار والإسراف وغياب مفهوم الفاقد والقيمة المضافة وقيادتها بطيئة التجاوب مع التحديات والفرص. ه أن غياب معظم جامعاتنا العربية عن التنافسية العالمية يعود إلى أسباب كثيرة من أهمها ضعف القيادات الجامعية العليا في ممارسة مهامها التطويرية وانغماسها في الأعمال 
الروتينية اليومية، وشيوع المركزية الإدارية واضعاف سلطة مجالس الأقسام والكليات، وطغيان المجاملة في كثير من المجالس الأكاديمية، فتحقيق مكانة مرموقة عالميا مرهون بالكفاعة والفاعلية الإدارية لقياداتنا باعتبار الإدارة عامل النجاح الأول في الاستثمار الأمثل للموارد المتاحة وقد أكد ذلك دراسة (دراسة صالح عبد الغقور، 10 • r م). 7

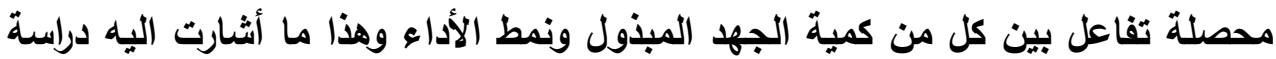

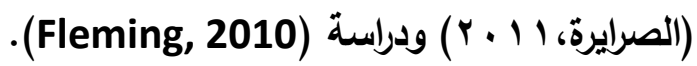
V ان الأداء الوظيفي الفعال في المنظمات يرتبط بمدي قدرة تلك المؤسسات على التكيف مع البيئة والاستقرار وتحقيق الروح المعنوية العالية للعاملين وحسن استغلال الموارد المتاحة وهذا ما أكدته دراسة (Yum Hamis \& ljad,2009). - - تميزت الاراسة الحالية عن الدراسات السابقة بأنها ريطت الموضوعين معا وهما القيادة الرشيقة وفاعلية الأداء الوظيفي. - - أن الدراسة الحالية قد تناولت بيئة مختلفة وهي جامعة الوادي الجديد التي لم يتم دراسة الموضوعين معاً في هذه الجامعة. - مقد أفادت الباحثة من الدراسات السابقة في منهجها، وفي التعرف على المبررات والعوامل التي تستدعي تطبيق الإدارة الرشيقة بمؤسسات التعليم العالي، والتعرف على مفهوم فاعلية الأداء الوظيفي واهميته وأهم المعايير التي يستند عليها، وكذلك بناء أداة الدراسة وتحليل وتفسير نتائجها. - وتثثابه الدراسة الحالية مع الدراسات السابقة في استخدام المنهج الوصفي، وفي تناولها لموضوع الإدارة الرشيقة من الجاتب النظري. - - وتختلف عنها في دراستها لموضوع الإدارة الرشيقة لاي القيادات الجامعية بمؤسسات التعليم الجامعي، ومحاولة التعرف على أراء عينة من أعضاء هيئة التدريس في واقع تطبيق الإدارة الرشيقة لاي القيادات الجامعية بجامعة الوادي الجديد، كذلك في الإطارين الزماني وإلمكاني للاراسة. 


\section{منهج اللدراسة}

تستخدم الدراسة الحالية المنهج الوصفي التحليلي لمناسبته لطبيعة الدراسة، مع إعئة الاستعانة باستبانة تم تطبيقها على عينة من أعضاء هيئة التدريس بجامعة الوادي الجديد للتعرف على آرائهم في درجة ممارسة القيادات الجامعية بالجامعة لمبادئ الادارة الرشيقة

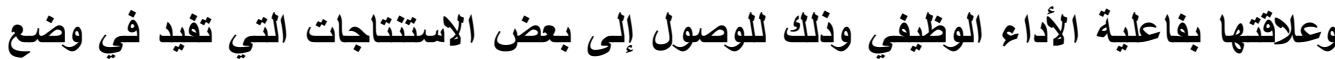
بعض الاقتراحات والتوصيات لتطبيق ذلك الاسلوب الإداري الحديث.

مصطاحات اللدراسلة والتعريفات الإجرائية

القيـادات الجحامعية؛وتثمل في الدارة الحالية كل من القيادات الأكاديمية والقيادات الإدارية وتعني:

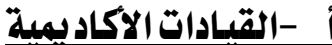

يعرف القائد الأكاديمي بأنه عضو في جماعة يرعي مصالحها، ويهتم بأمورها، ويقلر أفرادها ويسعي إلى تحقيق أهدافها عن طريق التفكير والتعاون المشترك في رسم الخطط وتوزيع المهام والمسؤوليات حسب الكفاءات والاستعدادات البشرية والإمكانات المادية المتاحة بالجامعة وتعرف كذلك بأنهم" أعضاء هيئة التدريس المتميزين المعينين بمناصب مدراء الجامعات "مدير الجامعة ونائب المدير ووكلائها"، وعمداء الكليات والمعاهد ووكلائهم، أو

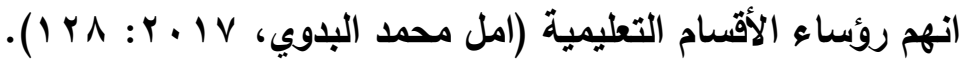
ويقصد بالقيادات الأكاديمية إجرائيا في هذه الدارسة بأنهم أعضاء هيئة التدريس المكلقين بمهام وأعمال إدارية بالجامعة بدءا، من رئيس الجامعة، ونواب رئيس الجامعة، الجادية وعمداء الكليات وإلمعاهد ووكلائهم، ورؤساء الأقسام ومدراء المراكز البحثية والتعليمية، والذين لهم دور فعال في رفع مستوي الأداء الوظيفي للجامعة وتطبيق معايير القيادة

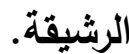

\section{ب - بالقيادات الإدارية}

تعرفها وصفية أبو معمر بأنها"(العمل الذي يقوم بـه القائد الإداري في الجامعات باستمرار للتأثير في موظفيه وإقتاعهم بقبول العمل ، وتسند إلى أثخاص يكونون مؤهلين

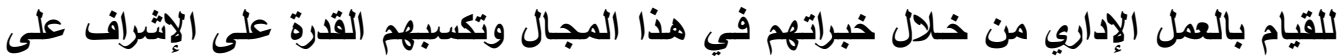


موظفيهم وإرشادهم وتوجيههم لكي يؤدوا الأعمال التي يريد القائد الإداري انجازها من أجل

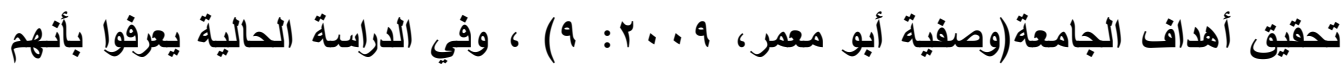
هم متذذو القرارات الذين يقومون بالتأثير في مرؤوسيهم لإقتاعهم وحثهر علي المساهمة الفعالة بجهودهم للقيام بنشاط متعاون داخل الجامعة، ويتضمنوا أمين الجامعة وأمناء الكليات ورؤساء الإدارات والإقسام المختلفة.

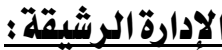

تعرف الإدارة الرشيقة في الدراسة الحالية بأنها فلسفة إدارية حديثة تقوم

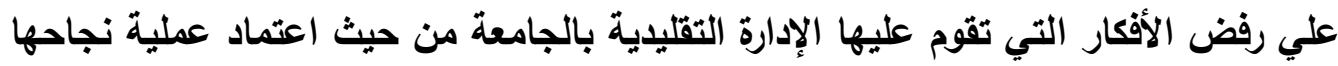
علي أصحاب الخبرة فقط ، وتعتبر ان جميع العاملين بالجامعة هم شركاء في اعمال التطوير التاري

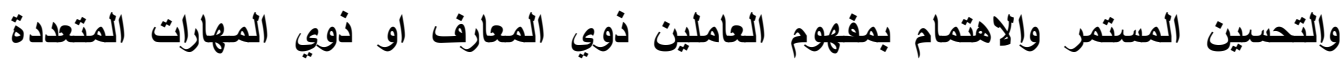

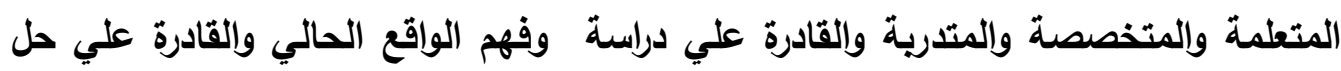

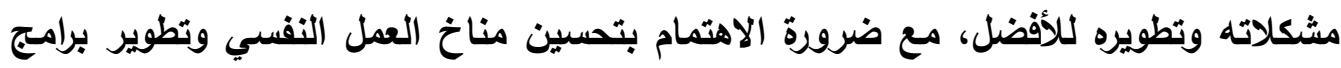

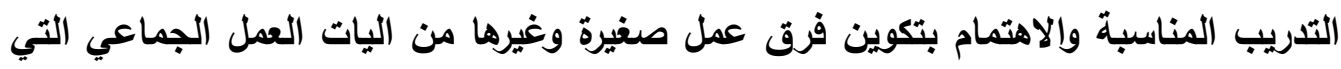

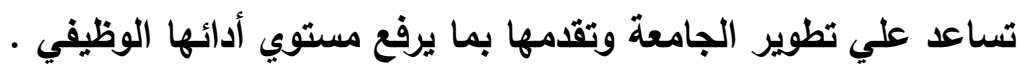

\section{أبعاد الإدارة|لرثيقيقة}

تقتصر الدراسة الحالية علي تناول بعض أبعاد القيادة الرشيقة وهي (رغد

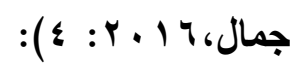

تنظيم موقع العمل: طرق تجعل العمل منظم ومرتب بشكل يحافظ على انسيابية العمل. التحسين المستمر : أسلوب ياباني يعمل على ادخال تحسينات بسيطة على النثاطات والخدمات بشكل مستمر.

العمل القياسي: أسلوب ارشادي علي شكل تعليمات لتوحيد الإجراءات التنفيذية. العاملين متعدي الوظائف: أسلوب لتدريب العاملين مع أكثر من مهمة أو عملية داخل

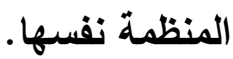
ستة سيجما: منهج استراتيجي لتحسين العملية والخدمات الجديدة باستخدام أساليب علمية واحصائية لرفع مستوي رضا العملاء عن الذدمات المقدمة لهم. 


\section{فاعلية الأداء الوظيفي}

تعرف فاعلية الأداء الوظيفي اجرائيا في الاراسة الحالية بأنها "مدي تحقيق القيادات

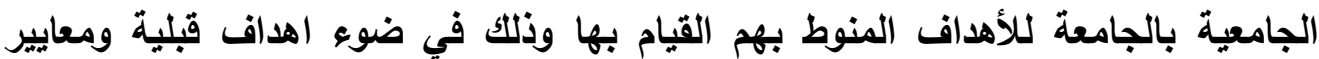
مسبقة تم الاتفاق عليها عند توليهم المهنة وذلك بما يعمل على تحقيق الهاف الجامعة.

\section{حلود اللدراسة}

الحد الموضوعي (الأكاديمي): اقتصرت الدارسة في حدها الموضوعي على دارسة موضوع القيادة الرشيقة وعلاقتها بفاعلية الأداء الوظيفي. الحد البشري: اقتصرت الدارسة على استجابات أعضاء هيئة التدريس بجامعة الوادي الجديد

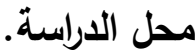
الحد المؤسساتي: تقتصر هذه الدارسة على كليات جامعة الوادي الجديد وهم كليات عملية وتثمل (الطب البيطري-العلوم -الزراعة) وكليات نظرية وتثمل (التربية-التربية الرياضيةالآداب). الحد المكاني: أجريت الارسة في جامعة الوادي الجديد.

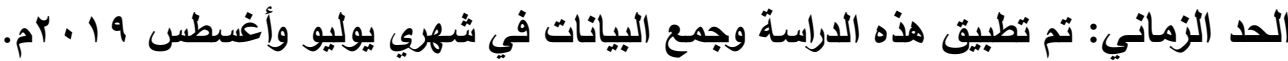

\section{الإطارالنطرئ}

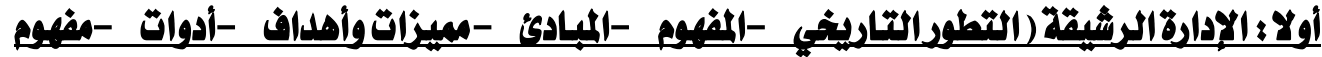

(atall

\section{1 - التطور التاريخي لمشطبح الإدارة الرشيقة}

يعود تاريخ ظهور مصطلح الإدارة الرشيقة إلى أوائل القرن العشرين عندما بدأ Toyoda Sakichi الوصول الي توقف العمليات تلقائيا عند انقطاع الخيط، ولقد سلط تطوير هذه الاختراعات الضوء على ثقافة تويوتا Toyota وظهرت ثلاث أوجه تقدم معتمدة عليها هي (أهمية الذهاب الي الميدان لتسجيل التحسينات التي يجب إدخالها على التقتيات، وتصنيع منتجات ذات جودة عالية عن طريق نظام مضاد للخطأ وفصل الرجل عن الآلة)(Liker,2012:12) . 
Toyota Production System ) ثم في الخمسينات من القرن الماضي تم بناء بناء علي ارث وأفكار Toyoda Sakichi والتي تم التركيز فيها علي مفهومين هما TPS القضاء علي الأخطاء وإختصارها (jidoka )وفي الوقت المناسب واختصارها ( jit) ثم بعد بضع سنوات أدركت الثركة أن هذا المفهوم يمكن توسيعه ليشمل الثركات الأخرى واتخذت الخطوات اللازمة لنشر مبادئ (TPS) الي مورديها الرئيسين(Toyota,2019). ويعتبر Taichin ohno اول من وضع نموذج الادارة الرشيقة منذ بلاية الخمسينات حيث بين ان أفكار الترشيق تم انشائها من مصنع تويوتا الياباني ، ثم بعد الحرب العالمية

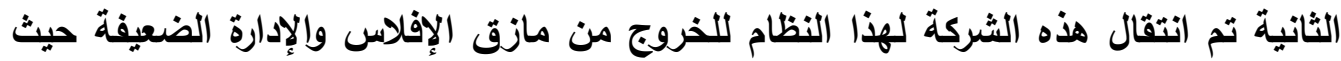
قامت الثركة بوضع برنامج قوي وضخم وهو برنامج تويوتا لتحسين TPS فقامت مجموعة من الباحثين منهم هنري فورد بالخطوة الاولي لعملية التحسين وهي اللجوء الي طريق خط الانتاج ومبادئه ، ثم أعقب ذلك دراسة Taylor Reidrich التي عملت على تحسين الكفاءة الصناعية كما قد جاء بمفهوم الجودة والذي ساهم بنهضة اليابان الصناعية(اسراء عبد

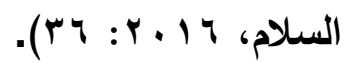
ومع بداية الستينات دخلت تويوتا السوق الامريكية وتوغلت فيها بعد السبعينيات وأصبحوا يفضلونها على (القلكسواجن) وهو ثاني أكبر منتج للسيارات لايهم، أما مفهوم كفاءة

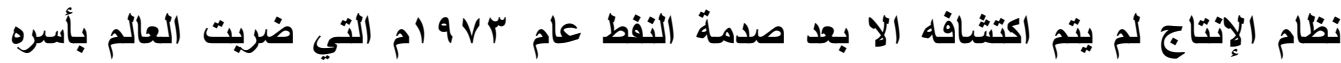
بسبب الركود العام، حيث نهضت شركة Toyota بسرعة من الازمة مقارنة بالشركات اليابانية الأخرى، وذلك بفضل أساليب الإنتاج المختلفة، ويعد عشرين عاما اكتثف العالم production Lean خلال كتاب (Liker,2012:32)(The machine that changed the world). وفي منتصف الثمانيات من القرن الماضي قام معهر (ماساتشوستس) التكنولوجي بمشروع بحث لتحليل الأداء الصناعي بمختلف مصانع العالم للسيارات ومقارنتها بنظام تويوتا، أما عام 991 ام قام الباحثان "جيمس وماك ودانيال جونز" بنشر دراستهما في كتابهما الالة التي غيرت العالم، The machine that changed worlds، فوصفوا نظام الإنتاج "تويوتا" ومقارنته مع الأساليب العالمية للتصنيع فوصفوه بكلمة Lean اي الإنتاج 
الرشيق ، ويغني تدبر امر كل من المساحة المادية وجهج العمل والاستثمارات الراس مالية

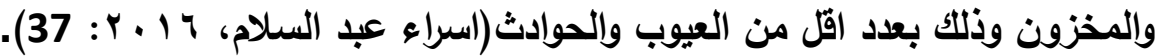
ثم في التسعينات من القرن الماضي أثشار عدد من الاقتصاديين على ان معدل

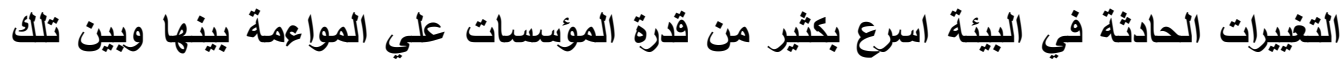
التغييرات حيث لم تتمكن هذه المؤسسات من الاستفادة المثلى من الفرص المتاحة، ويهذا

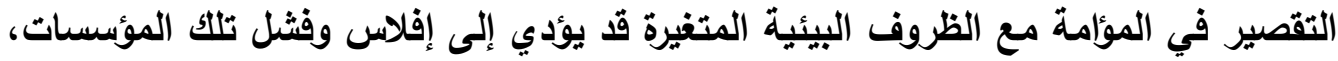

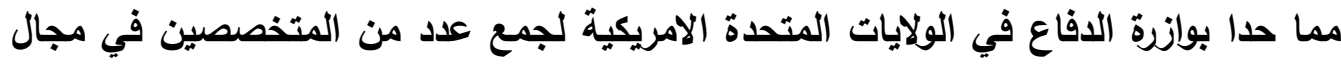

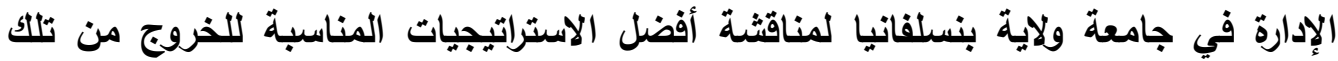
الأزمة، وكانت نتيجة عمل هذا الفريق تقريرا من مجلاين بعنوان "استراتيجية الأعمال الإنتاجية في القرن الحادي والعشرين" ومنذ ذلك الحين اصبح مفهوم الرشاقة من اكثر المفاهيم الإدارية استخداما ، ومن هنا كانت نقطة الانطلاق لكثير من الباحثين في تقديم الكثير من الارسات التي لها علاقة بهذا المفهوم ، حيث اعتبرت الرشاقة الاستراتيجية بانها

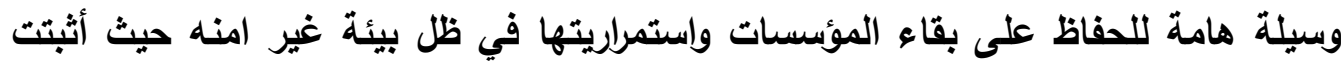
الرشاقة بانها مفتاح للنجاح المؤسسي ، وهذا النجاح يعد في حد ذاته ميزة تنافسية للمؤسسات والتي يمكن الحفاظ عليها عن طريق تقليم ابتكارات وخدمات ومنتجات ذات بوات بوداده عالية(khoshsima,2003:41).

وفي عام 997 ام نثر الباحثان "ووماك وجونز "كتابهما الثاني بعنوان الفكر الرشيق الذي فصل في مفاهيم والأدوات الرئيسة لأسلوب الإدارة الرثيقة وتم إعادة طباعته

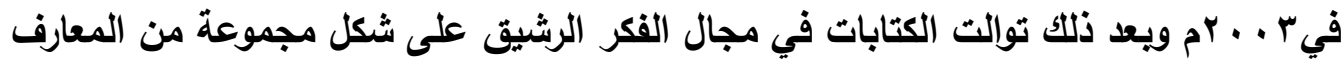
المتكاملة توضح المفاهيم وادواته التي تؤدي الىى التقليل او القضاء على الهار بحيث يعتمد على أدنى حد من الدخزون والتسليم وفق المواعيد والرقابة الاقيقة على الجودة والصيانة ومعايير جميع الوظائف والأنثطة مما شجع العديد من الوحدات الاقتصادية للعمل بهذا النظام(ابتسام سليماني واخرون، 9 1 ـ ب: 1 1 ؛). والجامعات اليوم مثلها مثل جميع المؤسسات المجتمعية تواجه قضايا عديدة نتيجة

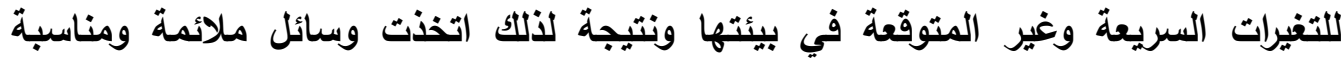
لمواجهة تلك التغيرات ومن اهم تلك الأساليب الإدارية الحديثة، ومن بينها أسلوب الرثاقة 
الادارية والتي تعد من الأساليب التي تتجاوز التكيف مع التغييرات وتتعداها إلى المواعمة بين الإجراءات المتبعة في المؤسسات مع التكنولوجيا الحديثة المتقدمة مما يترتب عليه تزويد العملاء بمنتجات عالية الجودة في أقصر فترة زمنية ممكنة(Hormozi,2001:132-143). لألك اعتبرت الرشاقة الإدارية استراتيجية كبري لتفعيل الإدارة الجامعية، فطبقا لكل من بيج ومورجن فان الرشاقة الادارية تعد مفتاح نجاح الجامعات في بيئة سريعة التغيير والتي تتمثل في القدرة على تقديم الدعم، وفي بعض الأحيان التغير

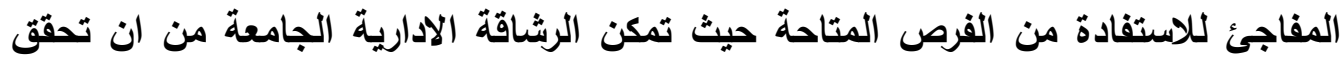
الكثير من الأهداف بدقة وسرعة، كالبدء بتطبيق التحركات التنافسية المرنة والأكية، لكي تستجيب للتغيرات التي تفرضها طبيعة البيئة الديناميكية المحيطة بها Rebert) .\&Kelly,2008:155-168) نلاحظ مما سبق انه علي الرغم من أن مصطلح الإدارة الرشيقة تمتذ جذورها التاريخية إلي خمسينيات القرن الماضي إلا أن الأفكار اليابانية المرتبطة بذلك المصطلح احتلت مكانة خاصة في العالم في الفترة من السبعينات إلى بداية التسعينات حينما أظهرت شركة تويوتا نتائج باهرة من حيث نسبة المبيعات وكذا أساليب تصنيعها مستعملة في ذلك إس عدة أساليب ونظريات تم تطويرها في هذه المؤسسة انظلاقا من حلقات الجودة وأسلوب الإنتاج في الوقت المحدد وصولا إلى نظام تصنيع شامل يسمى على اسم هذه المؤسسة أو ما اصطلح عليه بعد ذلك بأسلوب الإدارة الرشيقة (Lean management) • ويالتالي فإن العمليات الرشيقة أو Lean Operations هي الاستراتيجية الصناعية التي تتبعها تويوتا لإنتاج سياراتها، وتتمحور الاستراتيجية حول قدرة الشركة على تقليص حجم المهلر أو Waste من عملياتها وإبقاء ما يضيف قيمة للعميل، لذلك نجد أن المحصلة النهائية لاستخدام العمليات الرشيقة هي زيادة الكفاءة والإنتاجية لتصنيع منتج إبداعي عال الجودة بتكلفة صغيرة، والقدرة على استخدام هذه الاستراتيجية سيمنح الشركة القدرة على لهي إنتاج ما تريده كعميل بالتكلفة التي تناسبه ليصله في أقصر وقت ممكن، لذا يمكنتا القول بأن العمليات الرشيقة هي "الخلطة السرية" لنجاح تويوتا وتربعها على رأس جبل صناعة السيارات كأكبر شركة سيارات ريحية في العالم. كما أن انتهاج أسلوب الإدارة الرشيقة من قبل شركة تويوتا ويعدها من قبل عدة مؤسسات رائدة في الإنتاج مكنهم من تحقيق نتائج مبهرة فيما يخص التحكم في التكاليف 
والقضاء على مختلف أثكال الهُر وتحقيق الجودة في الإنتاج وارضاء العملاء، مما كان له أكبر الأثر في انتقال ذلك المفهوم الي مجالات الإدارة والتعليم بمختلف مراحله ومنها التعليم الجامعي.

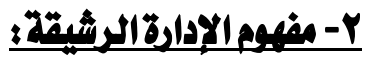

قبل التعرف على مفهوم الإدارة الرشيقة ينبغي في البداية التعرف على معني كلمة

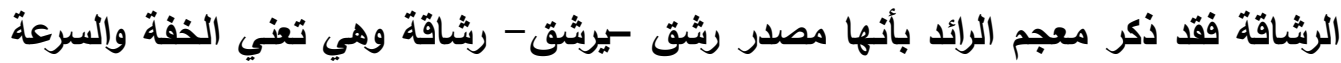

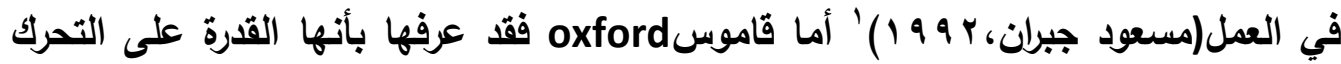
السريع والسهل(Audran,2001). أما من وجهه نظر الباحثين فقد عرفها Doveبأنها القدرة على إدارة وتطبيع المعرفة بفاعلية(Dove,2001) ، كذلك فقد عرفها Narasimhan بأنها نوع من أنواع المرونة وهي القدرة على الأعمال غير المخطط لها(Narasimhan,2006:440-457)، أما Erand \& (Erande فقد عرفوها بأنها القدرة على الاستجابة السريعة للتغيرات غير المتوقعة Verma .\& Verm,2008:32-44) كذلك فقد تم تعريفها بأنها تعبر عن مدى قدرة المنظمة على التعامل مع الظروف المحيطة، وسرعة التحرك والمرونة الكافية من خلال الاستفادة من نقاط القوة والضعف أو هي القدرة التي تحاول المنظمة امتلاكها وتستعد من خلالها لإحداث التغييرات الاستراتيجية المطلوية بشكل سريع في ضوء تحقيق الاستجابة المناسبة للأحداث البيئية المتسارعة التي

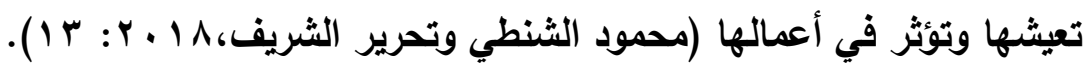
أما في علم الإدارة فإن مصطلح الرشاقة يعني ثلاث جوانب هي الرشاقة التصنيعية، والرشاقة التظيمية، والرشاقة الاستراتيجية، والرشاقة التصنيعية وتعني قرة المنظمة على التحرك بمرونة باستخدام العمليات والسياسات الداخلية(Ojha,2008) ، والرشاقة التظيمية وتعني قدرة المنظمة على تحقيق النتائج المرجوة التي تطمح لها من جراء تطويرها وزيادة معرفة مواردها، مما ينعكس بلوره على تنمية المنظمة وجعلها خفيفة الحركة في بيئة

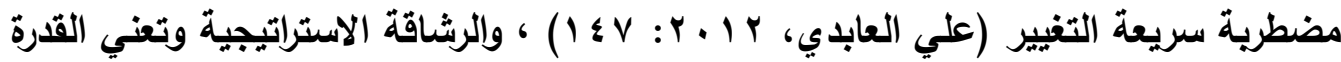
على إدراك والحصول على المزايا التي تتاح من الفرص البيئية، من خلال التخطيط للتغيير 
القريب والبعيد الذي قد يحدث في أنشطة منظمات الأعمال بشكل سريع وفاعل ويالشكل المطلوب(Ojha,2008).

أما عن مفهوم الإدارة الرشيقة فهو مصطلح يهدف الي انتاج منتجات وخدمات بأقل التكاليف وأسرع وقت ممكن، ويركز علي الكفاءة وتحقيق الحد الأدنى من الهـر والتالف وضياع الموارد وهذا يعرف باليابانية باسم( Muda) أي تحسين سرعة وزيادة الإنتاجية ، لذا منا فإن أهم المبادئ الأساسية لمفهوم الإدارة الرشيقة هو البحث عن الكمال في عالم دائم التغير ويشكل متسارع، وكأنها مشروع غير منتهي ، ويتطلب من كل فرد في المنظمة ان يشارك بشكل كامل في مبادئها ولكن التحديات تكمن في تتفيذها لأنه من الصعب ان نري الكمال أثناء عملية التصميم للأعمال ومن ثم يحتاج المديرون الي تغير اسلويهم لإدارة العاملين من حيث التحفيز ، واششراكهم في استخدام أدوات الإدارة الرشيقة ، فكأن تغيير أسلوب الإدارة والسلوكيات وطرائق تفكير الناس والثقافات التظيمية هو الجاتب الأكثر صعوية وأهمية في التحول الي استخدام منهج وأدوات الإدارة الرشيقة بدلا من التغير في الأدوات والعمليات

والأنظمة(Nylund,2013:7).

ويعرف قاموس الأعمال الإدارة الرشيقة بأنها قدرة الثركات على الحفاظ على قدرتها التنافسية في أعمالها من خلال التكيف مع الأفكار المبتكرة الجديدة واستخدام هذه الأفكار الإنشاء منتجات وخدمات جديدة بالإضافة إلى نماذج أعمال جديدة Business) .Dictionary)

وفي الادبيات تعرف الإدارة الرشيقة بأنها مجموعة من الأدوات والتقتيات التي تركز علي التحسين المستمر واحترام الافراد والقضاء علي أي نوع من التبذير في نظام الإنتاج )

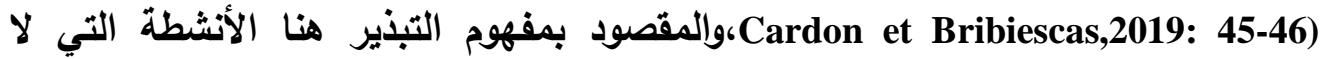
تضيف قيمة الي المنتج أو الخدمة من وجهه نظر العميل وتؤدي الي زيادة التكاليف أو الوقت أو الموارد، ويالتالي تعرف الإدارة الرشيقة علي أنها فلسفة تهدف المنظمة من خلالها الي تحقيق أقصي قدر من القيمة المقدمة لزيائنها من خلال التقليل من الضياع والهدر (Nicholas,2010:1).

كما تعرف بانها" قرة المنشأة على الأداء الإداري الأي يتميز بسرعة الاستجابة وسرعة تعديل أسلوب العمل بصورة تتناسب مع منطلبات التغيير، وهي الممارسة التي تركز على القيم والانسياب والاستقطاب والكمال وعمل الفريق وفوائده الجمة، والتي يمكن تلخيصها 
في الحماس الجماعي والمعرفة التجميعية وحسن استخدام الحقائق والبيانات وسرعة التجاوب

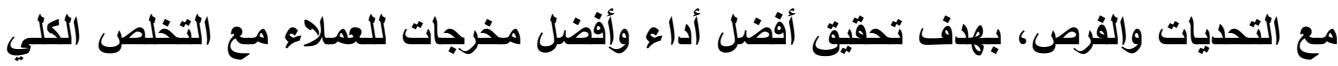
ما أمكن من كل نشاط أو جزئية لا تمثل قيمة مضافة للعمل أو العميل (هلال العسكر، .$(r \cdot r$

أيضا تعرف بأنها السلوكيات التي تضيف أو تخلق قيمة(Ligungblom,2012:59) أو تلك السلوكيات التي تحقق قيمة وتخفض مستويات الههر ذو العلاقة بالأفكار والعلاقات غير المنتجة وانخفاض مستويات التعاون أو انها السلوكيات التي قد لا تحقق قيمة لكنها تتجنب خسارة الموارد(Ligungblom,2012:59)، او هي طريقة منظمة لتحقيق التنفيذ الأفضل للأعمال من خلال الاحترام والثقة المتبادلة بين القائد والافراد بهدف تحقيق نسب أفضل من الكمال(Dombrowski,2013). كما عرفها البدراني أيضا بانها قرة المنظمة على التحرك السريع والسهل لتحقيق الاستجابة للمواقف المتغيرة غير المتوقعة، واكتساب المرونة والسرعة التي تمنح المنظمة القدرة على تغيير أعمالها نتيجة لامتلاكها القدرة الحقيقية لاتخاذ القرارات في الوقت المناسب، وهذا يتطلب قدرات متنوعة كالحساسية الاستراتيجية، والالتزام الجماعي وتحمل المسؤولية، وتدفق وتوجيه الموارد بأنواعها والتي تمثل أبعاد جوهرية لخفة الحركة الاستراتيجية (ايمان

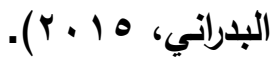
ويالتالي فإن مفهوم الإدارة الرشيقة له وجهتين نظر، المنظور الأول فلسفي مفاهيمي متعلق بالمبادئ التوجيهية والأهداف الثاملة، والمنظور الثاني العملي التطبيقي المتعلق بمجموعة من الممارسات والأدوات ، أو التقتيات الإدارية التي تتوافق مع المنظور الفلسفي(Shaikh \& Khalifeh,2014:5) ، وتقوم فلسفتها علي ركيزتين أساسيتين هما التحسين المستمر واحترام الناس(Badurdeen \& Gregory,2012) الامر الذي يتطلب التزام ومشاركة من قبل جميع العاملين، ومن الواضح أنتا عندما نتحدث عن مفهوم الإدارة الرشيقة فإنتا نتحدث عن فلسفة وكأنها مشروع غير منتهي ، ويتطلب من كل فرد في المنظمة ان يشارك بشكل كامل في مبادئها، وميع ذلك تعتبر فلسفة بسيطة في الفهم والتعلم، ولكن التحديات تكمن في تنفيذها، لأنه من الصعب أن نري الكمال أثناء عملية التصميم 
للأعمال، ومن ثم يحتاج المديرون إلي تغير أسلويهم لإدارة العاملين من حيث التحفيز واششراكهم في استخدام أدوات الإدارة الرشيقة. ويالتالي فإن مصطلح الإدارة الرشيقة هو نظام إداري متكامل يهدف إلى ازالة الهار والضياع خلال تطبيق المبادئ واستخدام الأدوات التي تساعد في التخلص من الأنشطة التي لا تضيف قيمة للعميل، ويالتالي جعل عمليات الإتتاج والتصنيع أسهل وأبسط مما يسمح بتقديم قيمة أفضل للعملاء والمؤسسة ككل. أما عن مصطلح الإدارة الرشيقة في التعليم الجامعي فقا عرفها عنتر عبد العال بأنها "قدرة الجامعات على الاستجابة السريعة للتغيرات المفاجئة في مجال عملها والتي تكسبها المرونة لتعديل وتغيير أهدافها وقرارتها وذلك بامتلاك مسئوليها الالتزام وتحمل المسئولية

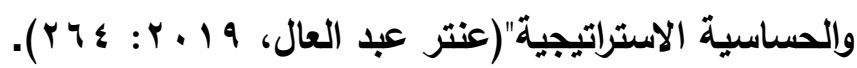
كما عرفها هنية بأنها " القدرة على مواجهة التغيرات في البيئة الداخلية والخارجية من خلال تصميم استراتيجي يتسم بالمرونة العالية للجامعات من اجل الاستجابة السريعة له له

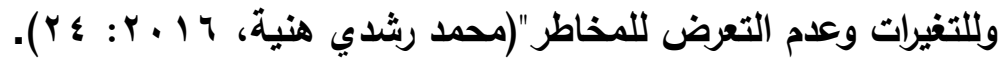
أما مغاوري فقد أثشارت الي أن مصطلح الإدارة الرشيقة إذا طبق في التعليم الجامعي فهو يسهم في الرفع من قدرة المؤسسة التعليمية علي استثعار التغيرات المتوقعة والغير متوقعة في بيئة العمل، سواء الداخلية أو الخارجية وسرعة الاستجابة لها والتعامل معها بفاعلية وإبتكار والاستفادة من تلك التغيرات باكتشاف فرص جديدة واستثمارها وتحويلها الي ميزة تنافسية جديدة وان تكون قادرة علي استباق الأمور بدلا من التعامل مع التغير بمنطق رد الفعل اتجاهه فقط (هالة مغاوري، 17 ـ ب ب: 9 ؛ 1 ). ويالتالي فإن المؤسسات الجامعية التقليدية تحاول كسر طرق التفكير التقليدية وتشجع على الابتكار وتعلم كيفية اكتشاف طرق جديدة وإستثارها لرفع كفايتها ويالتالي فهي تتمسك بأداء العمل بنفس الطرق التقليدية الروتينية وإلتي قد تتسبب في زيادة الوقت والمال فهي بالتالي جامدة في تصرفاتها وطريقة تعاملها مع المواقف فالتغيير بالنسبة لها يجلب الفوضى وتكتفي لمواجهته بزيادة حجمها وازدياد حدود عملياتها بدون تأثير علي الجودة وعملياتها، في حين ان المؤسسات الجامعية الرشيقة اهتمامها يكون موجهة نحو الاستجابة

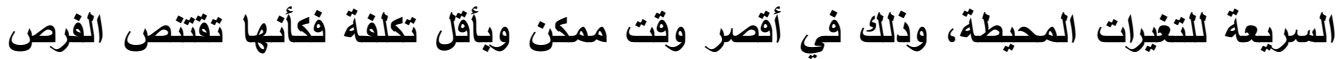


وسط التغيرات لتحويلها لمزيا تنافسية مؤكدة علي عدة أمور هي (السرعة والمرونةالاستجابة إلى التغيير وعدم اليقين- منتجات عالية الجودة ومتخصصة للغاية-منتجات وخدمات تتصف بالمعلومات العالية ومحو القيمة المضافة-تعبئة المقدرات الجوهريةالتجاوب مع القضايا الاجتماعية والبيئية- تجميع التكنولوجيات المختلفة-التكامل ما بين المؤسسات بعضها البعض -التكامل بين المؤسسات داخليا). وفي الاراسة الحالية تعرف الإدارة الرشيقة بأنها فلسفة إدارية حديثة تقوم علي رفض الأفكار التي تقوم عليها الإدارة التقليدية بالجامعة من حيث اعتماد عملية نجاحها علي أصحاب الخبرة فقط ، وتعتبر ان جميع العاملين بالجامعة هم شركاء في اعمال التطوير والتحسين المستمر والاهتمام بمفهوم العاملين ذوي المعارف او ذوي المهارات المتعددة المتعلمة والمتخصصة والمتدرية والقادرة علي دراسة وفهم الواقع الحالي والقادرة علي حل مشكلاته وتطويره للأفضل، مع ضرورة الاهتمام بتحسين مناخ العمل النفسي وتطوير برامج التدريب المناسبة والاهتمام بتكوين فرق عمل صغيرة وغيرها من اليات العمل الجماعي التي تساعد علي تطوير الجامعة وتقدمها بما يرفع قدرتها التنافسية.

\section{r - ميادئ الإدارةالرثيقة}

تقوم فلسفة الإدارة الرشيقة على مجموعة من المبادئ الأساسية التي لا يمكن لهذا

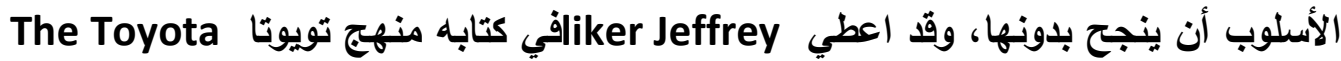
way

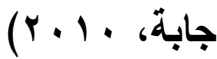
المبدأ الأول: تركيز قرارات المؤسسة الإدارية على استراتيجيات طويلة المدي باستثناء النواحي المالية تتم وفق استراتيجية قصيرة المدي. المبدأ الثاني: وضع خطة واضحة لمواجهة وحل مشكلات العمل. المبدأ الثالث: اعتماد نظام الإنتاج وفق متطلبات العملاء والبعد عن فكرة التخزين او الإنتاج الزائد.

المبدأ الرابع: انسيابية الأنشطة والابتعاد عن البيروقراطية. المبدأ الخامس: التأكيد في ثقافة المؤسسة على مبدأ الويعني التسليم في الوقت المحدد من أجل معالجة المشاكل من أجل ضمان مستوي جيد للجودة. 
المبأ السادس: اتباع قاعدة التحسين المستمر. المبدأ السابع: الإدارة المرئية-أي يجب أن تكون كل القواعد والأساليب الإدارية واضحة للكل ومعروفة عند الجميع مما يمكن من عدم بقاء الأخطاء متخفية. المبدأ الثامن: استعمال فقط التكنولوجيا المجرية في عملية الإنتاج وذلك لتفادي الوقوع في الأخطاء وهدر الوقت والموارد.

المبدأ التاسع: تكوين اشخاص قيادين على دراية كافية بتفاصيل كل العمليات داخل المؤسسة وقادرين على تكريس ثقافة وفلسفة المؤسسة بطريقتهم الخاصة. المبأ العاثر : تكوين فرق عمل متخصصة في الجودة تتبع فلسفة المؤسسة. المبدأ الحادي عشر: احترام الثركاء والموردين وتثجيعهم بالسعي دوما نحو الأفضل والتحسين.

المبدأ الثاني عشر: الاهتمام بالعمل الميداني من أجل معرفة ماذا يجري بالضبط وفهم الأوضاع بالشكل الصحيح. المبدأ الثالث عشر : اتخاذ القرارات بروية ومن دون تسرع ويالتوافق مع الاطراف الفاعلة داخل المؤسسة مع الاخذ بعين الاعتبار كل العوامل المحيطة. المبأ الرابع عشر: على المؤسسة ان تبقي دائما في طريق التعلم وتتبع أسباب مشاكل المؤسسة والعمل على حلها من أجل تحقيق فكرة التحسين المستمر. أما سليك slack فقد لخص مبادئ الإدارة الرشيقة تحت ثلاثة مجالات رئيسة هي \&lack\&) others,2004:524) 1 -تقليل الهرا: واعتبرها القضية الأهم في نظام الإدارة الرشيقة، ويالنسبة له فإن مفهوم الهُر يكون عبارة عن أي نشاط لا يضيف قيمة، ويالتالي تكون اول عملية لتقليل الهرر هي تحديد مصادر الهار والتي من الممكن أن تكون واحد من التالي: -الإتتاج الزائد ويعني انتاج أكثر من المطلوب ويعتبر أخطر أنواع الهدر. - أوقات الانتظار. -العمليات ويعد التصميم الضعيف لبعض العمليات مصدرا من مصادر الهذر حيث توجد عمليات لا داعي لها. -التخزين ويري انه ينبغي تقليل عمليات التخزين لأنها تزيد التكلفة. 
-المنتجات المعيبة: محاولة التقليل منها لأنها تقلل من الجودة وتزيد الهرر لذا ينبغي تتبع أسبابها

\section{أما الإدارة اليابانية فقد لخصت مصادر الهلر في ثلاث كلمات هي: Muda} Mura نموذجية محددة في أداء العمل. Muri والتوبيخ المستمر عليها اكثر من اتخاذ الفعل الصحيح. r - مشاركة الجميع: تهذف الإدارة الرشيقة الي تقديم نموذج عمل يضم كل الافراد وإلعمليات داخل المنظمة وتعد ثقافة المنظمة عنصر مهم جدا في دعم هذه الأهداف من خلال التركيز على مشاركة جميع الافراد في المنظمة في العمل ويذلك فهي تتشابه مع ثقافة الجودة الثاملة لذلك في بعض الأحيان يطلق على الإدارة الرشيقة اسم أنظمة الثقة بالعاملين واحترامهم حيث تتطلب انشاء فرق حل المشكلات المعتمدة علي الفريق واثثراء العمل وتدوير العمل والمهارات المتعددة ومنح مستوي عال من المسئولية للعاملين. ץ-التحسين المستمر: يعد تحقيق رضا العملاء ويمستوي عال من الجودة من اهم مبادئ الإدارة الرشيقة حيث يهتم بتعزيز العلاقة مع معايير الجودة بشكل مستمر وهذا ما يجعل فلسفة التحسين المستمر جزيء هاما من نظام الإدارة الرشيقة. كما قد تم عرض بعض المبادئ الأخرى للإدارة الرشيقة تمثلت في):Beauvallet,2009:85): 1 ـ تركيز القرارات على فلسفة طويلة المدي، باستثناء النواحي المالية وضع استراتيجية قصيرة المدي، وايجاد سياسة واضحة لمواجهة مشاكل العمل. r ـ التأكيد في ثقافة المؤسسة على ضرورة التوقف عند الحاجة وفي الوقت المناسب لمعالجة المشاكل من اجل ضمان مستوى جيد للجودة. r. احترام الشركاء وتثجيعهم بالسعي دوما نحو الأفضل والتحسين وتكريس مبأ العمل الميداني (أي فهم احتياجات ومتطلبات المجتمع المحيط) من اجل معرفة ماذا يجري بالضبط وفهم الوضعية بالشكل الصحيح. 
ع ـاتخاذ القرارات بروية ومن دون تسرع، ويالتوافق مع الأطراف الفاعلة داخل المؤسسة، مع الأخذ بعين الاعتبار كل العوامل المحيطة، وأن يتم العمل على تحديد أسباب مشاكل المؤسسة، والعمل على علاجها بشكل مستمر. ويتحليل المبادئ التي تم عرضها سابقا من خلال وجهات نظر الباحثين المختلفة نستخلص ان من اهم مبادئ التي تقوم عليها الإدارة الرشيقة ما يلي: 1 -تحديد القيمة التي سيحصل عليها العميل للمنتج من خلال روئيته ووجهة نظره لهذهان القيمة حسب نوع المنتج، ويالتالي يحرص مفهوم الإدارة الرشيقة علي تلبيه توقعاته ومتطلباته فيما يتعلق بالمنتج. r r تحليل سلسلة القيمة والمقصود بها إلغاء أي خطوة في العليات لا تحقق هذه القيمة، أي انه بعد تسليم المنتج النهائي للعميل تحليل العمليات التي مر بها المنتج حتى وصل للعميل واستبعاد العمليات التي تري المنظمة انه لا داعي لها وتعديل ما يحتاج للتعديل بحيث لا يحدث هدر في العمليات. r أن تكون هذه الخطوات وفق تسلسل قصير ومترابط وغير متشعب، بحيث تتدفق القيمة بسلاسة وسهولة للعميل.

؛ السحب وهو أن يتم إنتاج ما يحتاجه العميل بالفعل، وليس ما تريد تقديمه أنت. ه التحسين والتطوير المستمر من أجل الوصول بقيمة مثالية مقدمة في المنتج يحتاجها العميل دون أي هدر.

ويالتالي فإنه عند تطبيق مبادئ الإدارة الرشيقة في التعليم الجامعي ستكون اهم المبادئ التي يرتكز عليها مفهوم الإدارة الرشيقة تحقيق رضا الخريجين عن جودة الأداء الجامعي وفق الإدي متطلبات سوق العمل من الخريجين، وتعلم المهارات التي يتطلبها الخريج في ظل المجتمع المحيط وما يواجه من تغيرات وتطورات مستمرة، الي جانب تحقيق رضا العاملين وأعضاء هيئة التدريس والتحسين المستمر للعمليات وتقليل الهار في العمليات والوقت.

\section{4 - معيزات وأهداف المؤسسات التي تستخدم الإدارة الرئيقة.}

قبل التعرف على مميزات وأهداف المؤسسات التي تستخدم الإدارة الرشيقة سوف نعرض مفهوم المنظمة الرشيقة وهي المنظمة التي تتميز بوجود إجراءات صارمة ومنظمة للعمل، ونظام إداري جيد، واستراتيجية واضحة للتحسين المستمر، الي جاتب توفير عنصر 
الالتزام بمبادئ الجودة في الأداء من قبل العاملين بها فضلا عن انها تعتمد علي مدخل واضح واستراتيجية فعالة لحل مشكلات العمل، واعتبار توقعات ومتطلبات العميل والسوق المحيط اول متطلبات وشروط الإنتاج لايها، واعتماد سياسة الابداع في جميع النواحي الإدارية والتتظيمية والمرتبطة بالموارد البشرية بالمؤسسة(Bell stave,2006). ووفقا للتعريف السابق نلاحظ ان من مميزات المؤسسات التي تستخدم أسلوب الإدارة الرشيقة أنها تستند على دمج نظام تكنولوجيا المعلومات داخل المنظمة ويطريقة منسقة ومرنة بحيث تكون قادرة على الاستجابة بسرعة للأحداث والتغيرات في البيئة المحيطة،

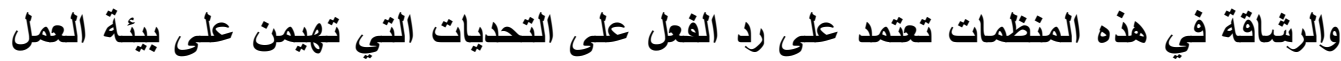
أو السعي لتحقيق النجاح، كما أن المنظمات الرشيقة تقيم باستمرار أداء الموظفين ، كما أنها تفكر بشكل أبعد من كيفية التعامل مع التغيرات، إنما تفكر في كيفية استغلال الفرص في بيئة شديدة التغير، وتحقيق مكانة مرموقة آخذة بعين الاعتبار قدراتها وكفاءاتها(محمد هنية،

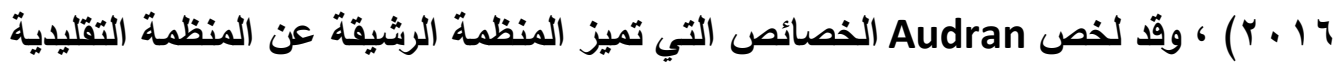

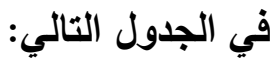

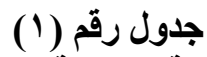

الفرق بين المنظمة الرشيقة والمنظمة التقليدية

\begin{tabular}{|c|c|c|}
\hline المنظمة التقليدية & المنظمة الرشيقة & المعيـار \\
\hline هرمي/رأسي & هيكل شبكي ذو شكل أفقي & الهيكل التنظيمي \\
\hline امتلاك الخبرة & تعدد الاختصاصات & كفاءة الوحدات والفرق \\
\hline مركزي & لا مركزي & تدفق المعلومات وصناعة القرار \\
\hline السيطرة و المراقبة & التسبيق والتسوية & دور المدراء \\
\hline وجود الاحترام، والكفاءة & التكيف، والمسؤولية، & نوعية الأفراد \\
\hline
\end{tabular}

أما بالنسبة لمميزات الجامعات التي تطبق مفهوم الإدارة الرشيقة فتكون كما يلي (سليمان

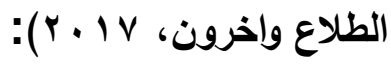


1 - احترام منسوبيها وذلك من خلال (الاهتمام بصحة العاملين وسلامتهم- توفز المعدات اللازمة لسلامة العاملين-تخصيص أوقات راحة للعاملين أثناء ساعات العمل الكثيفةتشجيع العاملين علي تبادل ومشاركة المعلومات وعدم عرقتها- توفير الجامعة منصة الكترونية لتبادل المعارف والخبرات بينها وبين الجامعات الأخرى-تخفيف الإجراءات الإدارية الطويلة -تشجيعهم علي الثقة المتبادلة في العلاقات بين العاملين داخل الجامعة--توفز درجة من الاستقلال والحكم الأتي للعاملين - تعزيز العمل الجماعي والتضامني وروح الفريق-تقديم الدعم والمساعدة للعاملين من طرف رؤسائهم المباشرين-اكتشاف إمكانات الموظفين وحثهم علي توظيفها وإتغلالها-توفر دورات تدريبية متخصصة تمس كل التخصصات-توفر ساعات تدريب كافية لجميع منسوييها). r - تقليل الهُر وذلك من خلال (تخفيض الهُر في مواردها-اعتماد أساليب إدارية تخفض الهار في أنشطتها المختلفة-نشر ثقافة ازالة الهار لكافة منسوييها-الالتزام بالإنفاق حسب بنود الموازنة المالية). r- خفض تكاليف عمليات الصيانة باستمرار وذلك من خلال استخدام أدوات مستحثثة لخفض التكاليف. ع - مراعاة متطلبات الخريجين وذلك من خلال اعتماد برامج تعليمية مناسبة لمتطلبات الطلاب المعرفية والتكنولوجية والثقافية وحاجات سوق العمل وتوفير عملية تعليمية إبداعية ذات جودة عالية وتركيز الخطط الدراسية على تنمية مهارات الطلبة العملية. ه- تعظيم القدرة التنافسية للجامعة وذلك من خلال تزايد أعداد الطلبة الملتحقين بالجامعة وخصوصا الدوليين وارتفاع في فرص التوظيف والعمل بالنسبة لخريجي والجامعة ويكون ذلتك بتوفير التخصصات التي يطلبها سوق العمل وغلق التخصصات الأخرى التي ترتفع فيها نسبة البطالة مع وضع خطة متجددة باستمرار لمتابعة ذلك، وتحديث المعارف والمقررات الدراسية باستمرار بحيث تتوافق والتغيرات المعرفية المحيطة واحتياجات الطلاب المختلفة وتثجيع أعضاء هيئة التدريس بها علي اجراء البحوث وخصوصا الدولية وارتباط ابحاثهم بمشروعات التنمية وحل مشكلات المجتمع المحيط بحيث تكتسب جانب تطبيقي تنموي وإيجاد نظام جيد للتقييم الذاتي الداخلي والخارجي. 
أما عن الأهداف التي تسعي الإدارة الرشيقة بالمنظمات المختلفة الي تحقيها فهي (سليمان

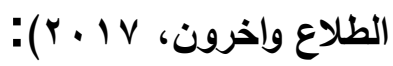

ا ـ خفض زمن تقايم الخدمة، وسرعة الاستجابة لمتطلبات العميل. r ب زيادة الإنتاجية وتحسين الجودة وتعظيم الريحية. r. تعظيم القدرة التنافسية القائمة والسعي لبناء قدرات تنافسية جديدة. ء. الحد من الفاقد بسبب الإنتاج الزائد، وفترات الانتظار (ققد زمني) وتكرار اعمال النقل، وعمليات غير مخطط لها جيذا، ومخزون غير ضروري، وحركات غير ضرورية للأفراد والمعدات (غير فعالة) وعيوب إنتاجية (عيوب بالمنتج)، وحوادث الافراد والمعدات والأعطال وزمن تسليم المنتج وتقليل عدد المخزون في كل مراحل الإنتاج وإي عناصر اخري تؤثثر في العملية الإنتاجية. كما أن فكر الإدارة الرشيقة يقوم على تغيير مؤسسي يشمل العديد من الممارسات والأدوات التي تساهم في جعل الأنثطة بسيطة وسريعة وإنسيابية مثل (تحسين بيئة العملتحسين مناخ العمل النفسي "علاقات العمل والعاملين"- الإنتاج بنظام وحدة وإحدة بدلا من الإنتاج الكمي-تظبيق نظم العمل الجماعي "فرق عمل تضم أفراد من ذوي المواهب والمهارات المتعددة" لاوائر الجودة ومشروعات التحسين وحل المشكلات-توظيف تقتيات تقلل الخطأتوظيف تقتيات المراقبة البصرية في كل الأنشطة المتاحة-الصيانة الإنتاجية الشاملة-بناء الجودة عند المنبع مع استخدام تقتيات متطورة-خفض زمن وتكاليف اعمال الصيانة-تطبيق مفاهيم اقتصاد الحركة لتحسين أداء الافراد-الاستثمار في المعرفة-تثجيع الابداع والابتكار الشفافية وتجنب الغموض -محارية الروتين-تعظيم مفهوم القيمة المضافة في تبسيط إجراءات العمل حيث يتم استبعاد أي اجراء اداري ليس لله قيمة مضافة بالنسبة للعمل او

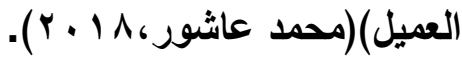
ويالتالي ووفقا لفكر ومبادئ الإدارة الرشيقة فإن أيه منظمة لن تتمكن من مواكبة مستجدات العصر والمتغيرات السريعة في عالم التقتية والمعلومات والعولمة من الأداء المتوازن وتحقيق الجودة والتطور والمنافسة الا بالتخلص من الإدارة الثقيلة ومشكلاتها البيروقراطية وعوائقها التظيمية والاجرائية وغيرها، والتحول الي الإدارة الرشيقة بمفاهيمها الحديثة وأساليبها المتطورة وشفافيتها المطلة ونظرتها الشمولية التي تمكن من استيعاب التهي 
المتغيرات الجديدة والاسهام الفاعل في التغيير والتظوير والتنمية الثاملة المستدامة بعقلية إدارية رشيقة.

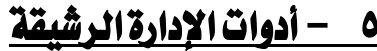

تتميز الإدارة الرشيقة بامتلاكها لمجموعة من الأدوات تستخدم للحصول على النتائج

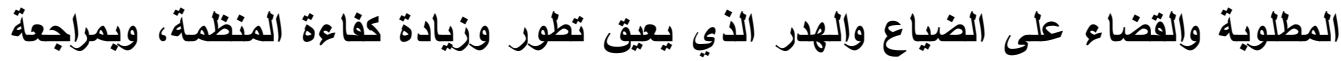
الاراسة لآراء بعض الباحثين حول أهم أدوات الإدارة الرشيقة وجد أن من أكثر الأدوات الشائعة في تطبيقات الإدارة الرشيقة، والتي تتداخل ضمنياً مع باقي الأدوات هي ما يلي: • السينات الخمس أو تنظيم موقع العمل: هذه القلسفة تعني الالتزام بمبادئ خمسة من اجل تحسين ظروف العمل داخل المنظمة من اجل تقليل الوقت الضائع في البحث عن أدوات العمل وضمان السلامة المهنية للعاملين من اجل تجنب الههر في مصاريف التامين والتعويض، وقد سميت بالسينات الخمس لأنها كلمات ياباتية تبدأ كلها بالحرف "S"

I. Seiri: وتعني التخلص من كل ما هو غير ضروري في مكان العمل. Y. . . Yeiton: وتعني تنظيم مكان العمل من أجل إيجاد الأدوات في أقرب وقت وضمان سلامة

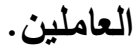

r. Seiso: وتعني تنظيف المكان من أجل إضفاء جو يبعث على الارتياح. ؟. - -Seiketu: وتعني جعل المعايير السابقة جزءا من إدارة مكان العمل. ه. Shituke: وتعني التريب وغرس الانضباط في عقول وسلوك كل العاملين المحيطين. وهي طريقة بسيطة توضح كيفية جعل مكان العمل نظيف وخال من الفوضى، ومنظم بشكل جيد، أي انها الأداة التي تستخدم لتنظيم وتحسين مكان العمل، والبيئة المحيطة بالعاملين لتعزيز انتاجيتهم وضمان ادخال العمل القياسي، بحيث يمكن من العثور علي الأثياء بسهولة والوصول اليها بسرعة ويدون تأخير \&ichalaskai \& Szewieczer,2007 ، وهي منهج أساسي ومنظم لزيادة الإنتاجية وتحسين النوعية والأمن والسلامة في جميع أنواع الاعمال أي يمكن اعتبارها كأسلوب للتدبير المنزلي \& Agrahari ) .chandratre,2015) 
• العمل القياسي: والذي يعد حجر الزاوية لأي جها يوجه نحو التحسين المستمر، فهو

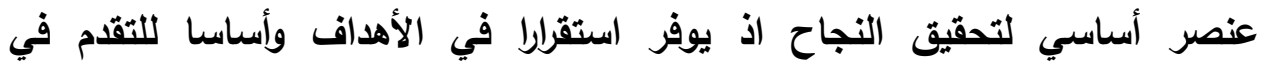
المستقبل، ويساعد هذا الأسلوب المنظمات للوصول الي أهدافها في التحسين المستمر، فضلا عن قدرته في توفير بيئة عمل مستقرة، ويمكن تعريف هذا الأسلوب بوصفه أفضل وسيلة للقيام بالعمل، وإنه يشير الي توحيد الإجراءات التنفيذية على موقع العمل لضمان رضا العملاء، أي يبين هذا الأسلوب ماذا؟ وأين؟ ومتي؟ ومن؟ وكيف؟ ينبغي القيام بالمهمات لضمان الخروج بأفضل النتائج (Krichbaum,2008:2). - التحسين المستمر(الكايزن): وكايزن كلمة يابانية معناها تحسين أو التغير المستمر للأفضل وتتبعها المؤسسات المختلفة من أجل تقليل الوقت وزيادة الكفاءة وتحسين الجودة ويتم عن طريق تحسين الكفاعة التشغيلية والإنتاجية وذلك بتحسين المباني والتجهيزات وطرق الإنجاز والمواد من أجل تحسين العوامل المرتبطة بتحويل المدخلات

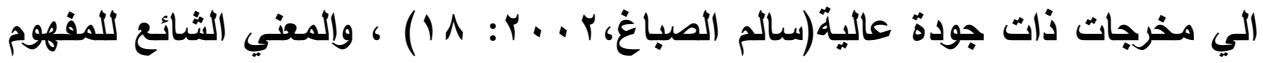
هو التحسين التدريجي المستمر، في جميع نواحي المنظمة، وليس فقط في سلسلة عمليات الإنتاج الأساسية، حيث ينخرط جميع العاملين في المنظمة في عملية التحسين وعلي جميع المستويات الادارية بغض النظر عن مراكزهم الوظيفية من الإدارة العليا الي العاملين في المستويات الانيا (Glover Jacksun,2014:41)، ويمر التحسين المستمر عبر دورة او فلسفة كايزن كالتالي: 1-التخطيط: يقوم فريق العمل في هذا المرحلة باختيار موضع التحسين ويتم توثيقه من خلال تحليل البيانات باستخدام طرق التحليل المختلفة مثل قوائم الفحص ومخطط السبب والنتيجة (عظم السمكة) والمدرجات التكرارية والاشكال البيانية وغيرها ثم تحديد أهداف التحسين وإلتكاليف والمنافع المترتبة على بدائل لتحقيق هذه الأهداف (حاتم كاظم، II ـ ب:

r-التفيذ: يسعى فريق العمل لتنفيذ خطة التحسين ومراقبة تقدمها وجمع البيانات بشكل مستمر لقياس التحسين في العملية الخاضعة للتحسين كما ان أية تغيرات فيها لابد من توثيقها وإعادة النظر اليها ان دعت الحاجة. 
r-المراجعة: في هذه المرحلة يقوم فريق العمل بتحليل البيانات التي تم جمعها في المرحلة الثانية للوقوف على مدى تحقيقهم للأهداف المرغوية والمحدة بمرحلة التخطيط وفي حالة وجود أي خلل او قصور فلابد ان يعاد تقويم الخطة او ايقاف العمل بها. ع -التصحيح: التحسين بناء على نتائج التقويم وهنا إذا كانت نتائج التقويم جيدة يتم توثيق العملية المحنة وتبليغها لكل العاملين وتدريبهم على تنفيذها اما إذا كانت النتائج غير ذلك جلته يتم تعديل الخطة واعادة الاورة من جديد. - أداة 7 sigma (متعدد الوظائف): يوجد عدة مفاهيم لمصطلح ستة سيجما تتراوح بين اعتبار المفهوم مجرد مقياس إحصائي لقياس الجودة، أو اعتباره استراتيجية أو مدخل أو فلسفة جديدة للتحسين المستمر، مما يؤدي إلى بناء سمعة عالية لمنتجات المنظمة وخدماتها، تعود بالفائدة على المستخدمين والعملاء والمساهمين، وتقوم الأداة 7 sigma التنظيمية - دعم الإدارة العليا. ويشير المصطلح الي الاتحرافات والتغيرات الكامنة في ايه عملية داخل النظام تسمح للمنظمة أن تستنتج عدد العيوب في المتوسط التي تحدث في العملية، هذه العيوب هي انحرافا عن حدود ملزمة محددة سابقا، أي تضع المنظمة حدودا عليا ودنيا ملزمة، والمنتج الذي يقع خارج هذه الحدود أي يكون اعلي من الحدود العليا او اقل من من مئ الدود الانيا يعد منتجا معيبا(Banuelas, R., and Antony,2002) ويمعني آخر فانه يعني العملية التي لا ينتج عنها أكثر من \&.ب عيب لكل مليون

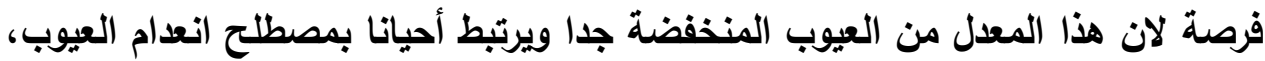
او هي عبارة عن منهج تطبيقي يعمل على تحسين جودة العمليات وتخفيض التكاليف

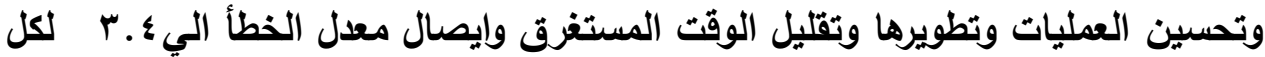

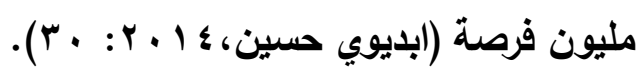

- العاملين متعددي الوظائف: ويشير مفهوم العاملين متعددي الوظائف إلى ذوي المهارات

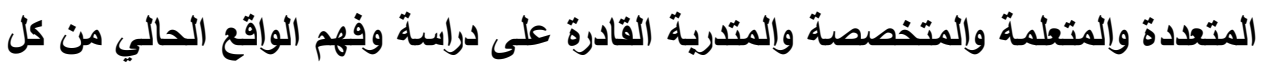
جواتبه والقادرة على حل مشكلاته، بل وتطويره إلى الأفضل، وذلك بخلاف الإدارة التقليدية التي تعتمد على أصحاب الخبرة. 
فبعد ظهور مصطلح الإدارة الرشيقة تعددت البحوث والدراسات لتحديد العناصر والأنشطة الضرورية لتحقيق مفهومها بوصفها تحقق مكاسب كبيرة لكل أصحاب المصلحة في أي نشاط، وتغيرت النظرة للعاملين بوصفهم الشريك الرئيس في اعمال التطوير والتحسين فضلا عن اهتمام المنظمات بتحسين مناخ العمل النفسي وتطوير برامج التدريب المناسبة ومفهوم مجموعات العمل الصغيرة وفرق المشروعات وغيرها من آليات العمل الجماعي ، فهو أسلوب لتدريب العاملين للتعامل مع اكثر من مهمة او عملية داخل المنظمة نفسها من اجل تحقيق أهدافها بالاستجابة السريعة لمتغيرات العمل او الوظيفة، والأخذ باقتراحات العاملين وذلك من خلال إثراكهم في صنع القرارات ووضع الخطط والسياسات اللازمة ( عبدالرحمن بن وارث وإحمد جابة ، 19 ـ ب ). - فلسفة الإنتاج في الوقت المحدد: يقوم هذا النظام على جعل نظام الإنتاج يعمل وفق ما هو مطلوب من دون زيادة أو نقصان، ويالتالي فهو يهدف إلى إزلالة كافة أشكال الهدر والتلف التي من المكن أن تقع أثناء عملية الإنتاج وحتى يتم إزالة الهار يجب إنتاج فقط ما يطلبه العميل ومن دون زيادة، هذه القلسفة تقوم على نظام Pull(سحب) أي الطلب الفعلي هو الأي يخلق الإنتاج ومن ثم المبيعات(Larry et autre,2004) ـ - فلسفة Jidoka: وتمثل المبدأ الفعلي الأي تقوم عليه الإدارة الرشيقة وتعني البناء على الإنى أساس الجودة أو الجودة من المصدر حيث أن عامل الجودة يجب أن يامج في كل العمليات من اجل اكتشاف العيوب في وقتها ويصفة مبكرة، وتقوم هذه القلسفة على مجموعة من المبادئ الأساسية هي: 1. التقتيش المباشر: عملية مراقبة الجودة يجب أن تكون من العمال أنفسهم ولا حاجة إلى هي استعمال مراقبين خاصين بالجودة، لأنه وحسب مبادئ الإدارة الرشيقة فان استعمال مثل هذا النوع من المراقبين يعتبر هدر في الطاقة البشرية. r. التقتيش من المصدر: عملية مراقبة الجودة لا تعني فحص المنتج إن كان به عيوب أو لا، وإنما تعني البحث عن كيف ولماذا حدثت العيوب وذلك من اجل معالجة مصدرها 
r. المسؤولية الواضحة: في مؤسسة الإدارة الرشيقة خطوات عملية التصنيع يجب أن تكون واضحة ومتى حدث العيب يتم التعرف بسهولة عن مصدر القطعة المعيبة والمسؤول عن

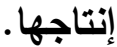
؛. التوقف الضروري عن العمل حين اكتثاف العيوب وعدم استئنافه إلا بمعالجة المشكلة واستئصالها من النظام ككل.

ه. تنميط العمل: ويعني أن عمليات الإنتاج ومختلف الإجراءات في كل مراحل الإنتاج يجب أن تكون مفصلة ومحددة وتصف بدقة الخطوات الرئيسية لكفاءة العملية الإنتاجية وهذا التوصيف يقلل من الاختلافات الممكن حدوثها في العمليات، كما أن عدم وضوح الإجراءات يؤدي بالعامل إلى ارتكاب أخطاء في الإنتاج ومفهوم تنميط العمل يتضمن

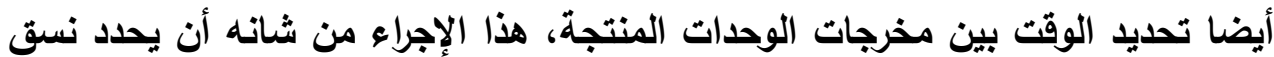
العملية الإنتاجية في مختلف الأقسام(Barac \& others,2010:329) Single Minute هريقة S.M.E.D: هذه الحروف هي الحروف الأولى لكلمات الجملة: Exchange of Die بتخفيض قر الإمكان وقت التهيئة والإعداد للعملية الإنتاجية من خلال التوصيف الاقيق لمختلف مراحل وخطوات هذه العملية واستعمال تقنيات بسيطة من اجل خفض وقت العمليات الداخلية للإعداد وهي العمليات التي لا يمكن القيام بها إلا عند توقف عملية الإنتاج.

الأخذ باقتراحات العاملين: وذلك من خلال إثراكهم في صنع القرارات ووضع الخطط والسياسات اللازمة، وهذا التقدير أساسه احترام العاملين وتوفير بيئة عمل مناسبة

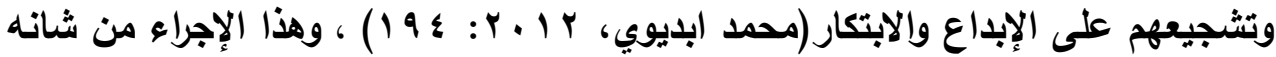
أن يجنب المؤسسة عدة مشاكل متعلقة بعدم الرضا للعمال الأي غالبا ما يكون مصحويا بإضرابات تؤدي إلى التوقف عن العمل، وهناك آلية تستعملها بعض المؤسسات لتثجيع Fiches ) الإبداع داخل المؤسسة حيث قامت باستحداث بطاقات سميت ببطاقات الإبداع (Innovation عليها مقترحاتهم لتحسين نظام الإنتاج وتكون هناك منح تقدم مقابل أحسن الاقتراحات(Bouville Gergor,2010). 
رضا الموظقين: ويعتبر الرضا المقياس الأساسي للأداء فكلما تحقق رضا العاملين عن عملهم كلما كانت النتائج مرضية حيث أن العلاقة طردية بين الرضا الوظيفي والإنتاجية

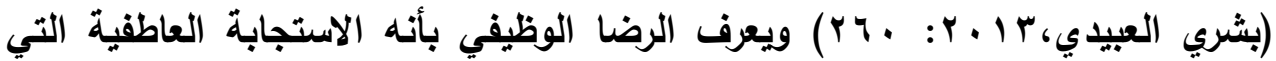
تصدر من الفرد تجاه جوانب من عمله وتثمل الشعور السلبي والايجابي تجاه وظيفته

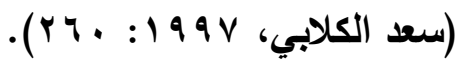

الريادة: وتعني تعزيز الابتكار وتتحقق من خلال سعي المنظمات الي التميز على المستوي المحلي والعالمي من خلال تبني الأساليب الحديثة في كافة المجالات وذلك بالتركيز على الدافعية في تحقيق اجود المخرجات وتحويل الأهداف التي تحقق الريادة الي واقع عن طريق إيجاد الفرص الداعمة لتحسين المخرجات والتطلع الي الأفضل من

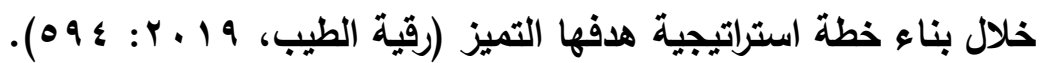
ويتحليل الأدوات السابقة للإدارة الرشيقة نلاحظ أن أداة 5sكذلك الإدارة المرئية يعتبروا من العناصر المرتبطة ارتباط وثيق بنظام الإدارة الرشيقة وسبب تميزها، إلا انهم وغيرهم من الادوات الأخرى يساهموا ويقسط كبير في المحافظة على موارد أي منظمة وخاصة الوقت منها، ولعل النجاحات المحققة في شركة تويوتا كان بفضل هذا الأسلوب والتخلص من الصراعات وقتة نسبة الهلدر ويالتالي تحقيق كفاءة المنظمة.

\section{的}

كما اتضح من تعريف الإدارة الرشيقة أنها تهتم بإزالة كافة أثكال الهُر في العمليات المختلفة داخل المؤسسات أو MUDA وهي كلمة يابانية تعني كل نشاط انساني يستهلك موارد انتاج بدون فائدة حقيقية كحركة العمال، وتثقل السلع من نقطة الي اخري بدون سبب حقيقي وحدوث توقفات في مرحلة معينة بسبب تأخر في مرحلة سابقة، كذلك سلع وخدمات لا تحقق رضا العميل (James \& Daniel,2009:3) ونستطيع أن نلخص أشكال الهُر المختلفة بالنسبة للإدارة الرشيقة من وجهه نظر

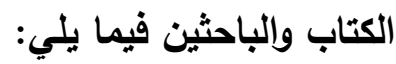
ا- الإنتاج الزائد: وهو الإنتاج الذي يفوق الطلب، أو الإنتاج الذي لا يباع مباشرة بعد الإنتاج، ويالتالي يسبب هدرا في المساحة والموارد المالية للمؤسسة \&ames ) 
Y - وقت الانتظار: هذا الوقت يعتبر بمثابة وقت ضائع يمكن أن يكون ناجما عن تدفق سيء في خطوط الإنتاج بسبب انتظار القطع لفترة معينة قبل المعالجة، أو انتظار العامل لوصول القطع الي مركز العمل، أو تعطل الالة وتوقفها لسبب معين، بالإضافة الي التوققات الناجمة عن توقف الإنتاج بسبب تغيير قالب آلة معينة من اجل البدء في عملية اعداد أو تهيئة عملية إنتاجية جديدة.

r- وقت المناولة: هو الوقت الذي يضيع في التنقلات الداخلية داخل المؤسسة بين مراكز العمل أو بين مختلف الورشات، لذلك فإن نظام الإدارة الرشيقة يقوم بتقليص عدد المرات التي يقوم فيها العامل بأخذ أو وضع القطع من دون إضافة قيمة مضافة للعملية الإنتاجية

.(Olivier \& others,2012:2)

ع- تحضير سيء للعملية الإنتاجية: يحدث هذا بسبب التقتيات الكلاسيكية التي يستعلها الإداريين للإعداد لعملية الإنتاج، فالإدارة الرشيقة تركز على فكرة تنميط ووصف جميع المراحل والعمليات للإعداد بالشكل الذي يجعل الجميع يعمل بنفس الطريقة، ويكون ذلك باستعمال تقنيات تتكيف مع التكنولوجيا الحديثة، مما يسمح بالتكيف الجيد مع طبيعة

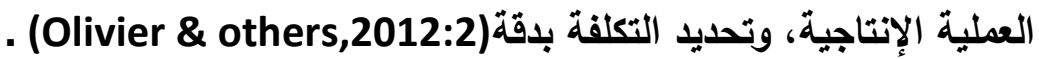
ه- المخزون: تعتبر الوحدات المخزنة هدرا في المال والمساحة وتحتاج إلى تكاليف إضافية من أجل الاحتفاظ بها لذا يجب القضاء على هذا النوع من المصاريف التي تعتبر المؤسسة في غني عنها. 7- الحركة غير الضرورية: هذا النوع من أشكال الهرر لله نفس طبيعة الهـر المتأتية من المناولة، ويدرج في هذا النوع من الهُر كل حركات وتنقلات العامل في مركز عمله الناجمة عن سوء التظيم(Olivier \& others,2012:2 ) ، فالعامل الذي يحتاج الي أداة معينة في عملة وتكون هذه الأداة موضوعة في مكان بعيدا عنه فانة يضطر الي الاتتقال عدة مرات لإحضارها مما يؤدي الي هدر الجها والوقت، لذا يجب على المؤسسات أن تنظم أمكنة العمل بالشكل الذي يجعل الأدوات التي يستعملها العامل قريبة والأدوات التي

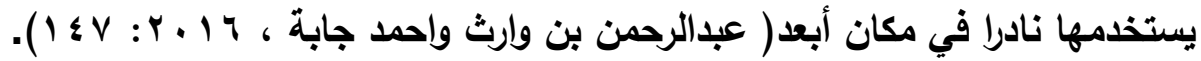
V- الأخطاء غير الضرورية: وهي كل الأخطاء الناجمة عن عملية التصنيع والتي تسبب حالة اللا جودة في المنتج، والعمليات فتكون مجموعة من الأخطاء، خطا في المنتج مما يسبب ارتفاع التكلفة، وخطأ في وثائق خاصة بإنتاج المنتج، تؤدي الي إعطاء معلومات خطأ في 
كافة مراكز العمل، وتأخر في الإنتاج أو التسويق، مما يؤدي الي تأخر دورة الإنتاج .(Barac \& others,2010:322) ^- عدم استعمال الطاقات والابداع الفكري للموظقين والمسؤولين والتي تعتبر تضييعا لفرص

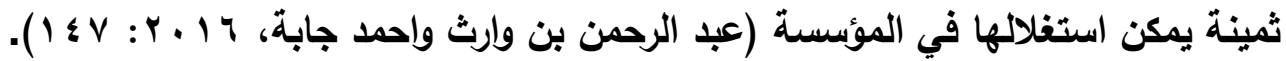
ويالتالي نلاحظ مما سبق أن أساس الإدارة الرشيقة هو اعتبار أن أي عملية لا تضيف

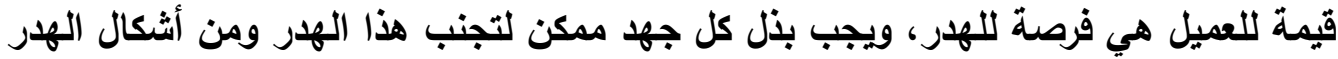
بالنسبة لمفهوم الإدارة الرشيقة (الإنتاج الزائد-وقت الانتظار -وقت المناولة ويقصد به وقت الإيداع وسحب القطع من والبي المخازن -تحضير سيء من طرف العمال للعملية الإنتاجيةالمخزون -الحركة غير الضرورية-الأخطاء غير الضرورية-عدم استغلال طاقات الموظفين).

كما تتمثل جواتب الهدر أيضا في وجود عيوب في المنتج والتي تحتاج إلى وقت إضافي، وموارد، ومال لإصلاحها وريما كان سبب تلك العيوب راجع الي سوء فهم احتياجات العملاء، أو ضعف السيطرة على عمليات الجودة، أو سوء تصميم العمليات، أو عدم وجود معايير يتم الرجوع اليها، ويالتالي للقضاء على العيوب قر الإمكان ينبغي تطبيق خطط عمل موحدة، ومراقبة أكثر صرامة للجودة على جميع المستويات، وفهم كامل لمتطلبات العمل واحتياجات العملاء.

كما قد يكون الإتتاج الزائد أحد أسباب الهدر والذي قد ينتج بسبب الإنتاج على أساس التوقعات فقط، كما ان احتياجات العملاء غير واضحة، والتي يمكن التظلب عليها وفق منهج الإدارة الرشيقة عن طريق وضع استراتيجية واضحة منذ البداية تحدد احتياجات العملاء. أيضا فان الانتظار من عوامل الهار وفقا لمنهج الإدارة الرشيقة والذي قد يكون سببه عطل شيء ما، أو نفاد من بعض المكونات اللازمة للعمل، والموظفين غير المؤهلين، وضعف مهارات التواصل بين الموظفين، ويمكن التعامل مع هذه المشكلة عن طريق تعيين الموظفين المناسبين الذين يمكنهم تحمل عبء العمل، والتحكم في الجودة والمخزون، والتأكد من أن المعدات تعمل في جميع الأوقات، والتدريب المشترك للموظفين. كذلك فان القدرات الغير مستغلة قد تكون سبيا في الهدر وفقا لمنهج الإدارة الرشيقة ويحدث ذلك عندما يكون الموظقون المؤهلون في وضع الخمول في انتظار انتهاء عملية من قبل موظف آخر، أو عند غياب العمل الجماعي، أو عدم وجود برامج تدريبية، أو التواصل 
الضعيف أو رفض المديرين تضمين الموظقين في عملية حل المشكلات كذلك سوء الإدارة، ولعلاج ذلك ينبفي تمكين العاملين، وتعديل أي خطأ في تدريبهم، وأن تعامل الموظفين المؤهلين وذوي الخبرة كخبراء في العمليات يعرفون ماذا يفعلون.

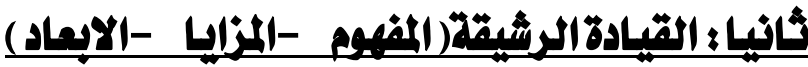

\section{1 - مفعوم القبادةالرشيقة}

يعتبر متغير القيادة الرشيقة من المتغيرات الحديثة التي لفتت انتباه الباحثين، وان انطلاقة هذا الاهتمام كان نتيجة تشخيص الباحثين خلال العشرين سنة الماضية الي الدور الكبير الذي تلعبه القيادة في تحقيق النجاح للمنظمات المختلفة وقد تخلل هذا التشخيص ظهور نظريات ونماذج عده تفسر ما الأي يجب علي القائد القيام به او عدم القيام به،

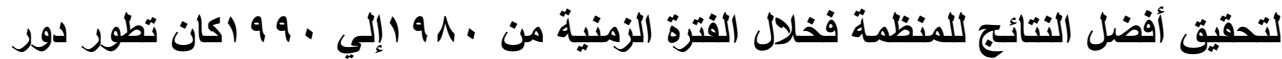
القيادة بشكل كبير من حيث تأثيرها المباشر علي مجريات العمل، اذ ظهرت في تلك القترة مفهوم القيادة التحويلية التي كاتت تركز علي تعزيز عمليات التحفيز والقيم الأخلاقية والأداء بين العاملين، ثم القيادة التبادلية التي بنيت افكارها علي الالتزام النفسي بإنجاز كل طرف(الافراد والمنظمة) ما يتوجب عليه تجاه الاخر بناء علي تبادل المصلحة ، وفي نهاية عام • 99 ام قدم نموذج اخر للقيادة يطلق عليه اسم القيادة التطويرية والذي يعد نموذج مطور للقيادة التحويلية وهو يشير الي تلك السلوكيات التي يكون من شأنها ان تجعل العمل يسير بصورة متسلسلة بدون روتين زائد او تعقيد في العمل(Ligungblom,2012:56). واستمر الاهتمام بأنواع القيادة وظهور تجلياتها ضمن سلوكيات وأفكار كثيرة كالقيادة

الروحية والاصيلة والخادمة وغيرها الي ان استفاد الباحثين من مفهوم الترشيق في العملية الإنتاجية للإثارة الي سلوكيات القيادة الرشيقة، اذ يتصف القائد ذو السلوك الرشيق بسلوكيات معينة منها مساعدة الافراد واحترامهم واعتماد الدعم للأفراد والتركيز على مجريات العمل وامتلاك

الروية المستقبلية والاهداف الواضحة والالتزام المستمر (Puvanasvaran,2012,930). وقد تم الإشارة الي القيادة الرشيقة بأنها السلوكيات التي تضيف أو تخلق قيمة(Ligungblom,2012:59) ، كما عرفت بأنها تلك السلوكيات التي تحقق قيمة وتخفض به

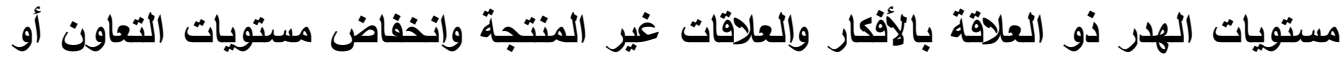

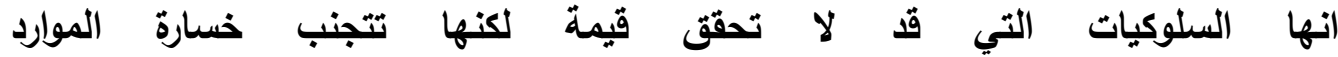


(Ligungblom,2012:59) ، او هي طريقة منظمة لتحقيق التنفيذ الأفضل للأعمال من

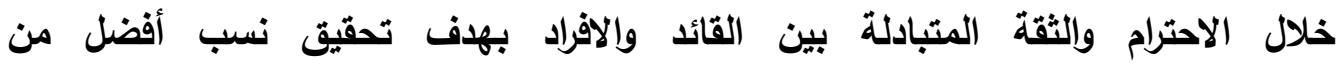
الكمال(Dombrowski \& Mielke,2013) ، كما عرفت بأنها القيادة ذات التعامل السهل ولينة الجانب وتمتلك مستويات عالية من الصبر فيما يخص الافراد وتدريبهم وتطويرهم فضلا عن الحزم في مواطن حل المشكلات، وعرفت بانها هي القيادة التي تحترم الوقت وتهتم بالأفكار المنتجة وتبتعد عن السلوكيات التي تسبب هار في الطاقات وتستخدم المهارات

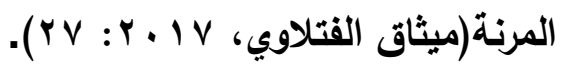
ويالتالي فإن القيادة الرشيقة هي القيادة التي تقوم بتصرفات حسنة وفاعلة في أداء ادوارهم فضلا عن جعل أدوار المروؤوسين لليهم قائمة على أساس التمكين الإداري.

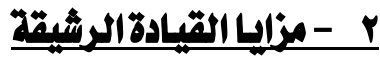

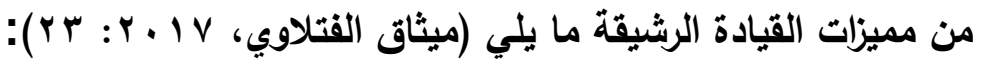
• تحقق فهما أفضل لماهية الأدوار التي يكلقون بها. • تحقيق انجاز أفضل لتطبيقات الرشاقة داخل المنظمة ويما يشيع ثقافة تحقى متطلبات السلوكيات الرشيقة من خلال تبادل المطلومات والتغذية العكسية. • يتضمن الفكر الرشيق للقيادة اعتقادا بان الافراد في المنظمة يشكلون رأس المال الفكري والاهم في تثكيلة هيكلية المنظمة وعليه يجب أن يكون دورهم واضح وفعال في اتخاذ القرارات والمشاركة في وضع الحلول الناجحة للمشاكل فضلا عن تقديم الاقتراحات البناءة. ان توفر مستويات عالية من سلوكيات القيادة الرشيقة يوجد روابط جيدة بين الثائد والعاملين قائمة على المحبة والاحترام المتبادل.

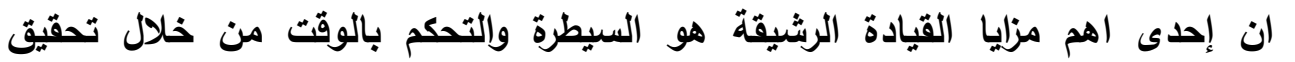
استخذاما أفضل للوقت وتقليل الهذر فيه ويالتالي تقليل هلار الطاقات. ويالتالي فان اهم ما يميز الإدارة الرشيقة انها طريقة إنسانية اكثر من كونها طريقة ميكانيكية لإدارة الأمور والأنثطة، حيث تركز علي إعطاء قيمة اكبر للأفراد والتواصل بينهر أكثر من تقييم الأدوات والعمليات، حيث يسعي القائد الرشيق الي معرفة دوافع فريق عملة الأيلة وأصحاب المصلحة ومعرفة الأثياء التي تحفزهم ويعدها يقوم بعمل موائمة لمهام وأنثطة 
العمل بما يتناسب مع دوافع ومحفزات فريق عملة والعملاء مما يصل بمعدل الإنتاجية لدية لأعلي درجة ، ومن الأمور التي يركز عليها تلبية احتياجات فريق العمل والسعي الي ازالة كل العوائق أمامهم وتقديم كل الدعم الممكن لزيادة إنتاجية فريق العمل ويقيهم من المقاطعات اثناء انجاز المهام والتتواصل المستمر معهم ومع العملاء وتوفير كل ما يحتاجونه من حوافز مادية ومعنوية.

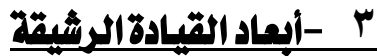

من الخصائص والسمات التي تتميز بها شخصية القائد الرشيق ما يلي: سمة التواضع: ان التواضع يعتبر سمة أخلاقية وفضيلة تتعلق بكيفية التفكير الأفضل حول الاعمال ويما ينسجم وإلميول الشخصية المقبولة والتي تؤسس لاندماج أفضل للفرد في المجتمع المحيط به ، وان مدي توافره نسبي فأوقات يبدو يتحسن في حين أوقات اخري يظهر بانخفاض متأثر بشخصية الفرد وما يحيط به من مجريات العمل وما يلاحظ

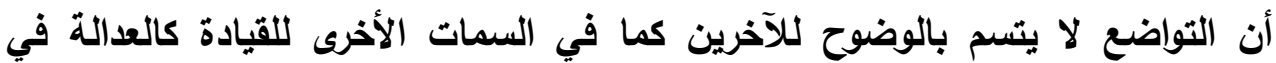
التعامل مع الافراد أو الإجراءات وغيرها مما يتجسد بشكل واضح للأفراد باعتماد المقارنة البينية أو غيرها فضلا عن انه يكتنف الكثير من الثبه وصعوية الحكم علي مدي توافره في القيادة(Vera \& others,2004: 393). سمة الهاوي: أن سمة الهـوء تعتبر نوعية هادئة في الحياة الإنسانية بسبب تشعب الحياة وكثرة العمل وإلمشاكل المحيطة بذلك، ومن هنا يتبين أهمية وجود سمة في القيادة خاصة عند اتخاذ القرارات المصيرية أو المتعلقة بالأفراد فالهـوء يمكن القائد من العمل بعمق ويطريقة أفضل لحل المشاكل الصعبة فضلا عن أن التأني يعطي حيز للنظر للموضوع من جميع جوانبه ويالتالي تميز في التصرف والقرار وهذا الحال يعزز من إيجاد أفضل الحلول والتنظيم لمجريات العمل وتحدياته(Kinsey,2010:3). سمة الحكمة في التصرف: تشير الحكمة الي تحقيق التوازن بين الموارد المتوفرة ومتطلبات العمل سواء السلوكية منها والمادية فالحكمة تعد مرحلة متقدمة من التفكير المبني على الاستدلال المنطقي، والدراسة الموضوعية لماهية القرار باعتماد معيار الخبرة العملية، والتجارب وغيرها من العوامل المساعدة على الوصول الي معيار الحكمة في 
التصرف، ويذلك فهي غالبا ما ترتبط أيضا بأفضل القرارات في حالة محدودية الموارد أو ركا الوقت وغيرها (Ligungblom,2012:10).

سمة الصبر:يعد الصبر من أهم السمات التي يجب أن تلازم القيادة الرشيقة، كونها تتعلق بتأخير الحصول علي بعض الحاجات أو الامتيازات أو تحقيق بعض الأهداف علي المدي القصير نتيجة للظروف المحيطة بالموقف ويما يحقق ما يصبو اليه القائد من (Kupfer, تجسيد لأفكاره علي مراحل علي مراحل وضمن مستوي مقبولية في بيئة العمل (آل J., 2004: 264) ، هذا من جهة ومن جهة اخري يعد الصبر مهم للقيادة كون تحقيق النجاح لا يعني فقط امتلاك الطاقة والمعرفة والحماس والجها المبذول لذلك وإنما يستلزم التحلي بمهارة الصبر المبنية علي بصيرة إدارية عالية وهي لا تعني التكاسل أو الخمول او غيرها، من معايير انخفاض الطموح فالعمل الجاد بواقعه لا يتحقق بدون صبر علي مراحلة ووقت تحقيقه وغيرها ويما يجعل القائد قادر علي التعامل مع الإخفاقات التنظيمية فضلا عن التصرف بتعقل اثناء الازمات وما يتطلبه النهوض بواقع الافراد داخل المنظمة .(Hueiju, Yu \& Fang, ,2009,894)Wenchang سمة الموضوعية: تتعلق الموضوعية بالعقلانية في تمكن القائد من امتلاك عقول الافراد والتأثير في سلوكياتهم فهي تعد من أبرز مميزات طرق التفكير العلمي فالواقع يشير الي أن الموضوعية تتجلي في جميع تفاصيل تفكير الفرد المتعلق بادراك المشكلة ومحاولة (Elmiliani, التفكير في الحلول الناجحة لها ضمن منهجية فكرية عقلية واضحة المعالم .M., ,1998:98)

سمة الثقة: ان نجاح القيادة في مجال عملها يعتمد على قرتهها علي خلق مستويات ثقة عالية لاي الافراد العاملين وضمن المطلوب منها بدون تفريط فيها فهي فكذا مستويات تزيد من ارتباط الفرد بالقيادة ويالتالي تعزيز جواتب النجاح المؤسسي Mineo, D) .2014:2) ويالتالي فان من أهم سمات القيادة الرشيقة الاهتمام بالشفافية وعدم إخفاء اخطائه بل الاعتراف بها ليمثل عمليا الأسلوب الأي يريد من مرؤوسيه العمل به، كما انه متطلع للأمام لايه روية للنهاية المطلوية للعمليات التي تتم، مؤهلا فنيا بحيث لا يكون مصدرا للإزعاج او إعاقة فريق العمل، لايه أدوات ومهارات مختلفة للتعبير عن روية فريقه 
ويمكن العاملين لايه بحرية، أي انه يعزز البيئة التعاونية من خلال تقاسم السلطة بينه وبين فريق العمل مع بناء الثقة بين أعضاء الفريق وتعزيز قدراتهم وتمكينهم.

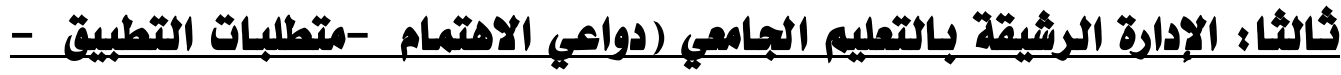

خوطوات التطبية)

\section{-}

من العوامل التي تستدعي تطبيق مفهوم الإدارة الرشيقة بالتعليم الجامعي ما يلي: • عدم الاستقرار العالمي نتيجة ظهور ونمو الصناعات الصغيرة، وتعدد المنتجات الجديدة وانخفاض لدورة حياة المنتج.

المنافسة الشديدة الناتجة عن النمو السريع للأسواق، وارتفاع التكلفة، وزيادة القدرة

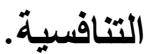

تعدد واختلاف الاحتياجات الفعلية للعملاء. التغييرات التكنولوجية السريعة وظهور برمجيات جديدة ومتطورة.

التغيرات في العوامل الاجتماعية ومنها ما يلي (زيادة الوصول إلى التكنولوجيا المنافسة المكثفة على تطوير التكنولوجيا - عولمة الأسواق والمنافسة التجارية- زيادة سرعه الوصول إلى التكنولوجيا - التغيرات في المرتبات والمهارات الوظيفية - المسؤولية (Eshrat Karami and Sara (البيئية ومحدودية الموارد - - توقعات العملاء المتزايدة)

.Fanati Rashidi ,2015) لألك يمكن القول بان التغييرات العالمية الحادثة في شتى مجالات الحياة والتي أدث إلى عدم الاستقرار العالمي وظهور ونمو الصناعات الصغيرة، والمنافسة الثديدة الناتجة عن لن النمو السريع للأسواق، وارتفاع التكلقة، وزيادة القدرة التنافسية، والتغييرات التكنولوجية والاجتماعية والاقتصادية كانت مبرر قوى لظهور الحاجة لتطبيق مصطلح الرشاقة الادارية بالجامعات والاستفادة من مبادئه وذلك لرفع مستوي أداء الجامعات ويالتالي رفع مستوي جودة خرجيها وعملياتها حتى تستطيع المنافسة في ظل الوضع التنافسي العالمي الجديد. 


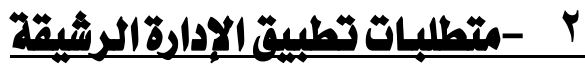

إن اعتماد أسلوب الإدارة الرثيقة كفلسفة إدارية في المؤسسات المختلفة بصفة عامة والمؤسسات الجامعية بصفة خاصة يتطلب توفر مجموعة من الثروط والمتطلبات التي تضمن نجاح هذا الأسلوب وتحقيق أهدافه ومن بين أهم هذه المتطلبات ما يلي:

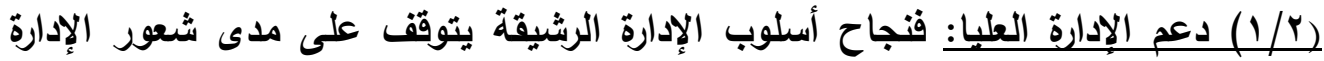
العليا ورغبتها في توفير الإمكانيات والثروط اللازمة لتطبيق هذه الفلسفة، وذلك من خلال

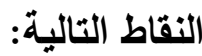
الالتزام الكلي بتوفير كل الإمكانيات المادية والبشرية والمالية والوقت من اجل إنجاح

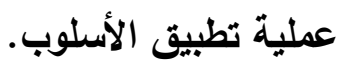
القبول الكلي للإدارة للتظلي عن الأساليب الكلاسيكية لتسيير العمل والتوجه نحو الفلسفة الحديثة للإدارة الرشيقة.

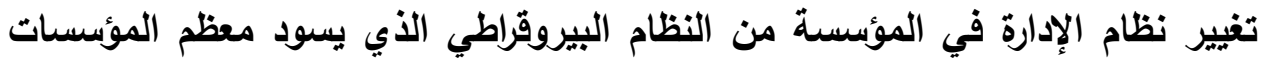

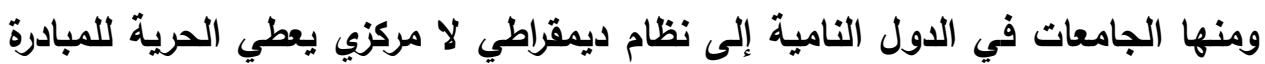

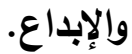

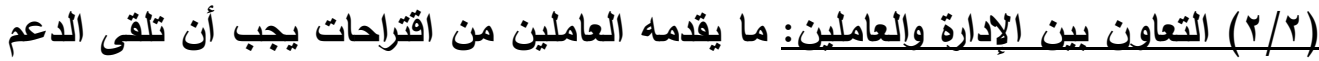

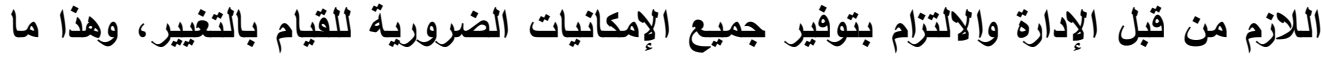

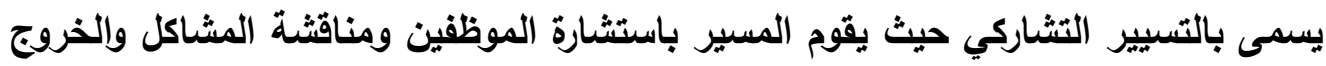
بحل جماعي لها (Hallinger, Philip 2009:199)، إذ تعطى للعمال مسؤوليات جديدة لتحسين عمليات إنتاج المؤسسة، هذه الأعمال تسمح للعاملين من تقسيم جهاهم من جهة في أعمال روتينية متعودين عليها ومن جهة أخرى مهام غير روتينية للتفكير في الكيفية

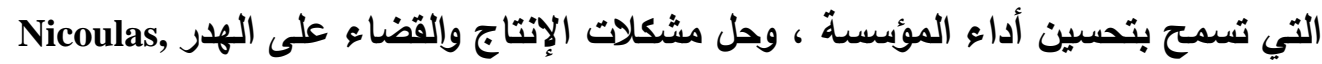
.Houy ,2009:82)( (T/Y) الاهتمام بالتكوين والتتريب نوعا وكما: يعرف التدريب على انه محاولة لتغيير سلوكى

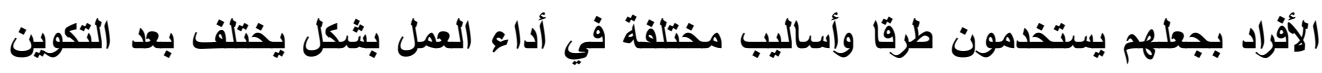

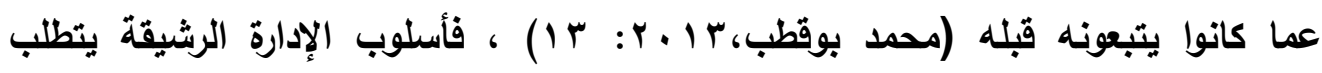

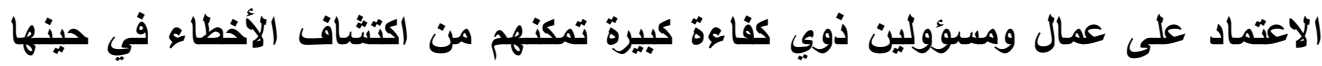


ويالتالي التقليل قدر الإمكان من فرص الضياع والهدر للموارد، وهذا يكون بإتباع سياسة تدريبية مبنية علي أسس موضوعية في كل جواتبها تثميز بما يلي:

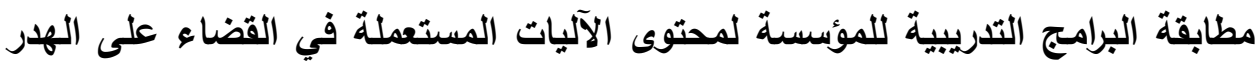
كطريقة S.M.E.D أو طريقة السينات الخمس. الاعتماد على التدريب المتعدد المهارات وذلك من أجل ريح الوقت وتمكين العامل التنفيذي من إجراء عمليات صيانة وقائية أو بعدية فورية دون الاعتماد على قسم

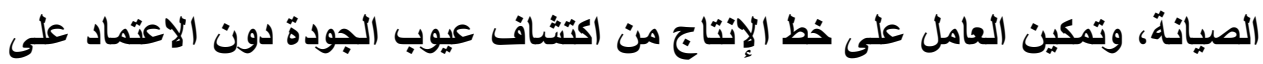
تحليل قسم الجودة. الاعتماد على دورات تدريبية تحسيسية لجميع العمال دون استثناء من اجل شرح مختلف أشكال الهرر داخل المؤسسة ومدى خطورتها على المؤسسة وكيفية معالجتها. (Y/Y) التغبير في ثقافة المؤسسة: إن النجاح الذي عرفه أسلوب الإدارة الرشيقة في شركة تويوتا خاصة راجع بالأساس إلى ثقافة العامل الياباني ومعثقداته وولائه الثديد لمؤسسته، لذا فان شروط نجاح هذا الأسلوب في الدول النامية ومنها العربية ترتكز على ضرورة تغيير

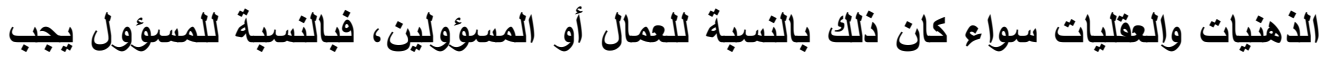
أن يكون مبادرا ويقبل المبادرة من أي مستوى إداري من شأنها أن توفر للمؤسسة مواردها، وكذلك الحال بالنسبة للعامل البسيط الذي يجب أن يعي ضرورة المحافظة على موارد المؤسسة ويعمل من أجل التقليل قرر الإمكان من التبذير والثهر على مستواه ويجعل استمرارية عمله مرتبطة باستمرارية المحافظة على موارد المؤسسة ( عبدالرحمن بن وارث الرّاث

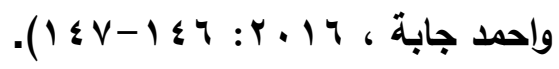

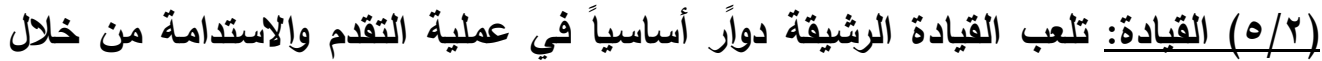
إزالة العوائق التي يواجها تطبيق مدخل الرشاقة إذ ينبغي أن تكون تصرفات القادة هي أفعال

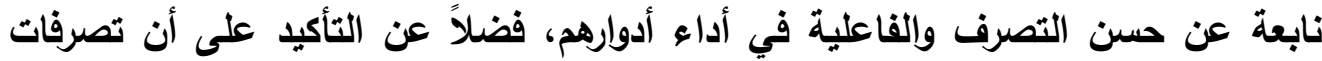
الأفراد العاملين لابد وأن تقوم على أساس التمكين، وان من الأنساسيات المهمة لنجاح قيادات المنظمات الرشيقة هو خلق الأجواء الثقافية المناسبة والحفاظ عليها، ولذلك فإن المنظمات بحاجة إلى إسناد المهام الصعبة إلى الأفراد ذوي الصفات القيادية، والأهم من ذلك دعم المنظمات للأفراد بغض النظر عن النجاح أو الفشل، فإن لم يكن الافراد يرغبون 
بالمخاطرة أو الانتقال إلى وظيفة ذات مخاطر عندها فإن القيادة الرشيقة سوف يحكمها الفشل.

(ץ/T)(الثقافة : أن الثقافة الرشيقة هي من السمات سهلة الفه ولكنها صعبة التنفيذ من خلال ترجمة هذه الثقافة إلى سلوكيات، فلكي تصبح منظمة رشيقة فإن هذا يتطلب عمليات ضبط أساسية في التفكير والمواقف والسلوك وتبني لمجموعة من المبادئ التحويلية والثقافية ، فالمنظمات الرشيقة تؤمن بأن مبادئ الثقافة الرشيقة هي أساس منظمتهم، ولذلك فإن إن إنان

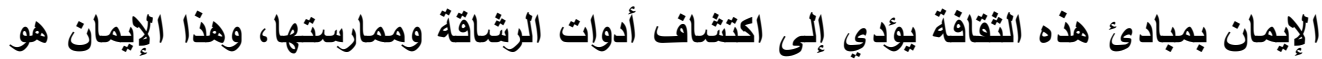

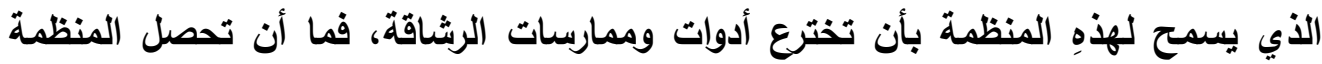

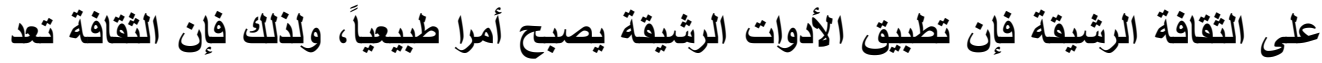

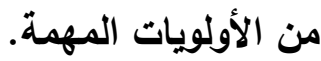
ذات الاتصالات الادارية: أن عملية الاتصالات في المنظمات الرشيقة هي عملية حوارية ذات اتجاهين وليست عملية باتجاه واحد، في المقابل عندما تكون اتصالات المنظمة ضعيفة

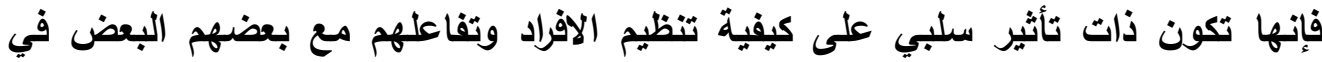
المنظمة وتزداد أهمية الاتصالات عندما يكون هناك عدة أفراد يعملون بالتوازي مع بعضهم البعض ويكمن الخطر في ذلك في أن فرداً ما سوف ينتظر تدفق مخرجات الأفراد الآخرين لغرض إنجاز أعماله، إذ يثكل التدفق أحد الجواتب الأساسية في عملية الاتصالات في

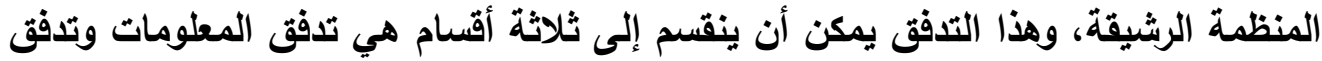

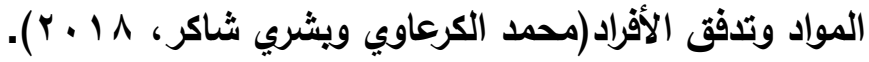

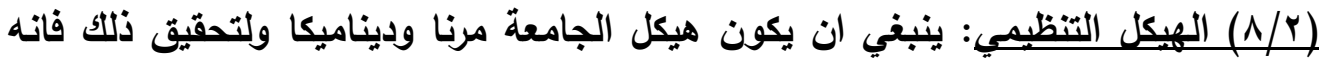
يتعين على الجامعات اتخاذ الإجراءات التالية: • زيادة عدد الثراكات مع المنظمات والمؤسسات الخارجية ذات الصلة.

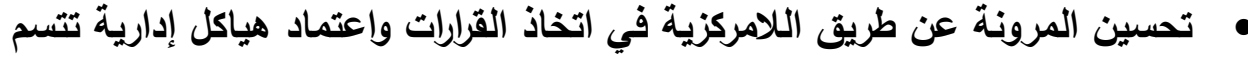

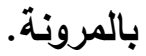
تنمية ثقافة التطوير والتحديث بين منسويي الجامعات. 
(q/ الموارد البشرية في الجامعة الرشيقة: حيث تؤدي قدرة الموارد البشرية القادرة على التعامل بمرونة مع التغييرات دوار فعالا وهاما لتحقيق الجامعة الرشيقة، ولتحقيق ذلك فانه يتعين على الجامعات اتخاذ الإجراءات التالية: • • تلدعيم الأنشطة الجماعية عن طريق فرق العمل وتعزيز ثقافة المشاركة. • • ت •

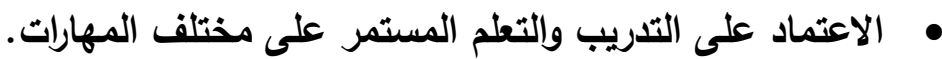
(1/r/r) التكنولوجيا: حيث يعتمد الإنتاج الرشيق وقدرته على مواجهه التغييرات غير المتوقعة على التكنولوجيا حيث يمكن ان تكون تلك التغييرات في نوعية نماذج الإنتاج أو في مواصفاتها ويالتالي يجدر على الجامعة الرشيقة ان تكون قادرة على إنتاج منتجات أو خريجين في مجالات وتخصصات جديدة تتلاءم مع التغييرات ومتطلبات سوق العمل، ومن الإجراءات التي ينبغي مراعاتها في ذلك: الاستثمار في تكنولوجيا الأجهزة الحديثة وإلمناسبة. • استخدام النظم المرنة لكي تستوعب التغيرات في احتياجات العملاء. • استخدام نظم الاعم المرنة لكي تتلاءم مع الظروف المتغيرة للأوامر. (1//Y) تكنولوجيا المعلومات: ان الجامعات الرشيقة تتطلب إجراء تطوير في مجال مرونة المعلومات ونظم الاتصالات بحيث تكون قادره على التعامل مع الظروف المتغيرة. (I الابتكار والإبداع: ينبغي للجامعات الرشيقة ان تقدم حلولا ابتكارية ومبدعه لمنسويها بدلا من بيع وتقديم خدمات لهم، فالمحصلة النهائية للإنتاج الرشيق هو التأكد من

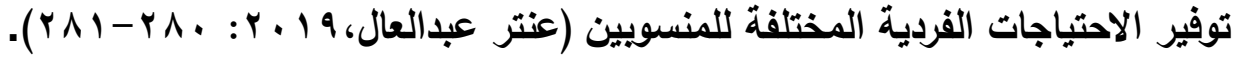
الي جانب ما سبق يتطلب تطبيق الإدارة الرشيقة بالتعليم الجامعي تثكيل إدارات شئون

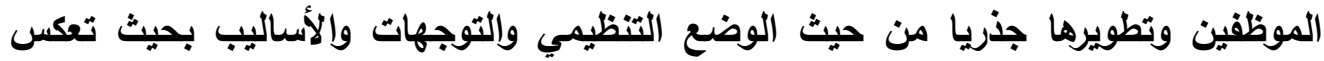
مجمل الأفكار العديثة للإدارة الرشيقة، والاتصال مع الخبرات العالمية في مجال الادارة الرشيقة، وتبادل المعلومات والمعارف بين كل أفراد المؤسسة بصفة عامة، والإدارة العليا بصفة خاصة ولا نتعجل في ظهور النتائج لأن ذلك يعتبر من أكبر معوقات تطبيق فلسفة 
أيضا يتطلب لتطبيق نظام الإدارة الرشيقة بالتعليم الجامعي تفعيل نظام المعلومات داخل الجامعة لضمان تدفق المعلومة بشكل انسيابي وتشجيع روح المبادر والعمل الجماعي بين العاملين، وتكريس مبدأ المغامرة في التسيير وعدم الاكتفاء بالأساليب التقليدية المعتمدة، وإنشاء لجنة متخصصة لتطبيق مبادئ الادارة الرشيق من مهامها تهيئة المؤسسة

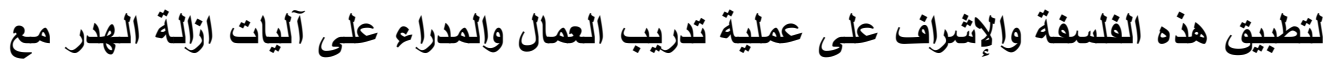
توزيع الأدوار بصورة واضحة ، و التأكيا على منح الفريق صلاحيات كاملة في تنظيم وتوجيه أنفسهم لتحقيق العمل المطلوب.

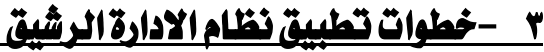

ينبغي على المنظمات التي تريد تطبيق مفهوم الإدارة الرشيقة أن تتبنى

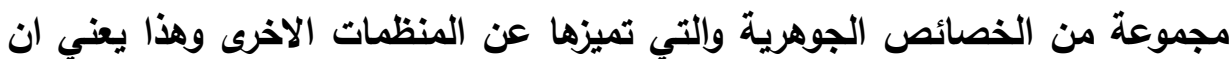
تطبيق هذا النظام لا يعتمد فقط على ادوات وإساليب وآليات وإنما بناء ثقافة تتسجم

وفلسفة هذا النظام ومنها (Lean production,2020 ): • ان تنظر الى الاخطاء على انها فرص للتحسين. • • لا مانع من بعض الاخطاء المحدودة.

الثقة المتبادلة بين الادارة والعاملين يسهم في الكشف عن الاخطاء. ان العاملين ليسوا هم المشكلة بل انهم هم الذين يحلون المشكلة. التركيز على ايجاد حل للمشكلة أكثر من التركيز على تحديد من هو السبب فيها. فالإدارة الرشيقة تعتبر استراتيجية لتطبيق التحسين المستمر في الاداء الكلي من من فئرئ خلال تقليص كل اشكال الهدر في الوقت والموارد وفي كل الانشطة وهذا يستلزم بالنسبة لأغلب المنظمات ومنها الجامعية تغيرا جذريا في ثقافاتهم واسلوب أداعهم للأعمال

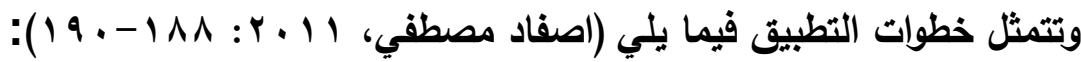
المرحلة الاولمى: - التعليم يكون التعليم على مستويات ثلاثة: المستوى الاول / الادارة العليا: من خلال التعريف بالنظام ويالنتائج التي سوف يحققها. المستوى الثاني / المديرون: - وهم المشرفين على العمل والكوادر الداعمة له. 
المستوى الثالث / العاملون في المنظمة(الجامعة): - حيث تقام لهم برامج تتعلق بتأثير هذا النظام على عملهم واليات تنفيذه. المرحلة الثانية: - تقيسم امكانات المنظمة (الجامعة) الحالية لتنفيذ النظام من خلال العناصر

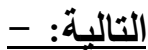
(ثقافة المنظمة -ادارة التكنولوجيا -ادارة العاملين -ادارة النظام -التدريب -تنظيم موقع (العمل) المرحلة الثالثة: - خطة التنفيذ ويتضمن جدولة تفاصيل العمل (الانثطة والمسؤوليات) تواريخ البدء وتواريخ متوقعه للإنجاز ، الموارد المطلوية للعمل. المرحلة الرابعة: - تحدبد مجال التنفيذ ويقصد بمجال التفيذ نشاط او عملية يبدأ فريق التنفيذ بتطبيق النظام عليها قبل نشر النظام في ارجاء المنظمة كلها وهذا يحتاج الى: • عديد هذا المجال بشكل جيد لان ذلك يسهل اكتشاف مشاكل هذا المجال وتصحيحها. اختيار الحلول للمشكلات التي تظهر في هذا المجال. تحديد الاهداف المرجوة والاداء المتوقع لهذا المجال وتوثيق النتائج بشكل يومي ومقارنتها بما هو متوقع. تشكيل فريق من العاملين من انشطة مختلفة ضمن هذا المجال وتدريبهم على اساليب

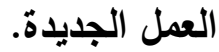
توثيق المشكلات وتوثيق حلولها لغرض اعتمادها كإجراءات نموذجية في مواجهة نفس

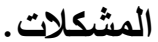

اشعار العاملين بان النظام الجديا يعمل بشكل جيد. دعم الاجراءات الجديدة لضمان استمرار نجاحها. المرحلة الخامسة: تثكيل مجموعة انثطة التحسين ويتم ذلك من خلال: • توفير قيادة قوية وتدريب جيد للمجموعة. تحديد مجالات العمل والاهداف والازمنة المطلوية للإنجاز لكل مجموعة. تحديد معايير لقياس اداء هذه المجموعات. 
• لضمان نجاح المجموعة يعهد اليها بمشكلات واضحة ومهمة كبداية. • قياس اداء المجموعة بشكل مستمر ومن ثم يجهز بالمواد المطلوية. المرحلة السادسة: تقيم اداء النظام

يتم تقييم اداء النظام من خلال تحديد مقاييس مناسبة للأداء اولا ومن ثم قياس الاداء الحالي ويتم بعدها تحديد الفجوة وتحليلها ثم اتخاذ الفعل التصحيحي المناسب وتعد هذه العملية عملية مستمرة لضمان استمرار النظام. المرحلة السابعة: نشر النظام في جميع ارجاء المنظمة (الجامعة) في هذه المرحلة يصبح النظام جزء من المنظمة(الجامعة) وتفاصيل العمل اليومي واسلوب اداء العمل. يتضح لنا مما سبق أن تطبيق مبادئ الإدارة الرشيقة لا يقتصر فقط على مجرد مجموعة من الإجراءات والأساليب وانما هو ثقافة وقيم وسلوكيات جديدة تتبناها المنظمة ويعتمدها العاملون في اداء أعمالهم والقادة في ادارتهم للعمل بشكل يومي.

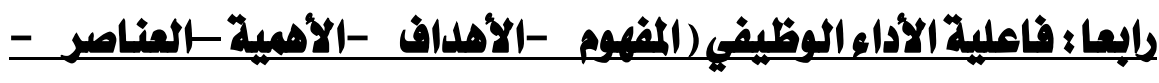

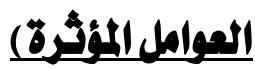

يعتبر مفهوم فاعلية الأداء الوظيفي مفهوم مركب لذلك سوف يتم التعرف في البداية على مفهوم الفاعلية ثم مفهوم الأداء ومنه الأداء الوظيفي، ثم الربط بين عناصر المفهوم وذلك كما يلي:

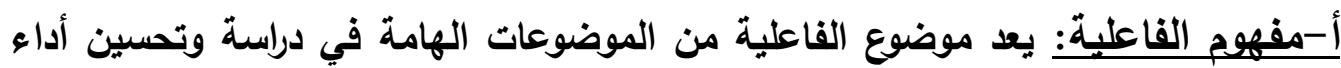
المنظمات الإنتاجية والخدمية علي حد سواء، ومدي قدرة هذه المنظمات على تحقيق أهدافها، فهي تمثل استخدام المنظمة لكل الطاقات المتوافرة لايها من أجل الوصول الي الأهداف المخطط لها(صفاء تايه والهام عزيز، 0 ا ب r). وتعرف المنظمة العربية للعلوم الإدارية الفاعلية بأنها "مدى صلاحية العناصر المستخدمة (المدخلات) للحصول على النتائج المطلوية (المخرجات) (المنظمة العربية للعلوم الإدارية)"، كذلك فإن قاموس الإدارة يعرفها بأنها "تحقيق الأهداف الصحيحة من وجهة نظر أفضل التفسيرات الممكنة لظروف التجارة وإمكانات الريج" (فيليب جلاد، ب . . ب). كما تعرفها دائرة المعارف الأمريكية بأنها" المدى الذي عنده تسنطيع المنظمة تحقيق نتائج مقصودة"، وتعتمد فاعلية المنظمات أيضاً على القدرة والتواصل والأخلاق، وتعتبر 
الأخلاق من أهم الأسس التي تعتمد عليها الفاعلية، فالمنظمة يجب أن تكون مثالاً للاحترام والأخلاق والإنصاف والنزاهة والجدارة، حتى تستطيع تحقيق التواصل مع جماهيرها للمساعدة

في تحقيق أهدافها المرجوة (Encyclopedia Americana) وعرفها الشماغ بأنها القدرة على تحقيق الأهداف في ظل الموارد المحدودة

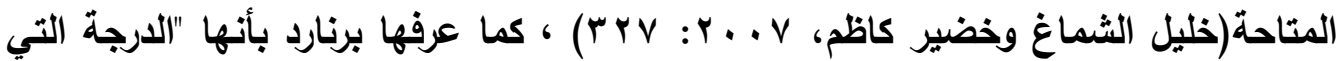
تستطيع فيها المنظمة تحقيق أهدافها "بمعنى أكثر فإن المنظمة تصبح اكثر فاعلية حينما

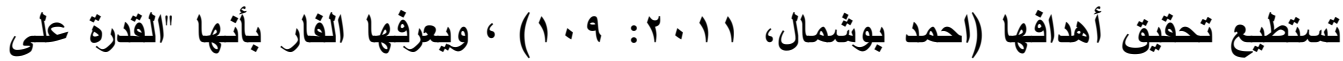
البقاء والتكيف والنمو بغض النظر عن الأهداف التي تحققها، كما وصفت بأنها النطاق الذي يمكن للمنظمة كنظام اجتماعي من الحصول على الموارد اللازمة والوسائل المؤكدة

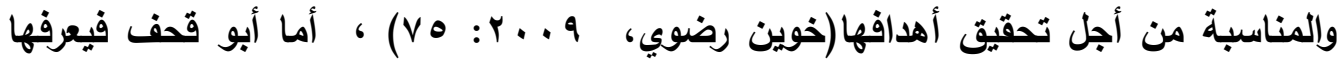
بقوله هي محصلة تفاعل مكونات الأداء الكلي للمؤسسة بما تحويه من أنثطة فنية ووظيفية

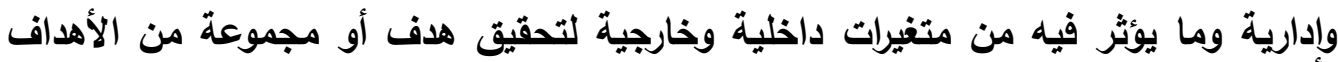

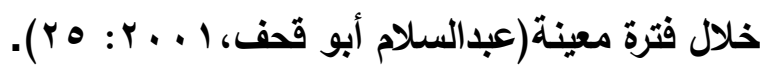

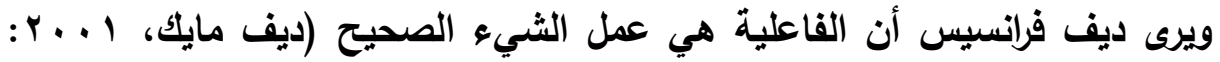
ه r) أما القاضي فيري بأنها "تحقيق الهُف والوصول إلى النتائج التي يتم تحديدها مسبقاً

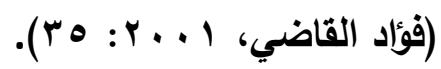

وعرفها عبد الوهاب وخطاب بأنها تعني تحقيق الهدف والوصول إلى التتائج التي يتم تحديدها مسبقاً، والهدف هو النتيجة التي يرد الوصول إليها بكمية معينة وفي وقت محدد،

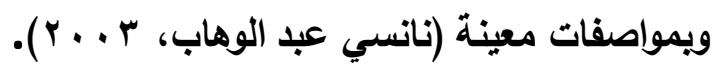

ويرىBarman أن الفاعلية "هي مدى تحقيق المنظمة لأهدافها، فإذا حققت الإدارة أهدافها توصف بأنها إدارة فاعلة، أما Norman, et al فيري ان الفاعلية هي "عمل الأثياء

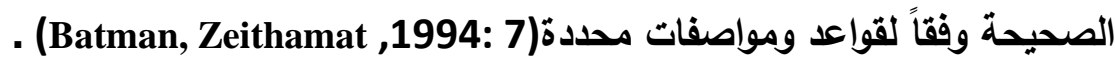
ويجدر الإثارة الي أن مفهوم الكفاعة يأتي دائما ملازما لمفهوم الفاعلية ولكن لا يجب أن يستخدما بالتبادل، بمعني انه قد تكون المنظمة فعالة ولكنها ليست كفؤ أي أنها

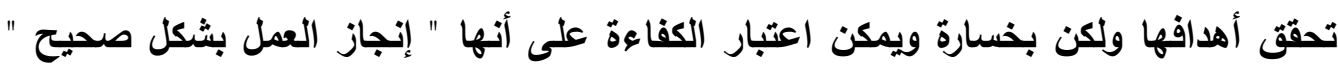
بينما الفاعلية هي "إنجاز العمل "وهكذا المفهومان يكمل كل منهما الآخر. 
وإذا كاتت الفاعِليَّة تشير إلى معنى تحقيق النتائج المطلوية وإحداث الأثر الإيجابي، فإن الكفاءة هي علاقة بين كمية المدخلات وكمية المخرجات، أي أنها نسبة ما بين الموارد المستخدمة والنتائج المنجزة، بمعنى أن الكفاءة تزيد كلما كاتت الموارد التي تم استعمالها أقل قياساً بالنتائج المتحققة. ويفسر عدد من علماء الإدارة مدلول الفاعِليَّة على أنّه يشير إلى أداء الأشياء الصحيحة (لكونها تتصل بالأهداف) أمّا الكفاءة فهي أداء الأثياء بطريقة صحيحة (فهي أكثر

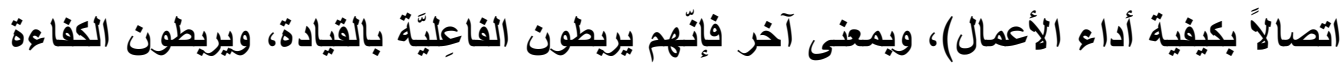
بالإدارة، فالقيادة هي التي تبيّن الأشياء الصحيحة المطلوب إنجازها، أمّا الإدارة فإنّها تبيّن كيفية إنجاز هذه الأثياء.

ويالتالي نستخلص مما سبق أن مفهوم الفاعلية بصفة عامة يعني أداء الأعمال الصحيحة، أما مفهومها في علم الإدارة فيعني الحصول على أكبر المخرجات من أقل هئل المدخلات وتعريف الفاعلية الإدارية نسبي يختلف باختلاف تصور المقيّم لها، أما مفهوم فاعلية القائد فهي تقاس بمدى الإنجاز الأي تحققه مجموعة العمل التابعة له في أهدافها. كما يتضح لنا من التعريفات السابقة أن الفاعلية بالنسبة للقائد الإداري او الأكاديمي تشمل عدة معايير أهمها تحقيق الأهداف وتأمين الموارد (المدخلات) والعمليات الداخلية وتكون الجامعة فعالة إن تدفقت المعلومات فيها بيسر وسهولة وساد الانتماء والرضا والالتزام الوظيفي بين العاملين مع أدنى قر من النزاع والصراع، وحققت رضا الجماعات والأطراف التي تتأثر مصالحها بالجامعة ولهم مصلحة في بقائها واستمرارها. ويالتالي يمكنتا القول بأن الفاعلية تمثل المحصلة النهائية لتفاعل مجموعة من العوامل في موقف معين، وأن مواجهة تلك العوامل يجعلها تؤدي دورها المنوط به مما يؤدي إلى تحقيق أهداف المنظمة، وتنعكس درجة تحقيق هذه الأهداف على درجة فاعلية المنظمة، حيث إنه كلما تحقق الوصول إلى هدف المنظمة كلما كانت هذه المنظمة فعالة. ويمكن تعريفها إجرائياً في الاراسة الحالية بأنها قدرة القيادات الجامعية بمؤسسات

التعليم العالي على تحقيق أهدافها المرجوة. ب- مفهوم الأداء:ذكر في اللغة أن الأداء لفظ مشتق من الفعل (أداء)، ويعني (أدى) الشيء أي قام به، واستعد له(المعجم الوسيط) ، أما أصل المصطلح اللاتيني 
Performance الصرايرة، 1 · r) أما معناه اصطلاحا في معجم المصطلحات الإدارية فإنه يعني " القيام بأعباء الوظيفة من مسؤوليات وواجبات وفقا للمعدل المفروض أداؤه من العامل الكفء

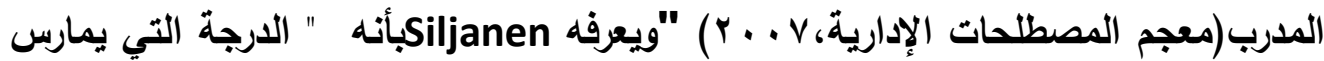
Siljanen, يها العاملون السلوك الذي يساهم في تحقيق وإنجاز أهداف الإدارة .) ("Mikael,2010)

ويعرفه سعود بأنه عملية أو مجموعة من العمليات لمساعدة الأنظمة على تحقيق أهدافها، وتهتم بوجود فهم مشترك بين المديرين وفريق عملهم عما يجب تحقيقه ثم إدارة وتظوير العاملين بطريقة تزيد من احتمال إنجازها على المدي القصير (سعود ال

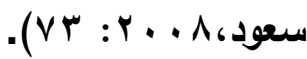

كما يعرفه مزهودة بأنه "قيام الفرد بالأنشطة ومهامه المختلفة التي يتكون منها عمله والكيفية التي يؤدي بها العاملون مهامهم أثناء العمليات الإنتاجية والعمليات المرافقة لها باستخدام وسائل الإنتاج والإجراءات التحولية الكمية والكيفية (عبدالمليك مزهودة، ال. . Y: . ( 19

ويعرفه حمادات بانه تنفيذ الموظف لأعماله ومسؤولياته التي تكلفه بها المنظمة أو

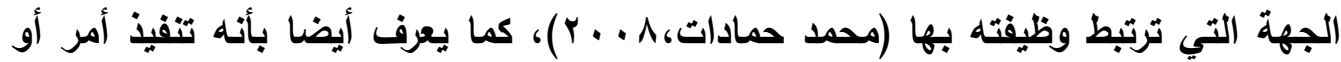
واجب أو عمل اسند الي شخص أو مجموعة للقيام به (احمد بليوي ومحمد مصطفي، ؛ 9 ) : .) 179 ويعرفه الشامسي بأنه: "المخرجات مقدرة بساعة عمل واحدة" أو أنه "كمية الإنتاج للعامل الواحد في الوحدة الزمنية (سالم الثامسي، ؛ . . †) "، أما السلمي فيري أنه "الإنجاز الذي يتحقق نتيجة ما يبذله الفرد في عمله من مجهود بلني وذهني، ويالتالي فهو انعكاس لمدى نجاح الفرد أو فشله في تحقيق الأهداف المتعلقة بوظيفته (على السليمي، ب99 19 1: .$(\circ)$ ويالتالي فإن مفهوم الأداء هو عبارة عن نظام متكامل يمثل الأداء الفردي العنصر الأساسي فيه، وهذا يرجع الي ان العنصر البشري هو العنصر الفعال في الأداء لما يتمتع به من خبرات وقدرات لإنجاز الاعمال (بسيوني البرادعي، 1 . . ب : ؛ ؟). 
ونستخلص من التعريفات السابقة أن الأداء يقصد به مجموعة الاعمال التي يؤديها

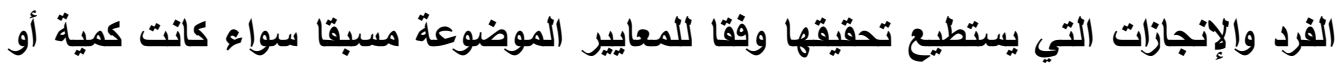
نوعية أو زمنية الي جانب سلوكياته في وظيفته سواء مع زملائه أو رؤساءه بالعمل. وفي الدراسة الحالية يعرف الأداء بأنه قيام القادة الإداريين والأكاديميين في الجامعة بالواجبات الإدارية الموكلة إليهم، بموجب الأنظمة والتعليمات المعول بها في الجامعة. ج-مفهوم الأداء الوظيفي: لقد اهتم الفكر الإداري التظيمي بموضوع الأداء الوظيفي نظرا لارتباطه بكفاءة وفاعلية المنظمات في تحقيق أهدافها والوصول إلى ما تصبو إليه من رؤى الهى وأهداف وقيم جوهرية، ومن هنا زادت الاهتمامات والألويات الفكرية بإدارة الموارد البشرية وتحسين مستوى الأداء الوظيفي للعاملين لأن نجاح أي منظمة مرتبط بمستوى أداء أفرادها وكفاعتهم.

ولقد تعددت مفاهيم الأداء الوظيفي وفقا لآراء الكتاب والباحثين في إعطاءهم مفهوم موحد، ولعل ذلك يرجع إلى منطلقاتهم الفكرية وتصوراتهم فمنهم من يعرفه بأنه درجة تحقيق واتمام المهام المكونة للوظيفة وهو يعكس الكيفية التي يحقى بها الفرد متطلبات الوظيفة وغالبا ما يحدث لبس أو تداخل بين الاداء والجه فالجها يشير إلى الطاقة المبذولة أما لهاب

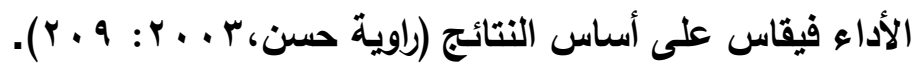
ويعرفه هلال بانه تتفيذ الموظف لأعماله ومسئولياته التي تكلفه بها المنظمة أو الجهة

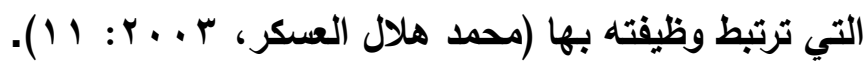

ويرى رضا أن الأداء الوظيفي ينتج من تفاعل عامل القدرة والدوافع المرتبطة بالسلوك البشري، فقد تنطوي مكونات القرد على أعظم القدرات للعمل ولكن بدون توافر الدافع للعمل ويالتالي ستنعدم العلاقة بين القدرات والأداء الوظيفي، والعكس صحيح فقد يتوافر لاى الفرد الدافع القوي للعمل ولكن بدون قدرة على العمل لدية ويالتالي ستنعدم العلاقة ما بين الدافع والأداء الوظيفي، والأداء هو نتيجة للتفاعل ما بين السلوك والإنجاز، حيث أن السلوك يمثل

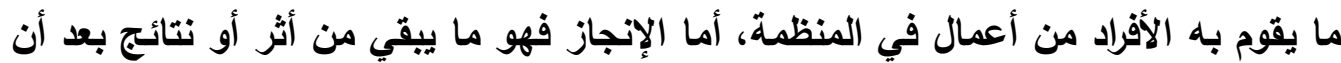
يتوقف الأفراد عن العمل، أي أن الإنجاز هو نتاج للسلوك، والأداء هو مجموع السلوك ملك

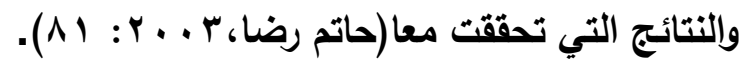


ويعرفه الفايدي بانه الناتج الفعلي للجهود المبذولة من قبل الفرد، ويتأثر هذا الأداء بمقدار استغلال الفرد لطاقاته وإمكاناته وفي نفس الوقت بمقدار الرغبة لاى الفرد في تأدية

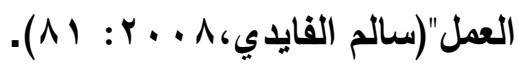

ويري سلطان أن مفهوم الأداء الوظيفي هو "ألأثر الصافي لجهود الفرد التي تبدأ بالقدرات وإدراك الدور أو المهام والأي يشير بالتالي إلى درجة تحقيق وإتمام المهام المكونة

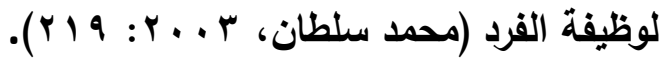
ويرى رضا أنه "نتاج جها معين قام بيذله فرد أو مجموعة أفراد لإنجاز عمل معين (حاتم رضا،r. . . Y : NV).

ومن خلال التعريفات السابقة يتضح أن الأداء الوظيفي هو قيام الفرد بإنجاز الأنشطة والمهام المختلفة التي يتكون منها عمله بطريقة صحيحة، ويتكون نتيجة لمحصلة تفاعل

$$
\text { ثلاث محددات رئيسية هي: }
$$

الافيةة: وهذا يتطلب أن يتوافر الدافع نحو العمل لدى الفرد. قدرة الفرد على أداء العمل: وهذا يتطلب توافر القدرة لدى الفرد على أداء العمل المحدد. مناخ العمل: يجب أن تتم تهيئة مناخ العمل المناسب بحيث يؤدي إلى إثباع حاجات

ومن خلال ما سبق يكون التعريف الاجرائي للأداء الوظيفي في الدراسة الحالية بأنه هو "إنجاز القيادات الجامعية بالجامعة للمهام والانشطة الموكلة إليهم خلال فترة زمنية محدة بحيث يبذلوا جهاهم حسب طبيعة الوظيفة، ضمن شروط واضحة للمؤسسة التي يعملوا بها لتحقيق أهداف المنظمة والوصول للنتائج المطلوية، مراعيا في ذلك الكفاءة والفاعلية في العمل.

د - فاعلية الأداء الوظيفي: ينبثق عن مجموعة المفاهيم السابقة مصطلح الأداء الوظيفي الفعال أو فاعلية الأداء الوظيفي حيث يعتبر من الموضوعات الحساسة التي تثير اهتمام الإداريين والقادة، لما لها من آثار إيجابية على الروح المعنوية للعاملين وعلى فاعليتهر

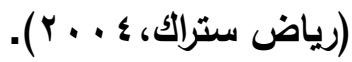

ولقد تعددت صور الأداء الوظيفي الفعال ومنها وجود روئة مشتركة عن الأداء المتوقع بين المدير والعاملين معه من خلال الوصف الوظيفي ومعاييز الأداء، والأهداف 
المحددة، ودعم المدير لأداء العاملين، وتحفيزهم للقيام بأدوارهم، ووضع البرامج التدريبية لهم، والمراجعة المستمرة التي تهلف إلى تسهيل أداء العاملين المستقبلي وتحسينها (شبل الثبل

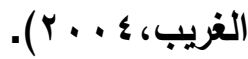

ويعد الأداء الوظيفي أحد أهم محاور فاعلية الأداء الكلي لأي منظمة من المنظمات، وذلك يتطلب ضرورة اهتمام واعتناء كافة المديرين والقادة في جميع المستويات التنظيمية

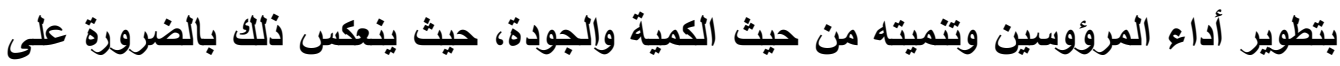
أداء جماعات العمل والنتيجة أو المحصلة النهائية هي فاعلية أداء المنظمة ككل. Becker, '(James C,2001: 86-90)

ويعرف الرشيدي فاعلية الأداء الوظيفي بأنها قدرة الفرد على تحقيق المهام والأعمال

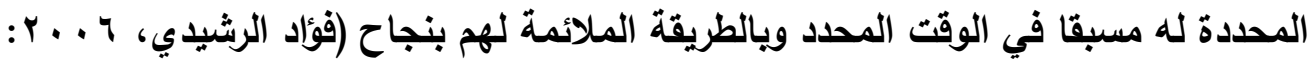
.$(r 4$

أما الحموي فيذكر بان فاعلية الأداء الوظيفي ترتكز على مدى تحقيق العاملين للأهداف والتوقعات الموضوعة، لذلك يجب توافر أهداف وتوقعات لكل وظيفة على مستوى المنشأة حتى يمكن إجراء التقويم بمقارنة الأداء الفعلي لثناغلي الوظيفة بالأداء المتوقع منه (حسين

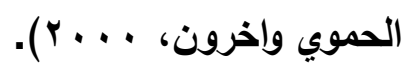

وفي الدراسة الحالية تعرف فاعلية الأداء الوظيفي بأنها "مدي تحقيق القيادات

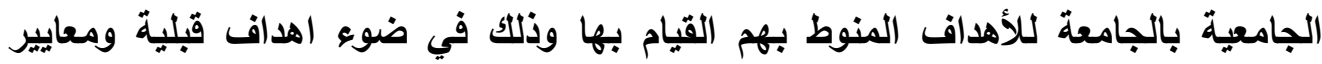

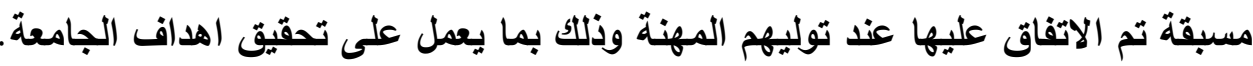

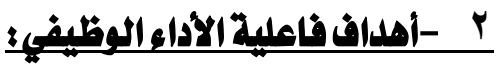

بصفه عامة يهذف تقييم فاعلية الأداء الوظيفي الي نقطتين رئيستين هما: هالتقييم وذك بهذف اتخاذ قرارات تخص شئون العاملين وتقيم تغذية عكسية عن أداء

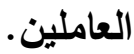

التطوير بهذف تقديم برامج تدريبية لتطوير أداء العاملين، وتقديم يد المساعدة للأعضاء

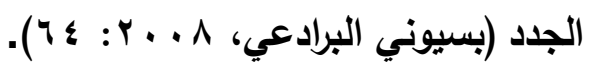

كذلك فإن من الأهداف التي يسعي لتحقيقها الأداء الوظيفي ما يلي (بسيوني

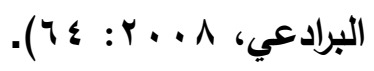


ا. مراقبة أداء الموظفين بشكلٍ دائم: وذلك باستخدام تقييم الأداء في الإثراف على

الموظفين؛ ومتابعتهم بشكل مستمر، وملاحظة تنفيذهم للمهام الموكلة إليهم. r. . دعم الموظفين لتحقيق الاجتهاد في الوظيفة: وذلك بتحفيز الموظفين على بذل جها كبير؛ بسبب إدراكهم أن أداءهم معتمد على التقييم من خلال الإدارة. r. دراسة إمكانية تعيين موظف جديد بشكل ثابت: وهو دور تقييم الأداء في تثبيت موظف بشكلٍ دائم بعد عمله خلال فترة تجريبيّة؛ بهاف دراسة قدراته ومهاراته للنجاح في الوظيفة. ع. تطوير المستوى الخاص بالخدمة المدنية: من خلال تحديد جوانب القوّة وجوانب الضعف

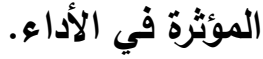
ه. معرفة الصلاحية الخاصة بنُظم الموظفين الأخرى: وذلك يعني اختبار مدى نجاح النُظم الخاصّة بالموظفين؛ من حيث تعينهم واختيارهم. 7. اكتثاف مجموعة من المشكلات التظيميّة والإداريّةة: عن طريق استخدام تقييم الأداء في التعرف على العيوب الإداريّة أو التنظيميّة، مثل عدم تحقيق أحد عناصر العمل المستوى المطلوب منه. كما قد أثشار الهييتي إلى ان عملية تقييم الأداء الوظيفي تستهدف ثثلاثة غايات تقع على ثلاثة مستويات هي المنظمة، والمدير والفرد العامل كما يلي:

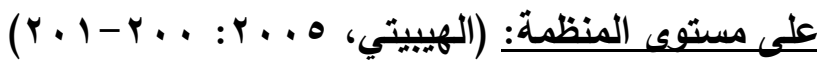
ا - إيجاد مناخ ملائم من الثقة والتعامل الأخلاقي الأي يبعد احتمال تعدد شكاوى العاملين تجاه المنظمة. r - مساعدة المنظمة في وضع معدلات أداء معيارية دقيقة، تمكنها من الاحتفاظ بالقوى العاملة ذات المهارات والقدرات المتميزة. ب - رفع مستوى أداء العاملين وإتثثمار قراتهم وإمكاناتهم بما يساعدهم على التقدم والتطور . ـ - تقييم برامج وسياسات إدارة الموارد البشرية كون نتائج العملية يمكن أن تستخدم كمؤشرات للحكم على دقة 
هذه السياسات.

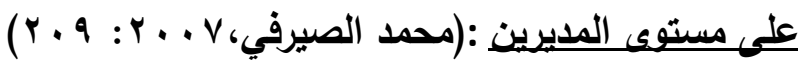

ا - تطوير العلاقات الجيدة مع العاملين والتقرب إليهم للتعرف على مشاكلهم والصعويات

التي تواجههم في العمل.

ץ - دفع المديرين إلى تنمية مهاراتهم وإمكاناتهم الفكرية حتى يمكنهم التوصل إلى تقييم سليم وموضوعي لأداء تابعيهم؛ فمواجهة المدير أو المشرف للقرد العامل للحكم على أدائه لا تعتبر عملية سهلة وإنما عملية تتميز بطابع التحدي الأي يدفع المديرين إلى تنمية مهاراتهم وإمكاناتهم الفكرية وتعزيز قدراتهم الإبداعية للوصول إلى تقييم سليم وموضوعي لأداء تابعيهم، وهذا ما يدفع باتجاه تطوير العلاقات الجيدة مع العاملين والتقرب إليهم للتعرف على مشاكلهم وصعوياتهما.

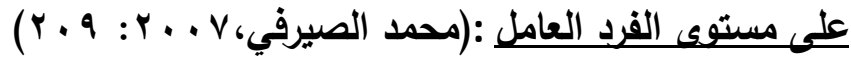
ا-دفع العاملين إلى العمل باجتهاد وجدية وإخلاص حتى يتمكنوا من الحصول على احترام وتقدير رؤسائهم.

r - شعور العاملين بالعدالة ويأن جهودهم المبذولة تؤخذ بعين الاعتبار.

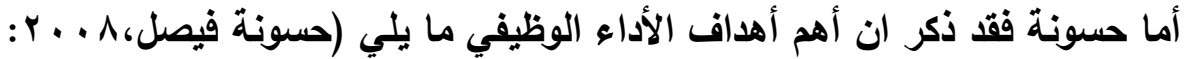

1 - تزويد المدراء ومتخذي القرار بمستوى أداء الموظفين في المنظمة. r - يساعد تقييم الأداء الوظيفي على معرفة مدى مساهمة الموظفين في تحقيق أهداف المنظمة، ومدى ملائمة الموظف للوظيفة التي يشغلها بشكل موضوعي وعادل. r- إثعار الموظفين بالمسؤولية وإعلامهم أنه سيتم تقدير جهودهم من قبل الإدارة وأن عملية الترقية والنقل والعلاوات لا تتم إلا عن طريق ذلك وتزويدهم بمعلومات عن مستوى أدائهم. ع - يساعد تقييم أداء الموظفين المدراء على اتخاذ قرارات بشأن تحسين وتطوير أداء الموظفين واقتراح المكافآت المالية بناء على مستوى الأداء وتميزه، مما يساعد على رفع الروح المعنوية وتقليل معدل دوران العمل. 
ه-يزود تقييم الأداء الوظيفي إدارة الموارد البشرية بمعلومات واقعية عن أداء العاملين في

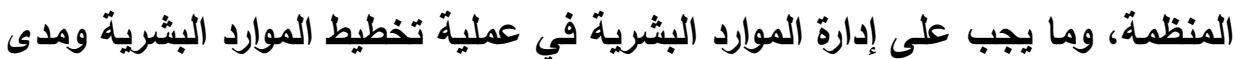

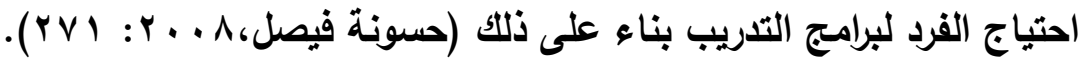
نستخلص مما سبق أن المنظمات المعاصرة ومنها الجامعات تهاف من وراء تقييم فاعلية الأداء الوظيفي إلى الوقوف بشكل موضوعي على أداء موظفيها ومعرفة الجواتب الإيجابية وإلسلبية ومحاولة معالجة الجوانب السلبية في أدائهم، وتوظيفها بشكل أكثر فعالية في تحقيق أهدافها وليس الهدف منها تصيد أخطاء الموظفين وإنزال العقويات عليهم أو عدم الثقة فيهم كما في الأساليب التقليدية التي تتبع طريقة ريط المكافآت والعقويات بنتائج التقييم الأي يجرى لهذه الغاية.

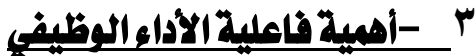

من المسلم به في حياة أيه منظمة أيا كان النشاط الذي تقوم به أن نجاحها يتوقف على أداء العاملين فيها، فإذا قاموا بأعمالهم وواجباتهز على النحو المطلوب فإن هذا سيقود المنظمة الي تحقيق أهدافها المنشودة، أما إذا كان الأداء دون المستوي المطلوب فإنه سيشكل عائقا كبيرا أمام المنظمة لتحقيق أهدافها، ويالتالي تتبلور أهمية الأداء الوظيفي فيما يلي:

ا. يعد مقياسا لأداء الفرد للعمل في الحاضر، وكذلك على أداء اعمال اخري مختلفة نسبيا في المستقبل ويالتالي يساعد في اتخاذ قرارات النقل والترقية. r. غالبا ما يتم ريط الحوافز بأداء الافراد وهذا يؤدي الي اهتمام الفرد بأدائه لعمله ومحاولة

تحسينه.

r. يرتبط الأداء بالحاجة الي الاستقرار في العمل، فاذا حدثت ايه تعديلات في نظام الإدارة فان العاملين ذوي الأداء المتلني يكونون مهددين بالاستغناء عن خدماتهم (نضال

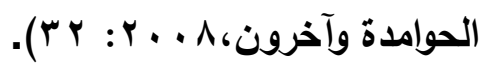

كما أن للأداء الوظيفي أهمية كبيرة داخل أية منظمة تحاول تحقيق النجاح والتقدم باعتباره الناتج النهائي لمحصلة جميع الأنشطة التي تقوم بها المنظمة، فإذا كان الناتج مرتفع فإن ذلك يعد مؤشرا واضحا لنجاح المنظمة واستقرارها وفعاليتها (شامي صليحة، 
كما ترجع أهمية فاعلية الأداء الوظيفي بالنسبة للمنظمات نتيجة الى ارتباطه بدورة حياتها في مراحلها المختلفة المتمثلة في مرحلة الظهور ومرحلة البقاء والاستمرارية ومرحلة الاستقرار ومرحلة السمعة والفخر ومرحلة التميز ثم مرحلة الريادة إذ أن قدرة المنظمة على تخطي مرحلة ما من مراحل النمو والدخول في مرحلة أكثر تقدما يعتمد على

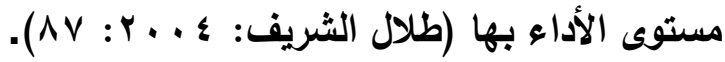
كما ترى ميسون الفقعاوي بان للأداء الوظيفي دور كبير في تحقيق أهداف البقاء

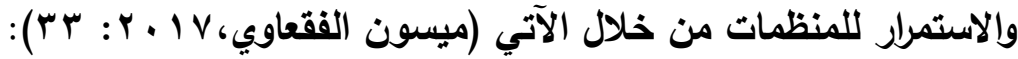
ا. يتضمن الأداء عددا من المضامين الواسعة والمتجددة نظرا لتعدد المتغيرات وإلظروف التي يرتبط بها فالبيئة بمتغيراتها وعواملها الخارجية أكثر تأثيرا في جوانب الأداء المختلقة. r. ترتبط التغيرات الكثيرة والتحولات الاستراتيجية والمالية والهيكلية بتاريخ الأداء ومن ثم فانه يزيد من اهتمامات إدارات المنظمات بالأداء وأهميته وجوانبه المختلفة من نتائج وقياسات. r. يرتبط الأداء بوجود المنظمات أو تلاشيها او انهيارها ومن ثم فان اهتمام المنظمات بالأداء يبقى مستمرا طالما بقيت هذه المنظمات موجودة. ويذكر أبو حطب أن أهمية الأداء الوظيفي تتمثل في: ع. يُمثّل أحد أساسيّات التطوّر الإداريّ: حيث يهتمّ بالتعامل مع عدّة جواتب تتصل بإجراءات العمل في المؤستّة، أو مع الموظفين بشكلٍ ذاتي؛ إذ يُساعد تقييم الأداء على توفير جميع البيانات المهمة حول مستوى الأداء الخاص بالموظفين، كما يُساهم في معرفة الطبيعة الواقعيّة التي يجب أن تنطلق منها الجهود الخاصة بالتطوير . ه. يُساهم في التعرف على القدرات الخاصة بالموظفين: ويُساعد ذلك على توزيع المهام والمسؤوليات بينهم. 7 ا ـ يُساعد على تطوّر الأداء الخاص بالموظفين: حيث تثمكّن الإدارة من اكتشاف جوانب الضعف عند كلّ موظف وتسعى إلى تقويتها، كما تختار الطريقة المناسبة لتوجيه

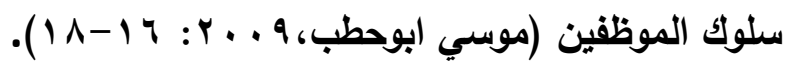


ويالتالي يعتبر تقييم الأداء الوظيفي وسيلة أساسية للحكم على فعالية وكفاءة أداء العاملين من ناحية وعلى دقة البرامج والسياسات التي تتبعها المنظمة من ناحية أخرى، ويمكن تلخيص أهمية تقييم الأداء الوظيفي في النقاط التالية (غربي علي وآخرون، V ... Y: $:(1 \leq 0-1) q$ 1. تحديد مدى كفاعة الفرد. r. المعاملة العادلة وحصول كل عامل على ما يستحقه (ترقية، علاوة، مكافأة، (الخ).

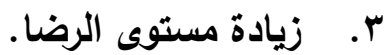
ع. خلق فرص الاحتكاك بين الرئيس والمرؤوس أو ما يسمي بخلق المناخ التنظيمي للعلاقات الحسنة والروح المعنوية الدافعة للعمل. ه. يؤدي شعور العاملين بأن جهة ما تقوم بتقييم نشاطهم، إلى الالتزام بتفيذ المهام فضلا عن شعورهم بالمسؤولية تجاه أنفسهم وعملهم معا. צ. يمثل الأداء الوظيفي وسيلة رقابية على المشرفين الذين يتابعون مراقبة وتقييم جهود العاملين. V. ترتبط هذه الوسيلة بتحديد مدى سلامة ونجاح الطرق المستخدمة في اختيار

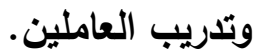
^. تساعد هذه الوسيلة على وضع الرجل المناسب في المكان المناسب. 9 . الاختيار على أساس مواصفات الوظيفة وتنمية مهارات وقدرات الأفراد. • 1 ـ الحكم على دقة السياسات والبرامج المتعلقة بالاستقطاب والاختيار والتعيين. 11 ا ـ يمكن التقييم الموضوعي أن يكون وسيلة جذب للموارد البشرية ذات المؤهلات النوعية.

r 1. التعرف على نقاط القوة والضعف تطوير نقاط القوة ومعالجة نقاط الضعف. با ا. توفير الأساس الموضوعي لأنثطة إدارة الموارد البثرية التوظيف، التريب الخ نستخلص مما سبق أن أهمية فاعلية الأداء الوظيفي تتمثل في انه وسيلة للتقييم الموضوعي القادر على جذب الموارد البشرية الجيدة، وخلق الدافعية لدى العامل، والاحتفاظ بالموارد البشرية المتخصصة ذات المهارات العالية، وأنه يكسب العامل 
مجموعة من السمات مثل درجة رضاه عن العمل وتحمل المسؤولية وتثبيع المنافسة كما انه يوجه السياسات للكشف عن العيوب التظيمية، وتحديد الاحتياجات التدريبية المساعدة في قياس الكفاءة الإنتاجية، وترشيد سياسة الأجور واختيار الأفراد الصالحين للترقية.

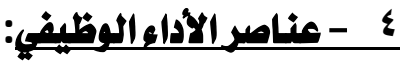

يتكون الأداء الوظيفي من مجموعة من العناصر أو المكونات الأساسية والتي بدونها لا يمكن التحدث عن أداء فعال، وتستخدم تلكك العناصر في قياس وتحديد مستوى أداء العاملين في المنظمات المختلفة ومنها الجامعات وهي: • المعرفة بمتطلبات الوظيفة: وتشمل المعارف العامة والمهارات الفنية والمهنية والخلفية العامة عن الوظيفة والمجالات المرتبطة بها. • نوعية العمل: وتتمثل في مدى ما يدركه الفرد عن عمله الذي يقوم به وما يمتلكه من رغبة ومهارات ويراعة وقدرة على التظيم وتتفيذ العمل دون الوقوع في الأخطاء. • كمية العمل المنجز: أي مقدار العمل الذي يستطيع الموظف إنجازه في الظروف العادية للعمل، ومقدار سرعة هذا الإنجاز. المثابرة والوثوق: وتثمل الجدية والتفاني في العمل وقدرة الموظف على تحمل مسئولية العمل وإنجاز الأعمال في أوقاتها المحدة، ومدى حاجة هذا الموظف للإرشاد والتوجيه من قبل المشرفين، وتقييم نتائج عمله. أما القرالة فيري أن عناصر الاداء الوظيفي ثلاث هي (عصمت القرالة،ه ـ . ب): الموظف: ما يمتلك من مهارات واهتمامات وقيم واتجاهات ودوافع. الوظيفة: ما تتصف به من متطلبات وتحديات وما تقدمه من فرص عمل تتمتع بالتحدي، وتحتوي على عنصر التغذية الراجعة.

الموقف: ما تتصف به البيئة التظيمية حيث تؤدى الوظيفة، والتي تتضمن مناخ العمل ووفرة الموارد والأنظمة الإدارية والهيكل التنظيمي.

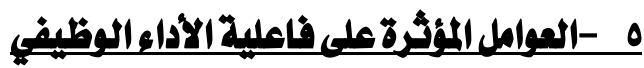

هناك العديد من العوامل التي تؤثثر في الأداء الوظيفي لعل من أهمها ما ذكره عبد

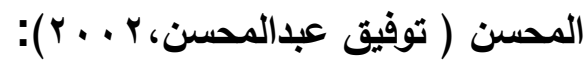


أولا: الاختلاف في حجم العمل فالمنظمة التي تعالج حجما كبيرا في العمل تحتاج إلى موارد أكثر مما قد تحتاج إليه منظمه أخرى لايها حجم اقل من العمل نفسه.

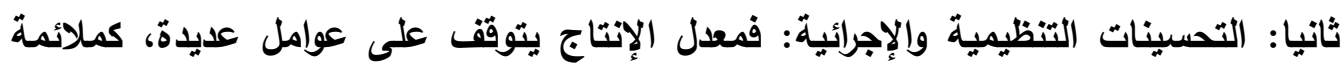
الترتيبات التنظيمية والإجرائية، واختصار خطوات العمل في عملية ما يقلل من الموارد المطلوية لإنهاء وحدة العمل.

ثالثاً: العوامل القتية والتكنولوجية: تتمثل في الإدخال المستمر للتكنولوجيا المتقدمة والحديثة من أجهزة ويرمجيات، حيث أن أداء الموظفين يتحدد بمستوى ونوعية التكنولوجيا المتوفزة لايههم.

أما من وجهه نظر شامي صليحه أن من العوامل التي تؤثر في فاعلية الأداء الوظيفي ما يلي:(النظام والسياسات التي تتبعها المنظمة- - أنماط القيادة- مدى التماسك بين جماعات العمل - ظروف بيئة العمل المادية فاستخدام اساليب التكنولوجيا الحديثة تساعد على تحسن الأداء-وجود ثقافة تنظيمية قوية داخل المنظمة-وضوح المسؤوليات والأهداف المطلوية من الفرد تحقيقها-مدى توافق متطلبات العمل من قدرات الفرد وامكانياته-مستوى فاعلية الإثراف- الظروف الاقتصادية والثخصية للفرد- حالة الفرد الصحية والنفسية- مدى التزام الفرد في العمل - مدى توافر المعلومات اللازمة لأداء

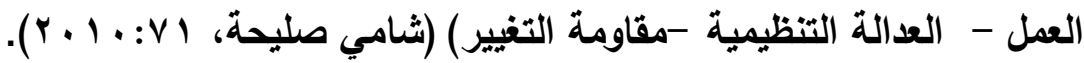
نستخلص مما سبق أن من اهم العوامل المؤثرة على عدم فاعلية الأداء الوظيفي هو عدم وجود اهداف محددة للمنظمة، او عدم دعم المشاركة في الإدارة واختلاف مستويات الأداء وعلد تحقيق الرضا الوظيفي لاي العاملين الي جانب وجود مشكلات في البيئة المادية او التطوير التظيمي والتسيب الإداري وضعف نظم الحوافز ونطاق الاشراف.

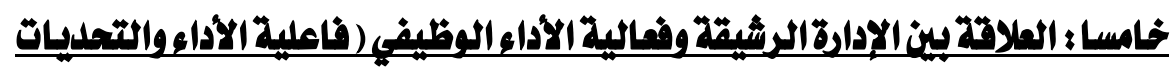

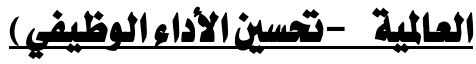
1-فاعلبة الأليط الوظيفي والتحديات العالمية ان ظهور العديد من التحديات العالمية في التطور التقني ونظم المعلومات والاهتمام بالبيئة المحيطة والعمل الجماعي أدت الي زيادة الحاجة الي مهارات إدارية قادرة علي الأداء المتميز وزيادة الاهتمام بتنمية الموارد البشرية وزيادة الإنتاجية والجودة 
والتحسين المستمر للأداء لذلك لابد علي المنظمة من الاخذ في الاعتبار بعض العناصر

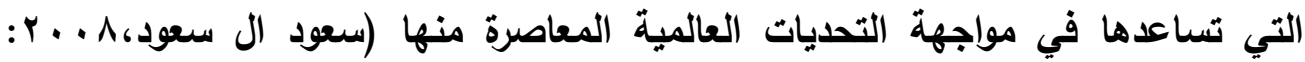
$:$ (^

(1/1) التحسين المستمر: ان مسئولية التحسين لا تقع على عاتق المدير فقط وإنما هي مسؤولية جميع العاملين بالمنظمة وجمهور المستفيدين من خدمات المنظمة وذلك من خلال فهمهم بما يحيط بالمنظمة من مستجدات وتحديات كما وان التحسين المستمر يتطلب تطوير كافة الأنظمة وأساليب الأداء في المنظمة وزيادة قرة المنظمة في تعاملها مع

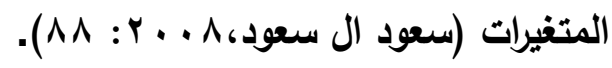

وهناك مجموعة من المقومات التي تساعد في تحقيق التطور المستمر منها: تعزيز القيم الأساسية الثابتة للمنظمة وذلك لتحقيق الاستقرار والتحسين المستمر. اشتراك العاملين في عملية اتخاذ القرارات وحل المشكلات مع تحفيزهم ومتابعتهم ان يكون التحسين مكونا حيويا من استراتيجية العمل بالمنظمة. بناء اتجاهات إيجابية لاي القادة والعاملين تدفعهم الي التطوير والتحسين

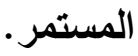
تحديد أهداف التحسين في الأداء الكلي. تصميم برامج تدريبية لكافة العاملين وذلك لان التدريب المستمر للعاملين يساهم في تحقيق التحسين المستمر . تسجيل أي تحسينات تحصل في الأداء والتظلب على المشكلات التي تحول دون تحقيق المطلوب.

المتابعة المستمرة لآراء العاملين والمستفيدين الخاصة بالتحسين والتطوير . الاستخدام الأمثل لجميع موارد المنظمة المادية والبشرية. ويالتالي ومما سبق يتضح انه لكي تضمن المنظمة الأداء المتميز لابد عليها من

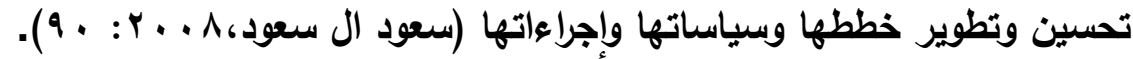
(Y/1) استثمار الوقت: يوجد ارتباط وثيق بين تحسين الأداء وإدارة الوقت واستثثاره وذلك عن طريق استخدام التقنية المعاصرة في تنفيذ الاعمال، وتنظيم الاعمال الروتينية وتحديد إجراء|تها والحصول على قرارات واضحة من الرؤساء وعقد الاجتماعات الهادفة. 
ويشير أحد الباحثين الي ان من أكبر أسباب ضياع أوقات المديرين وموارد المنظمة هو غياب الروية الاستراتيجية والاهداف والقيم الثابتة أو ضعف الالتزام بها ويضاف الي ذلك الك غياب التخطيط السليم وغياب توزيع المهام والمسئوليات وتلني مستوي الأداء وعدم المعرفة بكيفية إدارة الوقت واستثماره، فان استثمار الوقت هو تجسيد للإدارة الفعالة حيث ان استثماره يساعد في التخلص من مضيعات الوقت ويساعد أيضا في البدء في الاعمال المطلوب إنجازها حسب الأولوية وتفويض بعض الاعمال للمساعدين لذلك يجب استخدامه

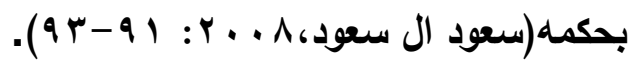

ومن الملاحظ من العناصر السابقة والتي تمثل الطرق المختلفة التي ينبغي على جميع المؤسسات ومن بينها الجامعات العمل بها لمواجهة التحديات العالمية المختلفة، بحيث تحقق جودة الأداء الوظيفي عنصري التحسين المستمر والاستثمار الفعال للوقت واللذان يمثلا أيضا المكونات الأساسية لنظام الإدارة الرشيقة، ويالتالي توجد علاقة وثيقة بين كل من فاعلية الأداء الوظيفي والقيادة الرشيقة.

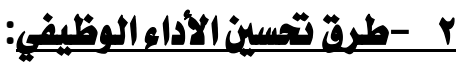
يمكن تحسين الأداء الوظيفي من خلال المداخل التالية: (Y/Y) تحسين أداء الموظف: ويرى البعض أن تحسين أداء الموظف هو أكثر العوامل صعوية في التغيير وإذا تم التأكد بعد تحليل الأداء بأن الموظف بحاجة إلى تغيير أو تحسين في الأداء فهناك عدة وسائل لإحداث هذا التحسين وهي: التركيز على نواحي القوة لاى الموظف، واتخاذ اتجاه إيجابي عن الموظف بما في ذلك مشاكل الأداء التي يعاني منها، والاعتراف بأنه ليس هناك فرد كامل، وإدراك حقيقة أنه لا يمكن القضاء على جميع نواحي القصور والضعف لاى الموظف، وتركيز جهود التحسين في الأداء من خلال الاستفادة لدى الموظف من مواهبه والعمل على تنميتها. التركيز على التوازن بين ما يرغب الفرد في عمله، ويبين ما يؤديه الفرد بامتياز، وإن وجود علاقة سبيية بين الرغبة والأداء تؤدي إلى احتمال حدوث الأداء الممتاز من خلال السماح للأفراد بأداء الأعمال التي يرغبون أو يبحثون عن أدائها، وهذا يعني توفير الانسجام بين الأفراد واهتماماتهم والعمل الأي يؤدي في المنظمة. 
ربط الأداء الوظيفي بالأهداف الشخصية، ويعني ذلك أن تكون مجهودات تحسين الأداء مرتبطة ومنسجمة مع اهتمامات وأهداف الموظف والاستفادة منها من خلال إظهار أن التحسين المرغوب في الأداء سوف يساهم في تحقيق هذه الاهتمامات مما يزيد من من من منه تحقيق التحسينات المرغوية من قبل الموظف. (Y/Y) تحسين الوظيفية: إن التغيير في مهام الوظيفة يوفر فرصة لتحسين الأداء، حيث تساهم واجبات الوظيفة في تدني مستوى الأداء إذا كان مملة أو تفوق قرات ومهارات الموظف ونقطة البداية في دراسة وسائل تحسين الأداء في وظيفة معينة هي معرفة ضرورة

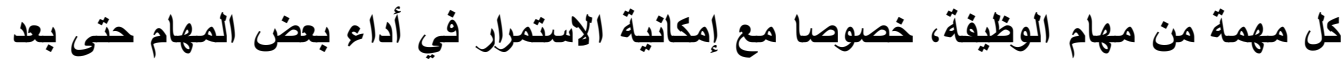

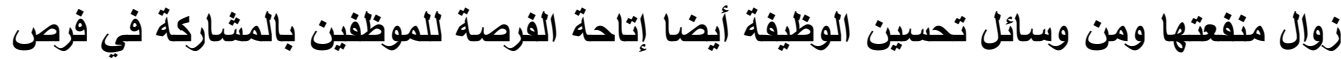
العمل، ويتم تحسين الوظيفة أيضا من خلال توسيع نطاق الوظيفة وإثراء الوظيفة، ويتضمن توسيع الوظيفة تجميع مزيد من المهام التي تتطلب نفس المستوى من المهارة بهاف زيادة الارتباط بين الموظف والمنتج النهائي، أما إثراء الوظيفة فيتضمن زيادة مستويات المسئولية

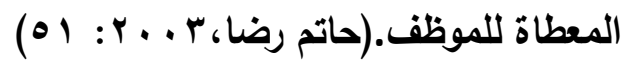
(r/r) تحسين الموقف: لا يتأثز سلوك الفرد في موقف معين بما يملكه من معارف ومهارات وقدرات وسمات شخصية فقط بل يتأثر أيضا بطبيعة الموقف الذي يواجه الفرد، والمواقف التي تؤدي فيها الوظيفة تعطي فرصة للتغيير، والذي يؤدي بلوره إلى تحسين الأداء من خلال

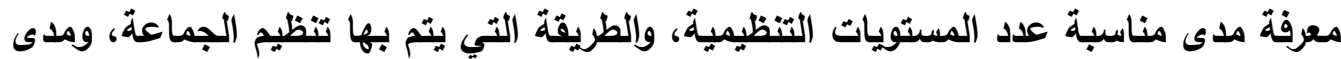
مناسبة ووضوح خط الاتصال، والمسئولية والتثاعل المتبادل مع الإدارات الأخرى مع الجمهور

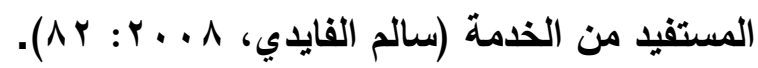
نلاحظ مما سبق أن الهرف الرئيس لعملية تحسين الأداء الوظيفي في المؤسسات بصفة عامة والجامعات بصفه خاصة لا يتحقق إلا من خلال الاراسة الثاملة لعناصر الأداء الوظيفي ومستوياته وتحليل العوامل الإدارية والفنية والتدريبية المؤثرة فيه والبحث عن الأساليب الفاعلة لتحسين وتطوير تلك العوامل، وفلسفة تحسين الأداء الوظيفي تمثل سياسة هامة تتتجها تلك المنظمات، حيث يسود الاقتناع بضرورة التحسين والتطوير المستمر لكافة العوامل الإدارية والقنية وإلتدريبية المتبعة في داخل المنظمة والتي تؤثثر على أداء العاملين بها بدءا بالموظفين وانتهاء بالقيادات الجامعية في كل مجال من المجالات الأكاديمية 
ويالتالي فهو بمثابة عملية تقويم شاملة لا تفيد العاملين فقط، بل تشمل المنظمة أو الجامعة بشكل عام من خلال نتائج تقييم الأداء للموظفين داخل المؤسسات، وذلك بتحديد مواطن القوة والضعف، والتي تستفيد منها المؤسسة لتنمية مهارات العاملين وتحسين أدائهم مما ينعكس علي نجاح المنظمة أو الجامعة، والذي يعتبر من أهم سمات وخصائص الإدارة الرشيقة والمبادئ التي تقوم عليها، ويالتالي يوجد ارتباط وثيق بين تطبيق مبادئ الإدارة الرشيقة بالمنظمات المختلفة وتحسين فاعلية الأداء الوظيفي.

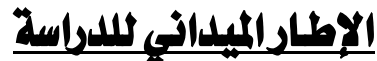

تهدف الدراسة الميدانية إلى التعرف على درجة ممارسة القيادات الجامعية بجامعة الوادي الجديد للإدارة الرشيقة وعلاقتها بفاعلية الأداء الوظيفي من وجهه نظر أعضاء هيئة التدريس بالجامعة، ويتضمن الإطار الميداني ما يلي:

- 1

استخدمت الباحثة استبانة ذات طرفين، تم بناؤها في ضوء الإطار النظري

والاراسات السابقة، وتكونت الاستبانة من قسمين أساسين هما: أ-القسم الأول: يتكون من ؛ 4عباره مقسمة إلى خمسه أبعاد مرتبطة بمبادئ الإدارة الرشيقة، وتم صياغة العبارات بحيث تكون استجاباتها (موافق، موافق إلى حد ما، غير الهى موافق)، ويتكون كل بعد من عدة عبارات كما يلي: - البعد الأول: تنظيم موقع العمل ويتضمن 1 - عبارات.

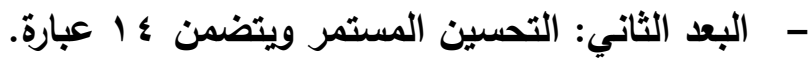
- البعد الثالث: العمل القياسي ويتضمن ه عبارات. - البعد الرابع: العاملين متعددي الوظائف ويتضمن ه عبارات. - البعد الخامس: ستة سيجما ويتضمن ؛ 1 عبارة. ب-القسم الثاني: خاص بفاعلية الأداء الوظيفي ويتكون من بrاعبارة، وتم صياغة عباراته بحيث تكون استجاباتها (موافق، موافق إلى حد ما، غير موافق)، وتكون من بعدين الأول خاص بالقيادات الأكاديمية ويتكون من 1 الأعبارة والثاني خاص بالقيادات الإدارية ويتكون من r إن عبارة. 
وقد استخدمت الباحثة مقياس ليكرت الثلاثي لقياس استجابات أفراد العينة للعبارات وأبعاد

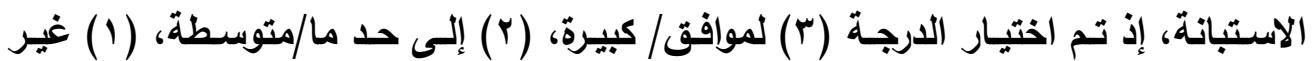
موافق/ضعيفة.

\section{r ب - ثـات وصلدق أداة اللدراسة:}

r/ ا - الصدق الظاهري للأداة: تم التحقق من الصدق الظاهري للاستبانة عن طريق صدق

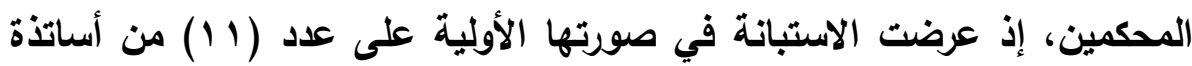

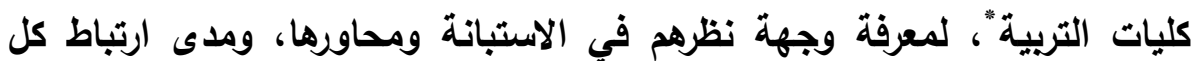
عبارة للمحور الذي تنتمي إليه، ويناء على آرائهح تم تعديل بعض العبارات، وحذف لهف

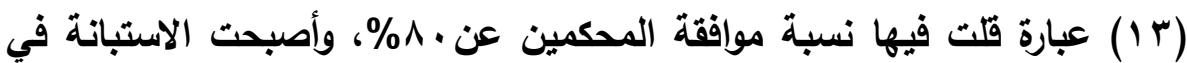
صورتها النهائية مكونة من (TV) عبارة بدلا من ( • (^) عبارة. צع/r - الصدق الداخلي للأداة: تم التحقق من صدق الاتساق الداخلي للاستبانة ومحاورها،

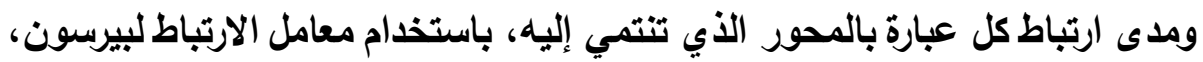

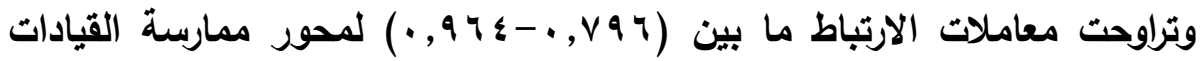

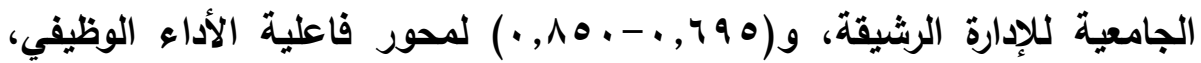
وجميع هذه القيم دالة إحصائيا عند مستوى الدلالة (1, (·) )، مما يدل على التماسك الداخلي لمحاور الاستبانة والعبارات المرتبطة بها. r/r - ثبات الأداة: اعتمدت الباحثة في التحقق من ثبات الاستبانة على استخدام معامل ألفا كرونباخ Cronbach's Alpha، إذ بلغت معاملات الثبات لمحور ممارسة القيادات

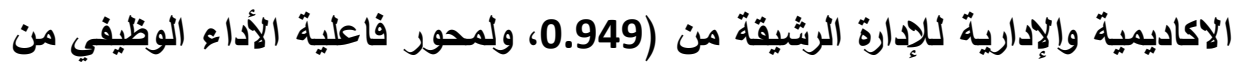

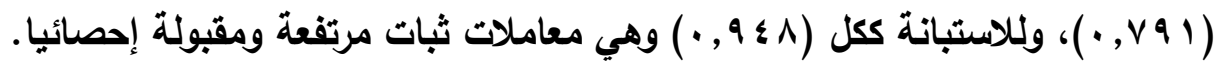

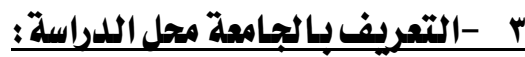

أسست جامعة الوادي الجديد عام 2018 مستقلة عن جامعة أسيوط، بقرار من رئيس

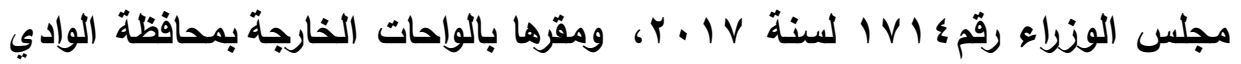
الجديد، و كانت في السابق فرع الوادي الجديد يتبع جامعة أسيوط، ثم أستقلت، وتضم بوراء 
حتي وقت اجراء الدراسة الحالية ست كليات هي كلية التربية والآداب والزراعة والعلوم والتربية الرياضية والطب البيطري*.

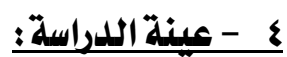

بلغ إجمالي عينة الاراسة (I rVV) عضواً من أعضاء هيئة التدريس بست كليات

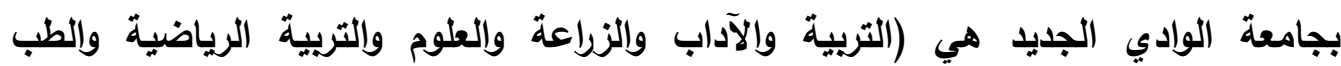
البيطري) وذلك كما موضح بالجدول التالي:

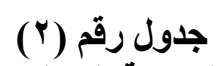

نسبة عينة الدراسة إلى المجتمع الأصلي (بأي

\begin{tabular}{|c|c|c|c|c|}
\hline نسبة العينة إلى المجتمع & العينة & الأصلئمع & البيان & المتغير \\
\hline$\% \leq 7.01$ & $\Lambda \wedge$ & ivi & ذكر & \multirow{2}{*}{ الجنس } \\
\hline$\%$ & rq & 89 & انثى & \\
\hline$\% Y^{\prime} 1.00$ & IYV & $r r$. & \multicolumn{2}{|c|}{ المجموع } \\
\hline$\% 1 \ldots$ & $r$ & $r$ & كليات عملية & \multirow{2}{*}{ نوع الكلية } \\
\hline$\% 1 \ldots$ & $r$ & $r$ & كليات نظرية & \\
\hline$\% 1 \ldots$ & 7 & 7 & \multicolumn{2}{|c|}{ المجموع } \\
\hline$\%$ \% $9 . \leqslant 7$ & ro & $0 \leqslant$ & أستاذ & \multirow{3}{*}{ العلمية } \\
\hline$\% 79.0 \mathrm{~V}$ & $\leqslant 0$ & $\vee \wedge$ & أستاذ مساعد & \\
\hline$\% \circ \wedge, 17$ & $\Delta V$ & 91 & مدرس & \\
\hline$\% 00 . Y 1$ & $1 Y V$ & $r r$. & g & \\
\hline
\end{tabular}

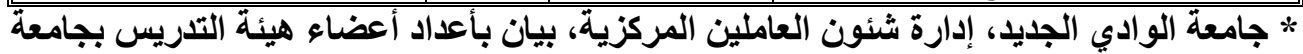

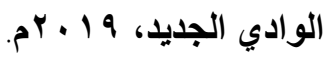

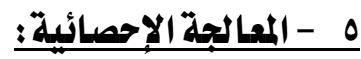

اعتمدت الباحثة في معالجة البيانات واستخراج النتائج على برنامج الحزم الإحصائية

للعلوم الاجتماعية (SPSS)، وقد تم استخدام الأساليب الإحصائية الآتية : - عامل ألفا كرونباخ لتحديد معامل ثبات الاستبانة.

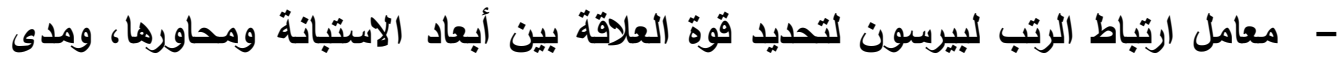
ارتباط العبارات بمحاورها.

- المتوسطات الحسابية والانحرافات المعيارية لتحديد الأهمية النسبية لاستجابات أفراد العينة تجاه عبارات وأبعاد الاستبانة. 
- اختبار (T test) لتحديد الفروق بين متغيرات الدراسة. - تحليل التباين الأحادي (ANOVA) واختبار (F) لتحديد الفرق بين أكثر من متوسطين.

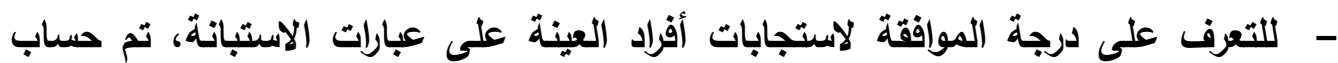
قيمة وزن الاستجابات للاستبانة، ومن ثم تصبح درجة الموافقة أفراد العينة على العبارة

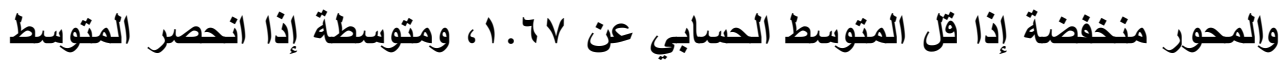

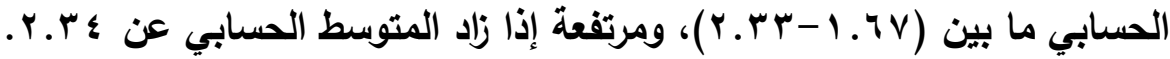

\section{1 - تخليل وتفسير نتائج اللدراسة:}

(1/7/ السؤال الثاني: ما واقع ممارسة القادة الجامعيين للإدارة الرشيقة بجامعة الوادي

الجديد من وجهة نظر أعضاء هيئة التدريس؟ مأع همأس

للإجابة عن هذا السؤال تم حساب المتوسط الحسابي والانحراف المعياري لاستجابات أفراد العينة في الأبعاد الخاصة بمبادئ الإدارة الرشيقة، ويوضح ذلك الجدول التالي: جدول (r)

المتوسط الحسابي والانحراف المعياري لاستجابات عينة الاراسة في الأبعاد الخاصة بمحور

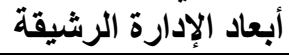

\begin{tabular}{|c|c|c|c|c|c|}
\hline الممارسيرة & الترتيب & الالحعراف & الحستوسطي & الابعاد ( المجالات) & b \\
\hline مرتفع & 1 & 0.415769 & 2.38845 & تنظيم أماكن العمل & 1 \\
\hline متوسط & $r$ & 0.413950 & 2.33408 & التحسين المستمر & $r$ \\
\hline متوسط & $\xi$ & 0.5938 & 2.231 & العمل القياسي & $r$ \\
\hline متوسط & 0 & 0.5518 & 2.216 & العاملين متعددي الوظائف & $\varepsilon$ \\
\hline مرتفع & $r$ & 0.436374 & 2.37177 & ستة سيجما sigma & 0 \\
\hline متوسط & & •.\&AYTHAT & $1 . \Lambda 7 Y \cdot 7$ & المحور ككل & \\
\hline
\end{tabular}

- يتضح من الجدول السابق أن أفراد العينة ككل يجمعون على أن درجة ممارسة أبعاد

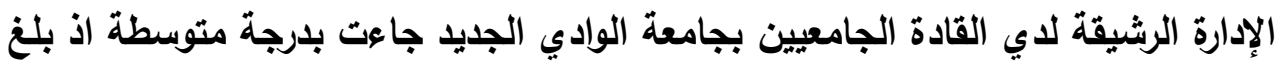
المتوسط الحسابي للمحور ككل 1.862 و الانحراف معياري 0.48 . - - تختلف هذه النتيجة مع ما توصلت اليه دراسة (بن وارث وجاية، 7 ـ ب ) ودراسة (رغد

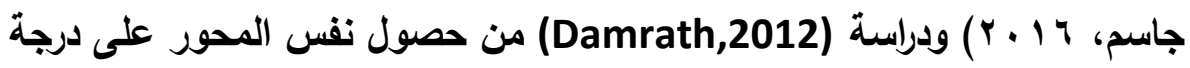
مرتفعة من وجهة نظر عينة الدراسة، وتتفق مع ما توصلت اليه دراسة ( Sparrow \&) .Otaye, 2014 
- يتضح من الجدول السابق أن البعد الاول "تنظيم أماكن العمل" قد احتل المرتبة الأولى

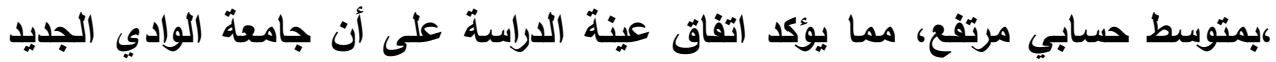

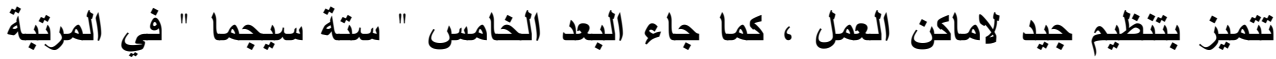

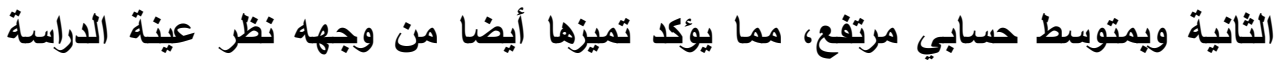
بالقدرة على تحسين جودة العمليات وذلكك من خلال خفض التكاليف، وتحسين العمليات وتطويرها وتقليل الوقت المستغرق لإنجاز العمليات ، واحتل البعد الثاني "التحسين

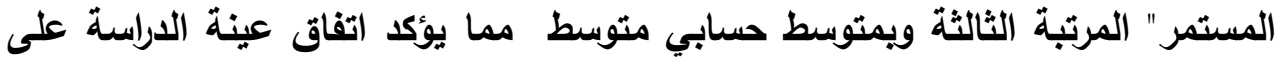
أن الجامعة تقوم بإجراء تحسينات جيدة ومستمرة لتحقيق جودة العمل، ولكنها تحتاج لمزيد من الاهتمام والعناية، كما احتل البعد الثالث "العمل القياسي" المرتبة الرابعة، بمتوسط حسابي متوسط حيث اتفقت عينة الدارسة على أنه ينبغي الاهتمام من قبل الجامعة بصورة اكبر بتوحيد الإجراءات التتفيذية للعمل لضمان رضا المستفيدين، أما لئه البعد الرابع "العاملين متعدي الوظائف" فقد احتل المرتبة الأخيرة من منظور عينة الدراسة، بمتوسط حسابي متوسط ، وقد يرجع السبب في تأخر هذا المحور إلى ان ان النيان الجامعة تعتبر من الجامعات الحليثة نسبيا حيث تم انفصالها عن جامعة أسيوط في العام

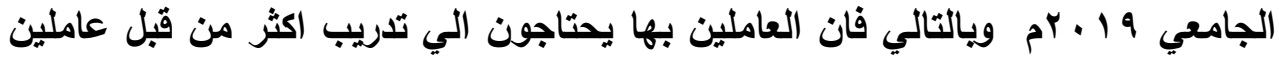
اخرين يتمتعوا بمهارات متعددة متعلمة ومتخصصة ومتدرية وقادرة على دراسة وفهه الواقع الحالي والعمل على حل مثكلاته، بل وتطويره الى الأفضل.

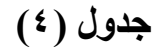

المتوسط الحسابي والانحراف المعياري لاستجابات عينة الاراسة في الأبعاد الخاصة بحدور

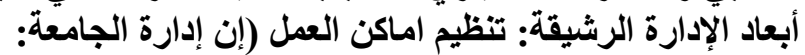

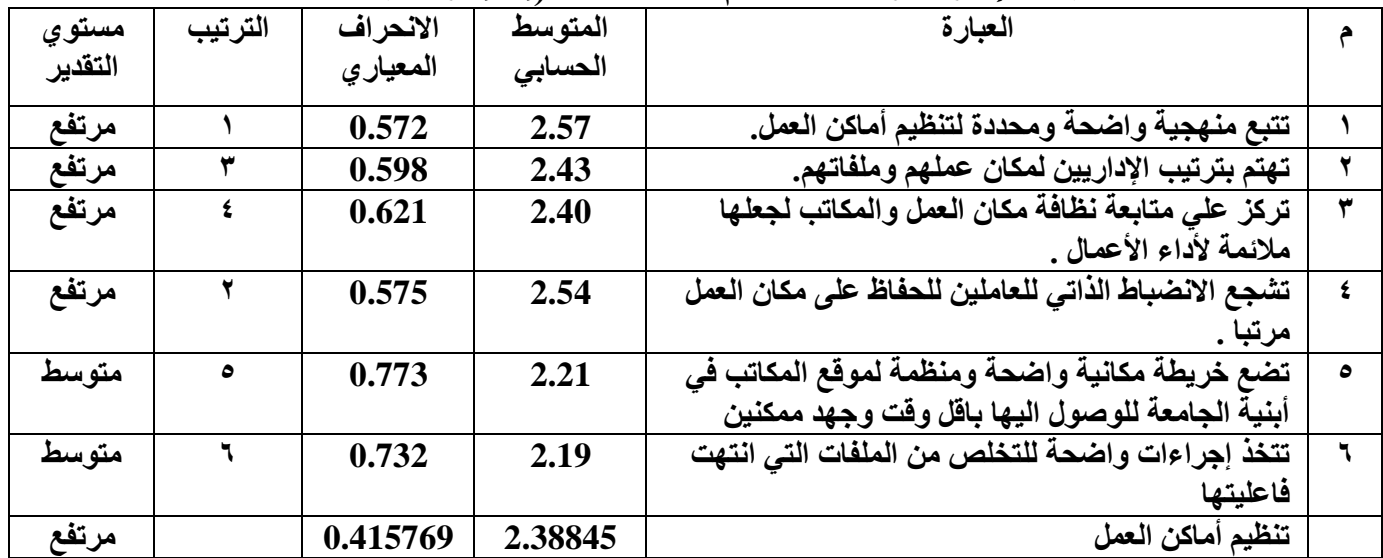


- - يتضح من الجدول السابق أن أفراد العينة ككل يتفقون على أن محور تتظيم أماكن العمل

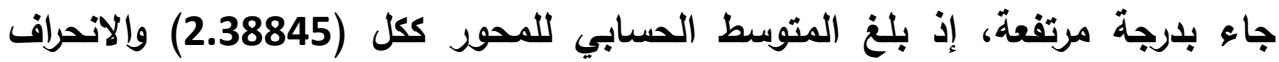
معياري (0.415769).

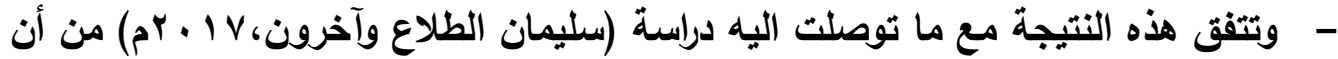
تنظيم أماكن العمل والذي يعتبر مبدأ من مبادئ الإدارة الرشيقة يعمل على إيجاد بيئة إبداعية في الكليات، ودراسة الكفل ( Niccolo Curatolo , 2014) مبادئ تطبيق معايير الإدارة الرشيقة يؤثرث علي أداء الممارسين الطبين والاداريين ويالتالي الي تحسن العمليات وتوفير الوقت والموارد كطريقة جيدة للاستثمار داخل المؤسسات الطبية. - أما بالنسبة إلى ترتيب هذه الأبعاد فيمكن توضيحه فيما يلي: - - أن البعد الأول والأي ينص علي " تتبع منهجية واضحة ومحددة لتنظيم أماكن العمل "بترتيب الأول والبعد الرابع والذي ينص علي " تثجيع الانضباط الذاتي للعاملين للحفاظ على مكان

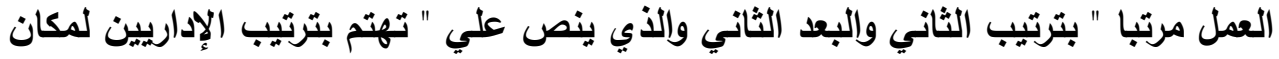

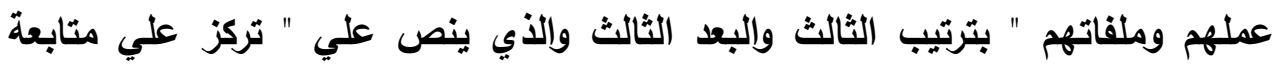

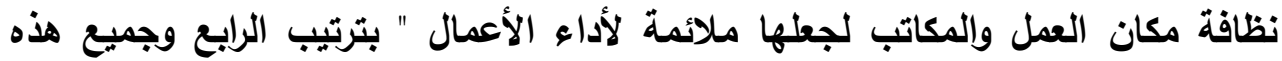
القيم مرتفعة ، أما العبارة الخامسة والتي تنص علي " تضع خريطة مكانية واضحة ومنظمة لموقع المكاتب في أبنية الجامعة للوصول اليها باقل وقت وجها ممكنين" والعبارة السادسة والتي تنص علي "تتخذ إجراءات واضحة للتخلص من الملفات التي انتهت فاعليتها " في المراتب الخامسة والسادة الأخيرة علي الترتيب وجميع هذه القيم متوسطة.

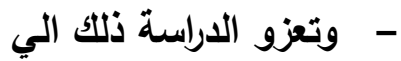
1-اتباع الإدارة الجامعية منهجية واضحة ومحددة لتنظيم أماكن العمل وتجهيزاتها بهذف

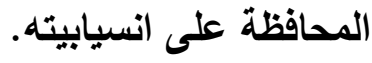


r-اهتمام الإدارة الجامعية بأن يقوم العاملون بترتيب أماكن عملهم وملفاتهم ووضعها بمكانها الصحيح تسهيلا للحصول عليها عند الحاجة، مما ينتج عنه بالنهاية أداء العمل بله بشكل مريح مما يعطي انطباع إيجابي في نفوس المراجعين للجامعة وادارتها المختلفة. ب-احتياج إدارة الجامعة الي وضع خريطة مكانية واضحة ومنظمة لموقع المكاتب في أبنية الجامعة للوصول اليها بأقل وقت وجه ممكنين وايجاد طرق فعالة وغير مضرة بالبيئة للتخلص من الملفات المنتهية الصلاحية.

جدول (0) (0)

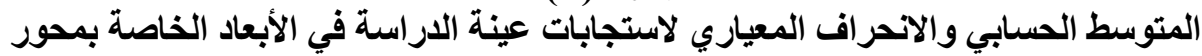
أبعاد الإدارة الرشيقة: التحسين المستمر (إن إدارة الجامعة:

\begin{tabular}{|c|c|c|c|c|c|}
\hline مستوي & الترتيب & الانحراف المعياري & المستوسط & العبارة & r \\
\hline مرتفع & $\varepsilon$ & 0.658 & 2.40 & تشخصل المناسبة لهات التي تواجه الاقسام وتوفر & $\checkmark$ \\
\hline مرتفع & 7 & 0.576 & 2.38 & تبأعمالهم الامكانيات التي تمكن العاملين من القيام & $\Lambda$ \\
\hline مرتفع & 9 & 0.657 & 2.34 & تحفز العاملين باستمرار لتطوير قدراتهم. & 9 \\
\hline متوسط & 1. & 0.641 & 2.32 & تلوفلين. حزم تلريبية لزيادة الكفاءة المهنية & 1. \\
\hline متوسط & 11 & 0.651 & 2.31 & والاقتر آلية واضحة & 11 \\
\hline مرتفع & $r$ & 0.612 & 2.43 & تقيم الأداء باستمرار من أجل تطويره. & Ir \\
\hline متوسط & Ir & 0.704 & 2.23 & 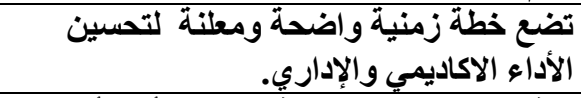 & ir \\
\hline مرتفع & 0 & 0.667 & 2.39 & 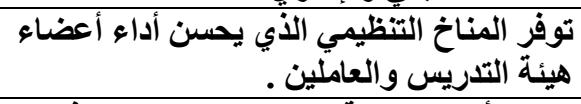 & $1 \varepsilon$ \\
\hline مرتفع & $r$ & 0.651 & 2.45 & 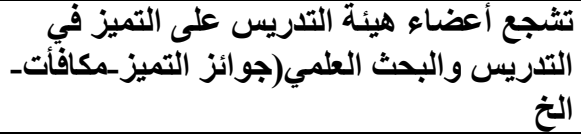 & 10 \\
\hline مرتفع & V & 0.635 & 2.35 & 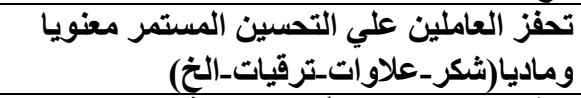 & 17 \\
\hline متوسط & $1 \varepsilon$ & 0.742 & 2.14 & 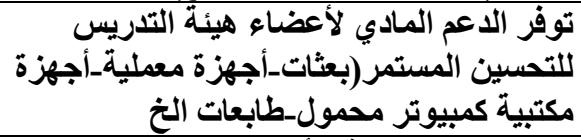 & iv \\
\hline متوسط & $1 \%$ & 0.725 & 2.17 & تضع معايير داخلية للأداء ومطابقتها مع & 11 \\
\hline متوسط & 11 & 0.729 & 2.31 & التوظفية ما يتناسب وطبيعة نشاطها واحتياجاتها & 19 \\
\hline مرتفع & 1 & 0.676 & 2.46 & المستمدر. تعائج تقيـم الأداء كأسـاس للتحسين & $r$. \\
\hline متوسط & & 0.41395 & 2.33408 & التحسين المستمر & \\
\hline
\end{tabular}


- يتضح من الجدول السابق حصول محور" التحسين المستمر " من وجهة نظر عينة الدراسة على درجة متوسطة من حيث المتوسط الحسابي 334082والانحراف المعياري 0.41395.

- وتختلف هذه النتيجة مع ما توصلت اليه دراسة (عبد القادر مسلم وشذا أبو سليم،

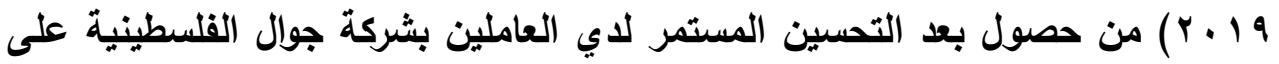
متوسط حسابي مرتفع من وجهة نظر عينة الدراسة.

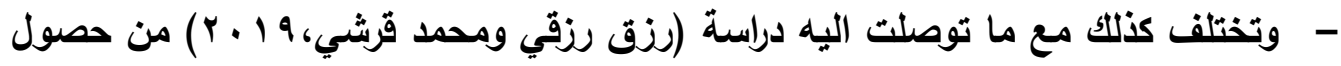
بعد التحسين المستمر على درجة منذفضة من وجهة نظر عينة الاراسة بالمستثفيات الاستثفائية بالجزائر .

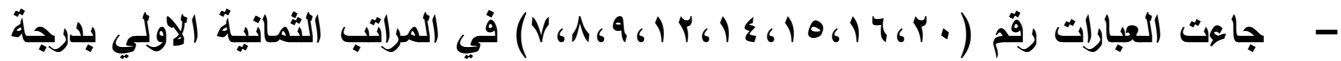
مرتفعة من وجهه نظر العينة من حيث المتوسط الحسابي والانحراف المعياري. - - وتعزو الدراسة ذلك لان الجامعة تتبني برامج ومنهجيات جيدة ترتبط بالتحسين المستمر

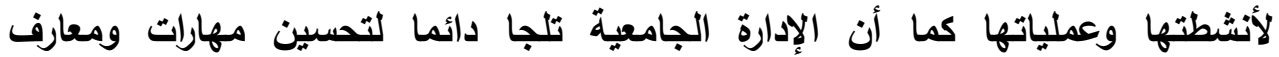

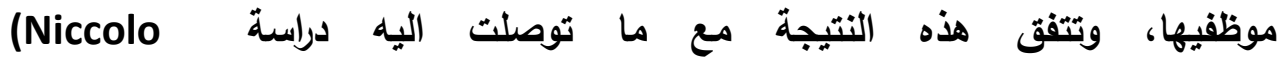
Curatatolo,2014)

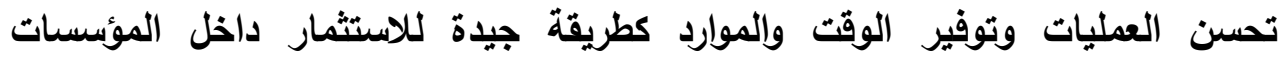
المختلفة.

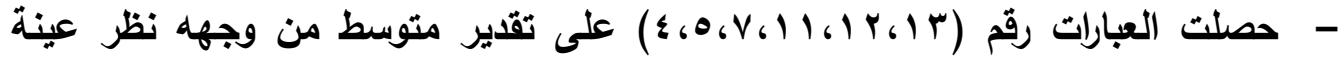
الدراسة من حيث المتوسط الحسابي والانحراف المعياري.

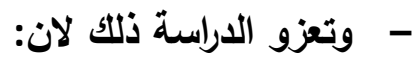
1 - الجامعة تحتاج الي مجموعة كبيرة من الحزم التدريبية للعاملين بها خصوصا ان الجامعادة

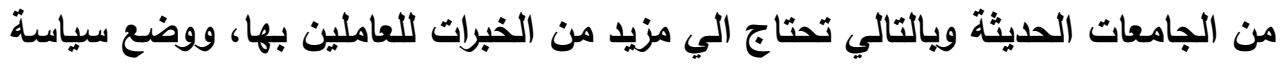

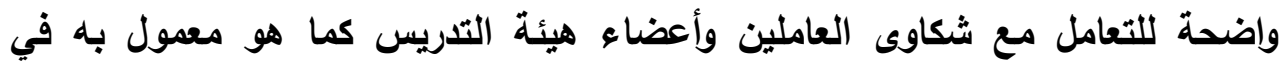

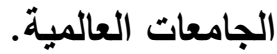
ץ- الجامعة توفر مستوي متوسط من التقييد بالمعايير العالمية للأداء والاستغلال الأمثل لمواردها، وينبغي أن تأخذ بعين الاعتبار طاقاتها المادية والبشرية المتاحة. 
ب- عمليات التقييم التي تتم داخل الجامعة لا تكون الا بناء على طلب من الإدارات العليا

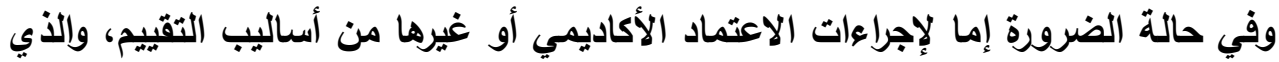
يكون في اغلب الأحيان غير فعال. ع -ثقافة التحسين المستمر غير موجودة بصورة كبيرة لاي الكثير من العاملين بالجامعة الامر الذي يتطلب تغير نحو الأفضل من قبل الإدارة العليا للجامعة.

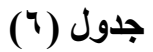

المتوسط الحسابي والانحراف المعياري لاستجابات عينة الدراسة في الأبعاد الخاصة بمحور أبعاد

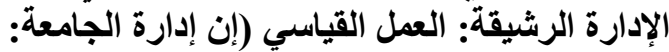

\begin{tabular}{|c|c|c|c|c|c|}
\hline مستوي & الترتيب & المعياري & الحسابي & 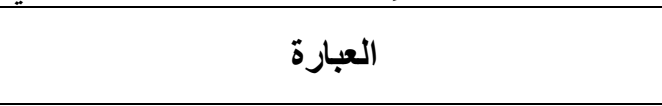 & p \\
\hline مرتفع & 1 & 0.639 & 2.46 & في ضو مجمهو تقييم اداء معايير الأداء الجيا التي يتم & 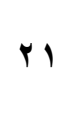 \\
\hline متوسط & $r$ & 0.737 & 2.23 & 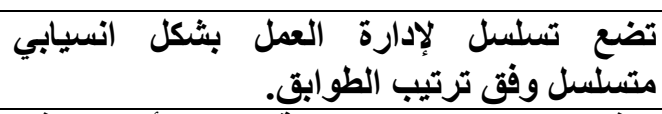 & $Y Y$ \\
\hline متوسط & $\varepsilon$ & 0.808 & 2.07 & الزوفر مكتب مخصص لهصا. لمتابعة انجاز الأعمال وفق & $r \mu$ \\
\hline متوسط & $r$ & 0.810 & 2.20 & 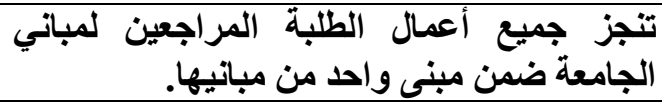 & $r \leq$ \\
\hline متوسط & $r$ & 0.864 & 2.20 & 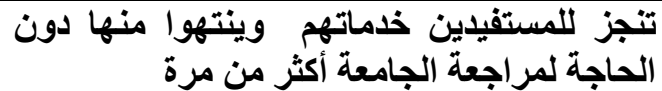 & ro \\
\hline متوسط & & 0.5938 & 2.231 & العمل القياسي & \\
\hline
\end{tabular}

- يتضح من الجدول السابق حصول محور" العمل القياسي " من وجهة نظر عينة الدراسة

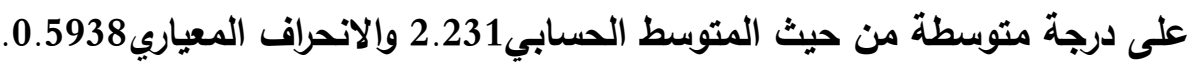
- متختلف هذه النتيجة مع ما توصلت اليه دراسة (عبد القادر مسلم وشذا أبو سليم،

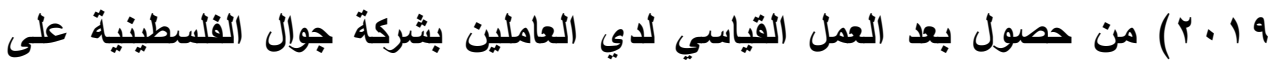
متوسط حسابي مرتفع من وجهة نظر عينة الدراسة، وكذلك دراسة (سليمان الطلاع وآخرون، V · Pم) من حصول نفس المحور من وجهة نظر عينة الدراسة بالكليات

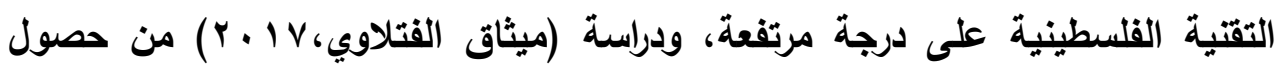
نفس المحور على درجة مرتفعة بالشركة العامة لصناعة السيارات بالعراق على درجة 
- جاعت العبارة رقم (Y I) في المرتبة الاولي بلرجة مرتفعة والوحيدة من وجهه نظر عينة الاراسة من حيث المتوسط الحسابي والانحراف المعياري. - عزو الدراسة ذلك لان الجامعة تعمل علي وضع إجراءات للعمل بداخلها بحيث تقلل الي حد ما من الإجراعات الزائدة والغير ضرورية.

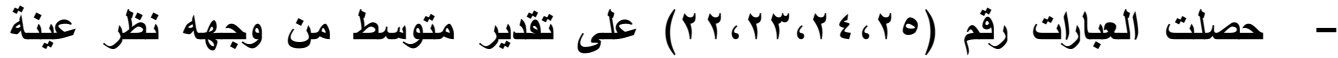
الاراسة من حيث المتوسط الحسابي والانحراف المعياري. - - تعزو الدراسة ذلك لأنه حتى الان لم يكتمل اعمال البناء بالجامعة لأنه تم انثائها عام

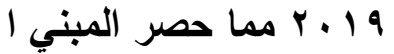
- لإداري للجامعة في مبني واحد ومجموعة من الكليات المتفرقة في أماكن مختلفة حتى اكتمال المبني الخاص بالجامعة.

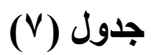

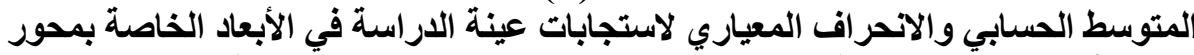

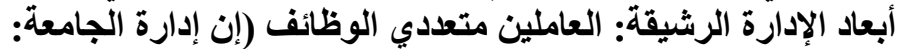

\begin{tabular}{|c|c|c|c|c|c|}
\hline مستويري & الترتيب & الانحراف & الحسابي & 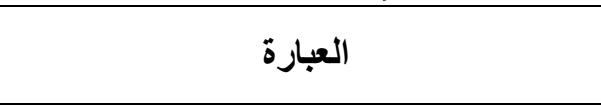 & p \\
\hline متوسط & $r$ & 0.794 & 2.19 & تدرب العاملين بها علي جميع مهام الوحدات & YY \\
\hline متوسط & $r$ & 0.771 & 2.18 & 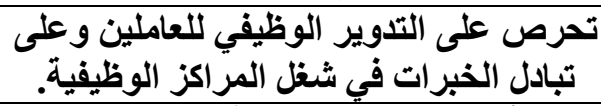 & $r v$ \\
\hline متوسط & $r$ & 0.771 & 2.18 & تطور أداء العاملين بالجامعة عند الجامعة. الاتثقال من & $r \wedge$ \\
\hline متوسط & $\varepsilon$ & 0.741 & 2.12 & تباي اهتمامسا كبيرا لأسلوب تفيير العمل . & rq \\
\hline 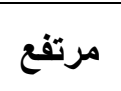 & 1 & 0.647 & 2.41 & تكسب موظفيها مهارات متنوعة من خلال & $r$. \\
\hline متو & & 0.5518 & 2.216 & العاملين متعددي الوظائف & \\
\hline
\end{tabular}

- يتضح من الجدول السابق حصول محور" العاملين متعدي الوظائف " من وجهة نظر عينة الاراسة على درجة متوسطة من حيث المتوسط الحسابي 216.2والانحراف المعياري

- تختف هذه النتيجة مع ما توصلت اليه دراسة (عبد القادر مسلم وشذا أبو سليم، 9 ( ا ب ) من حصول بعد العاملين متعددي الوظائف على متوسط حسابي مرتفع من وجهة نظر عينة الاراسة، وحصولها على متوسط حسابي منخفض بدراسة (وارث وجاية، 


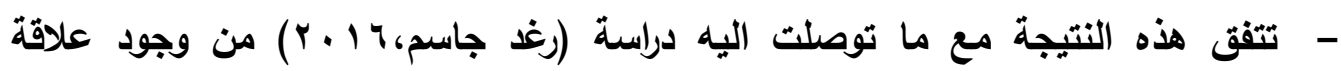
إيجابية موجبة بين أدوات وممارسات الإدارة الرشيقة وممارسات الموارد البشرية بالمؤسسات المختلفة.

- جاعت العبارة رقم (·× الوحيدة في المرتبة الاولي بلرجة مرتفعة من وجهه نظر عينة الاراسة من حيث المتوسط الحسابي والانحراف المعياري. - - تعزو الدراسة ذلك لأنه في كثير من الأحيان يتم نقل بعض العاملين من إدارة لأخري مم يتطلب التدريب على مهارات الإدارات الجديدة. - حصلت العبارات رقم (YY،YV،YA،Yq) على تقدير متوسط من وجهه نظر عينة الاراسة من حيث المتوسط الحسابي والانحراف المعياري. - تعزو الاراسة ذلك لان فكرة التدوير الوظيفي من الأفكار التي لا تنال استحسان الكثير من العاملين باي إدارة من الإدارات ولدي العديد من العاملين بالجامعة وهذا ما أشارت

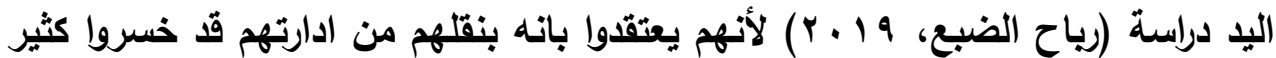
من الخبرات التي اكتسبوها في سنوات حياتهم المهنية، ولم ينظروا لجانب اكتساب

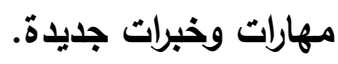




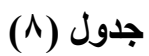

المتوسط الحسابي والانحراف المعياري لاستجابات عينة الاراسة في الأبعاد الخاصة بمحور

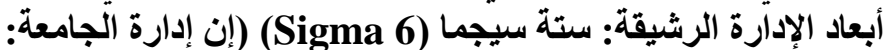

\begin{tabular}{|c|c|c|c|c|c|}
\hline مستوي & الترتيب & الالانحراف & الحستوسط & العبارة & م \\
\hline مرتفع & 1 & 0.592 & 2.61 & 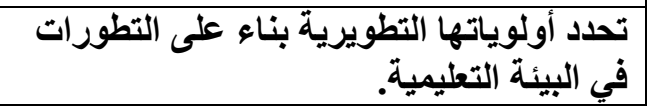 & $\mu_{1}$ \\
\hline مرتفع & $\Lambda$ & 0.645 & 2.34 & 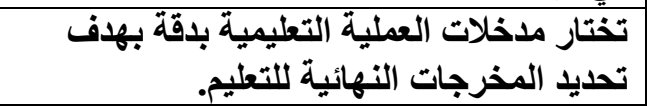 & rr \\
\hline مرتفع & 7 & 0.646 & 2.40 & تعتمد في تطويز خططها على تجارب الجامعات & $r r$ \\
\hline مرتفع & $\mathrm{V}$ & 0.647 & 2.35 & منسود المسؤوليات بشكل دقيق لجميع & $r \varepsilon$ \\
\hline متوسط & 9 & 0.761 & 2.31 & 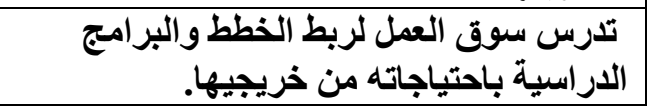 & $r_{0}$ \\
\hline متوسط & 11 & 0.720 & 2.28 & تصنيم ادوات بخبراء القياس المطاس والتقويم والاحصاء في & $r q$ \\
\hline متوسط & & 0.726 & 2.26 & تدرس أسباب تعثر الطلاب. & $r v$ \\
\hline متوسط & 1. & 0.703 & 2.29 & لأعضل الفجوة بين الاداء الهية المتوقع والاداء الفعلي & $\mu \wedge$ \\
\hline متوسط & $1 \%$ & 0.776 & 2.22 & 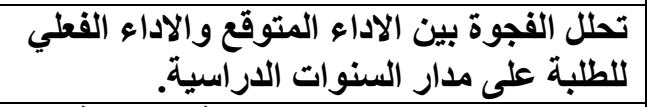 & $r q$ \\
\hline متوسط & Ir & 0.761 & 2.24 & و تحلل الفجوة بين مخرجي العمل. الطلبة التعليمية & $\varepsilon$. \\
\hline مرتفع & $\mu$ & 0.589 & 2.48 & 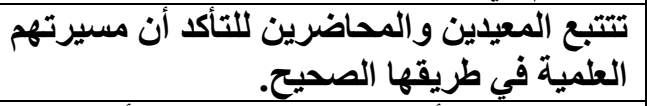 & \&1 \\
\hline مرتفع & $\theta$ & 0.582 & 2.41 & تضعل مقاييس أداء تمثل معايير لضبط أداء & $\varepsilon r$ \\
\hline مرتفع & $r$ & 0.587 & 2.55 & 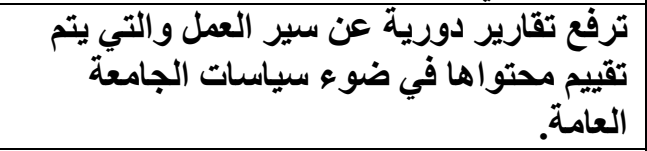 & $\varepsilon r$ \\
\hline مرتفع & $\varepsilon$ & 0.676 & 2.47 & 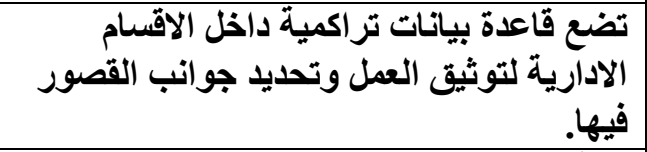 & $\varepsilon \leqslant$ \\
\hline مرتفع & & & 2.3718 & 6 sigma ستة سيجما & \\
\hline
\end{tabular}

- يتضح من الجدول السابق حصول محور" ستة سيجما " من وجهة نظر عينة الدراسة على درجة مرتفعة من حيث المتوسط الحسابي 3718.2والانحراف المعياري 0.43637. 
- تختلف هذه النتيجة مع ما توصلت اليه دراسة (عبد القادر مسلم وشذا أبو سليم،

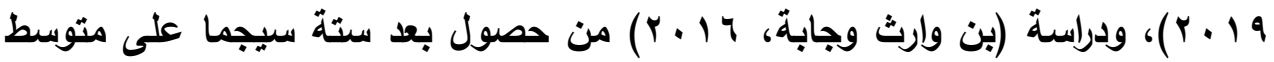
حسابي مرتفع.

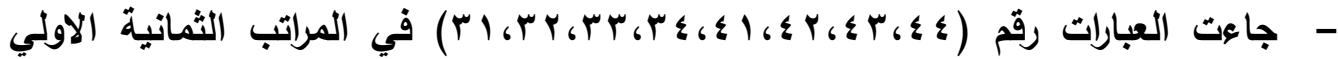
بلرجة مرتفعة من وجهه نظر عينة الدراسة من حيث المتوسط الحسابي والانحراف المعياري. - - وتعزو الدراسة ذلك لان الجامعة تقوم بتحديد مشاكل العمل بصورة دقيقة، وأيضا تقوم بقياس الأداء الفعلي ومقارنته مع الخطط لتحديد الفجوة بينهما. - متعزو الدراسة ذلك أيضا لأنه من اهم المجالات التي يمكن تطبيق أسلوب ستة سيجما بالتعليم الجامعي فيها هو تطوير الخطط والبرامج الدراسية، والجودة وعمليات التخطيط الاستراتيجي والاعتماد الجامعي والتي تعتبر محور اهتمام معظم الجامعات حاليا وليس جامعة الوادي الجديد وحدها.

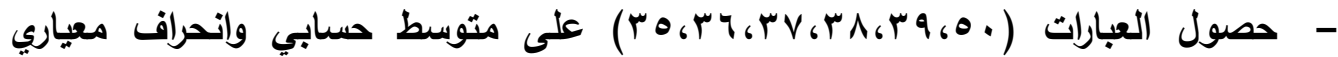
متوسط. - وتعزو الدراسة ذلك لان العائق الأكبر نحو عدم تحقيق مبادئ الإدارة الرشيقة بدرجة جيدة هو غياب روح التعاون بين الإدارة والعاملين، وهذا يحتاج لاعم من قبل الإدارات العليا. (Y/؟) السؤال الثالث: ما واقع فاعلية الأداء الوظيفي لدي القادة الجامعيين بجامعة الوادي الجديد من وجهه نظر أعضاء هيئة التدريس؟ للإجابة عن هذا السؤال تم حساب المتوسط الحسابي والانحراف المعياري لاستجابات أفراد العينة في الأبعاد الخاصة بفاعلية الأداء الوظيفي، ويوضح ذلك الجدول التالي: جأول (9)

\begin{tabular}{|c|c|c|c|c|c|}
\hline الممارسية & الترتيب & المعياري & الحسابي & الابعاد ( المجالات) & r \\
\hline مرتفع & r & 0.314372 & 2.51396 & فاعلية الأداء الوظيفي للقيادات & 1 \\
\hline مرتفع & 1 & 0.284453 & 2.53215 & فاعلية الأداء الوظيفي للقيادات & $r$ \\
\hline مرتفع & & •.Y१q & Y.OYT.OQ & المحور ككل & \\
\hline
\end{tabular}


- يتضح من الجدول السابق أن أفراد العينة ككل يجمعون على أن تقيمهم لفاعلية الأداء الوظيفي لاي القادة الإداريين والأكاديميين بجامعة الوادي الجديد جاءت بلرجة مرتفعة اذ بادي

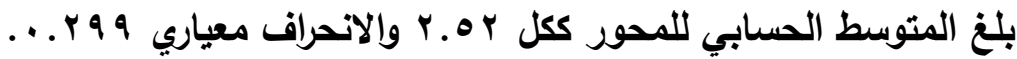
- تختلف هذه النتيجة مع ما توصلت اليه دراسة (فريدة الاندونس، 19 ــr) من ان درجة رضا عينة الدراسة عن مستوي فاعلية الأداء الوظيفي بجامعة ام القري جاء بلرجة مارة

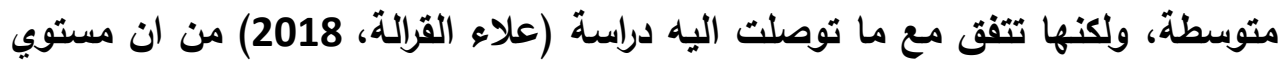
رضا عينة الاراسة عن فاعلية الأداء الوظيفي بجامعة نجران جاء مرتفعا. - - يتضح من الجدول السابق أن البعد الثاني "قاعلية الأداء الوظيفي للقيادات الإدارية" جاء في المرتبة الاولي بلرجة مرتفعة بمتوسط حسابي 2.53وانحراف معياري 0.28وهذا

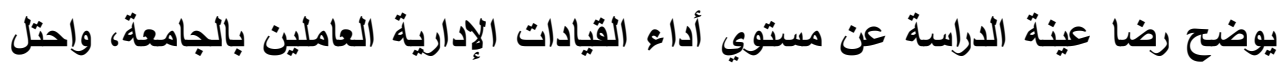
المحور الأول فاعلية الأداء الوظيفي للقيادات الأكاديمية المرتبة الثانية بلرجة مرتفعة بمتوسط حسابي 2.51 وانحراف معياري 0.31 مما يؤكد رضا عينة الاراسة عن فاعلية الأداء الوظيفي للقيادات الاكاديمية أيضا.

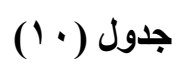

المتوسط الحسابي والاتحراف المعياري لاستجابات عينة الدراسة في الأبعاد الخاصة بمحور

فاعلية الأداء الوظيفي

\begin{tabular}{|c|c|c|c|c|c|}
\hline مستوي & الترتيب & الانحراف & الحستوسطي & القيادة الاكاديمية وتتمتع بما يلي: & 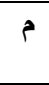 \\
\hline مرتفع & $\varepsilon$ & 0.686 & 2.56 & الكفاءة المهنية والخبرة العملية. & $\leqslant 0$ \\
\hline مرتفع & 0 & 0.601 & 2.54 & المحافظة على سرية المعلومات التي تتطلب السرية. & $\leqslant 7$ \\
\hline مرتفع & 9 & 0.698 & 2.44 & التعامل بإيجابيةة مع أعضاء هيئة التذريس. & $\varepsilon V$ \\
\hline مرتفع & 7 & 0.628 & 2.51 & الجامعة. أوقات الدوام في إنجاز مهامها وواجباتها بما يخدم & $\varepsilon \wedge$ \\
\hline مرتفع & 1 & 0.596 & 2.65 & لديها شخصية قيادية وحاسمة عند اتخاذ القرارات. & $\varepsilon 9$ \\
\hline مرتفع & 1. & 0.695 & 2.42 & 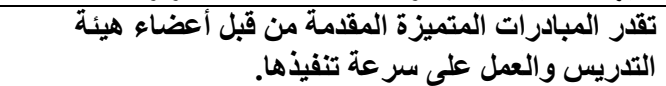 & 0 . \\
\hline مرتفع & $\Lambda$ & 0.628 & 2.49 & في تطوير العملية التُليمية. ومقترحات ألعضاء أعضاء هيئة التّريس & 01 \\
\hline مرتفع & $\mathrm{V}$ & 0.665 & 2.50 & 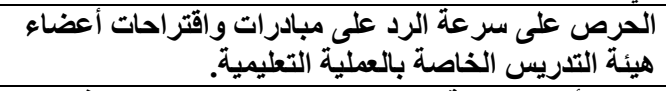 & or \\
\hline مرتفع & $r$ & 0.623 & 2.58 & تُشئجع أعضاء هيئة التذريس على التجديد والابتكار في & or \\
\hline مرتفع & r & 0.670 & 2.60 & الحرص على التوجيه والمتابعة للأقسام. & $0 \leq$ \\
\hline مرتفع & 11 & 0.686 & 2.36 & انجاز الأعمال المسندة إليهم بدقة عالية. & 00 \\
\hline مرتفع & & $\begin{array}{c}0.3143 \\
72\end{array}$ & 2.51396 & المحور ككل & \\
\hline
\end{tabular}




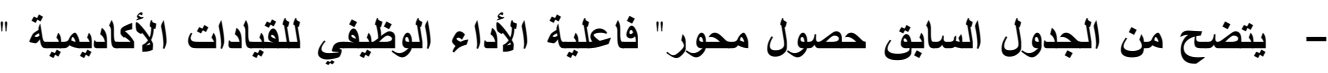
من وجهة نظر عينة الاراسة على درجة مرتفعة من حيث المتوسط الحسابي

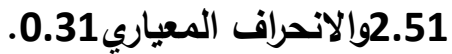
- تختف هذه النتيجة مع ما توصلت اليه دراسة (منيرة الثرمان، ؛ ا + ب) من حصول نفس المحور على درجة متوسطة من وجهة نظر عينة الدراسة.

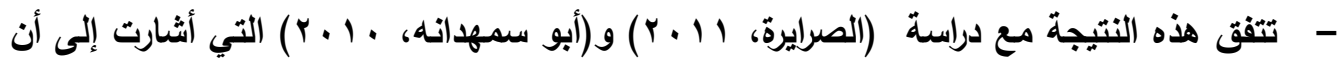
مستوى الأداء الوظيفي جاء مرتفعا. - - جاءت جميع عبارات المحور بدرجة مرتفعة من وجهه نظر عينة الدراسة.

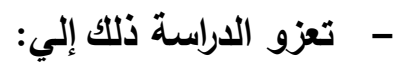
1. وجود مناخ تنظيمي جيد داخل الجامعة يشجع القيادات الاكاديمية على العمل الجيد

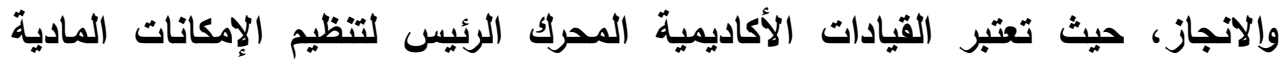
وتتسيق الجهود، كونهم مركز العمليات ومنطلق التوجيهات التي تضمن التطوير لمهام

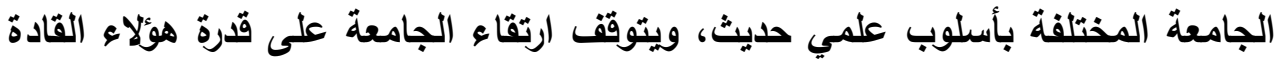

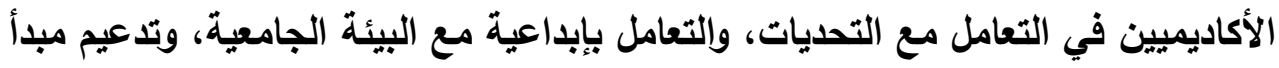

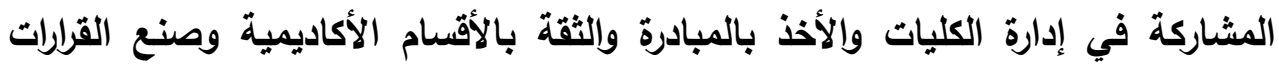

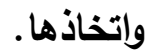

r. أن تحسين وتطوير بيئة العمل دور مهم في انتماء القيادات الأكاديمية لمؤسسات عملهم،

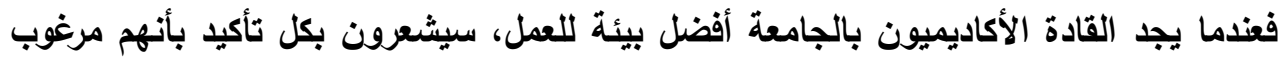

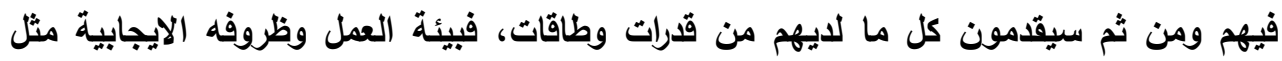

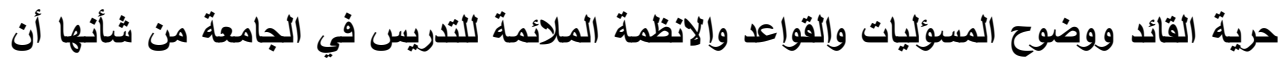

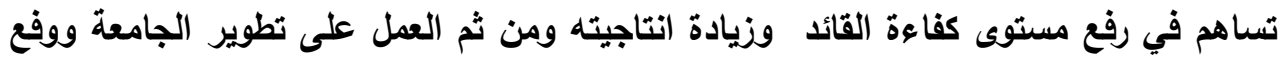

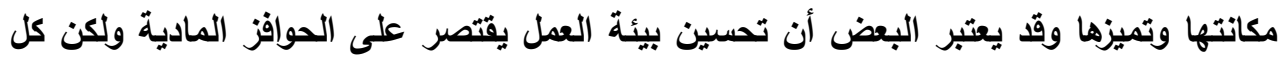

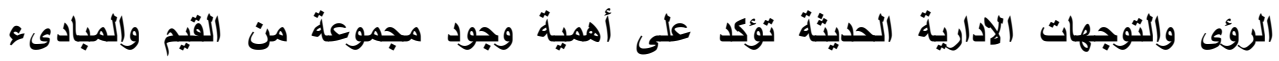
والأخلاقيات والمشاعر وسبل التواصل التي تعد ذات قيتيمة أيضاً وتثبعر القائد الأكاديمي باستقلاليته ويثخصيته المميزة النابعة من مكانته كوضو مهم في الجامعادية

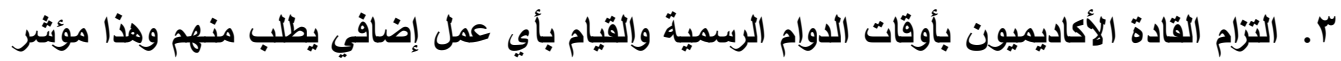
لـ الروح الفريق وحب العمل التعاوني. 
ع. أن المناخ التنظيمي داخل الجامعة يتسم بالأجواء الطيبة، وأن أعضاء هيئة التدريس يتقنون اقامة العلاقات الإنسانية فيما بينهم، وميع قياداتهم الاكاديمية، ويظهر ذلك من خلال تعاملاتهم

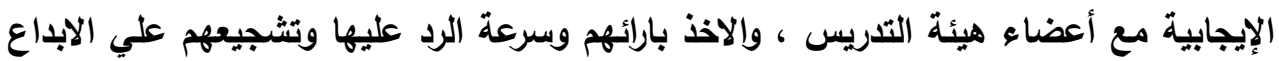

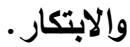

جدول (11)

المتوسط الحسابي والانحراف المعياري لاستجابات عينة الاراسة في الأبعاد الخاصة بمحور فاعلية الأداء الوظيفي

ثانيا: القيادات الإدارية:

\begin{tabular}{|c|c|c|c|c|c|}
\hline مستوي & الترتيب & المعياري & الحسابي & 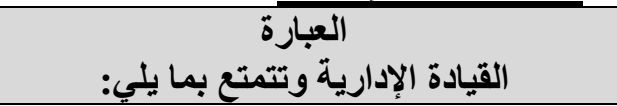 & p \\
\hline مرتفع & 1 & 0.642 & 2.62 & الالتزام بأوقات العمل الرسمية. & 9 \\
\hline مرتفع & 0 & 0.602 & 2.53 & 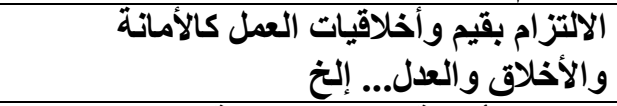 & $\bar{v}$ \\
\hline مرتفع & 9 & 0.710 & 2.46 & الالتزام بأنظمة العمل بالجامعة وإجراءاتها. & $\Lambda$ \\
\hline مرتفع & $\Lambda$ & 0.641 & 2.49 & معرفة أخطاء العمل وتصحيحها. & 09 \\
\hline مرتفع & $\bar{v}$ & 0.628 & 50 & تحقيق أهداف الجامعة بجودة عالية. & 7. \\
\hline مرتفع & $\mathrm{V}$ & 0.653 & 2.50 & 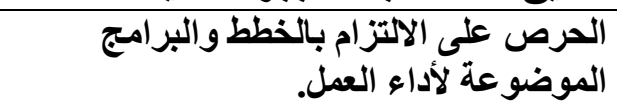 & 1 \\
\hline مرتفع & 7 & 0.532 & 2.52 & الصرائدة بجميع الإدارات بالإيجابية. الإنسانية & Tr \\
\hline مرتفع & $\varepsilon$ & 0.574 & 2.54 & التنتلفيقة والجامعةن. بين قيادي الإدارات & 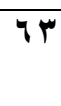 \\
\hline مرتفع & $r$ & 0.571 & 2.57 & الوظفرفةة الكافية بمهامهم ومسؤولياتهم & $4 \pi$ \\
\hline مرتفع & ○ & 0.602 & 2.53 & الرغبة والحماس لإنجاز العمل المطلوب منهح. & $7 \varepsilon$ \\
\hline مرتفع & 7 & 0.615 & 2.52 & التكييف و التعامل مع الحالات الطارئة بالعمل. & 70 \\
\hline مرتفع & Y & & 2.60 & تحمل مسؤولية الأعمال الموكلة لهم. & 79 \\
\hline مرتفع & & 0.284453 & 2.53215 & المحور ككل & \\
\hline
\end{tabular}

- - يتضح من الجدول السابق حصول محور" فاعلية الأداء الوظيفي للقيادات الإدارية " من وجهة نظر عينة الدراسة على درجة مرتفعة من حيث المتوسط الحسابي 2.53والانحراف المعياري0.28.

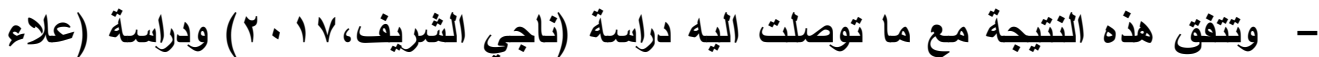

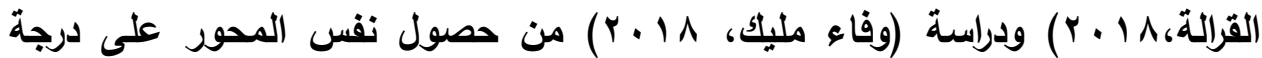
مرتفعة، وتختلف مع ما توصلت اليه دراسة (فريدة الاندونس، 9 ـ ـ ) من حصول نفس المحور على درجة متوسطة. 
- - جاعت جميع عبارات المحور بلرجة مرتفعة من وجهه نظر عينة الدراسة. - تعزو الدراسة ذلك لوجود رضا من قبل عينة الدراسة عن مستوي الأداء الوظيفي للقيادات الإدارية، وذلك لان القيادات الإدارية تمثل الثروة البشرية لأي مؤسسة ومن

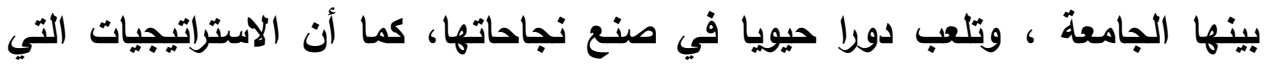
تستخدمها تشكل الخيارات العلمية والتطبيقية للجامعة من خلال الاستفادة من قراتهم ومعارفهم ، فالقيادة الإدارية هي المسئولة عن تسيير العمل داخل الجامعة عن طريق هن هني دفع الأفراد وحفز الهمم ويث روح الحماس والنشاط في نفوس العاملين داخل الجامعة من أجل تحقيق الأهداف المنشودة وأن التطور والتقدم والنجاح الذي يصادف مؤسسات التعليم العالي إنما يقاس بمقدار فعالية هؤلاء القادة، وهذا ما تحقق من وجهة نظر عينة الدراسة فيما يخص القيادات الإدارية بجامعة الوادي الجديد.

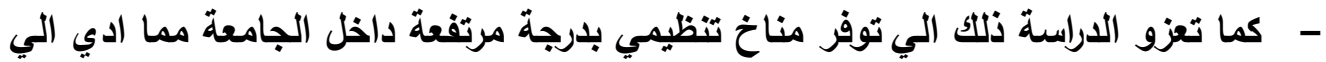
فاعلية الأداء الوظيفي حيث ان العاملين التزموا بارجة كبيرة بأوقات العمل الرسمية ويقيم واخلاقيات العمل والتزامهم بأنظمة العمل بالجامعة والخطط والبرامج الموضوعة لأداء اعمالهم. (†/ץ/ السؤال الرابع: هل توجد فروق ذات دلالة إحصائية حول درجة ممارسة القادة الجامعيين للإدارة الرشيقة من وجهه نظر أعضاء هيئة التدريس بجامعة الوادي الجديد وفقا

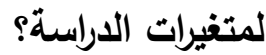
للإجابة علي هذا التساؤل تم تطبيق اختبار (t- test) لمعرفة الفروق بين مجموعات العينة حسب متغير نوعية الكلية والجنس ، واختبار (ANOVA) لمعرفة الفروق بين استجابات أفراد العينة حسب متغير الدرجة العلمية، ويوضح ذلك الجداول التالية : 


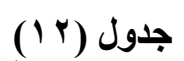

نتائج اختبار (ت) لحساب دلالة الفروق بين استجابات أفراد العينة حول حول ممارسة القادة الجامعيين للإدارة الرشيقة حسب متغير نوعي الكلية(نظرية/عملية)

\begin{tabular}{|c|c|c|c|c|c|c|c|}
\hline مستوى & قيمة ت & الحرجية & الالحعراف & الحستوسي & العينة & \multicolumn{2}{|c|}{ الأبعاد } \\
\hline \multirow[t]{2}{*}{0.285} & \multirow[t]{2}{*}{4.271} & \multirow[t]{2}{*}{125} & 0.384000 & 2.51351 & 74 & نظرية & \multirow{2}{*}{ أمنظيم } \\
\hline & & & 0.398149 & 2.21384 & 53 & عملية & \\
\hline \multirow[t]{2}{*}{0.159} & \multirow[t]{2}{*}{2.802} & \multirow[t]{2}{*}{125} & 0.435258 & 2.41892 & 74 & نظرية & \multirow{2}{*}{ التصستمين } \\
\hline & & & 0.353134 & 2.21563 & 53 & عملية & \\
\hline \multirow[t]{2}{*}{0.661} & \multirow[t]{2}{*}{3.711} & \multirow[t]{2}{*}{125} & 0.5884 & 2.389 & 74 & نظرية & \multirow{2}{*}{ الوتعدئيق } \\
\hline & & & 0.5326 & 2.011 & 53 & عملية & \\
\hline \multirow[t]{2}{*}{0.249} & \multirow[t]{2}{*}{3.557} & \multirow[t]{2}{*}{125} & 0.5432 & 2.357 & 74 & نظرية & \multirow{2}{*}{ القياسي } \\
\hline & & & 0.5058 & 2.019 & 53 & عملية & \\
\hline \multirow[t]{2}{*}{0.323} & \multirow[t]{2}{*}{3.568} & \multirow[t]{2}{*}{125} & 0.440719 & 2.48359 & 74 & نظرية & \multirow{2}{*}{$\begin{array}{r}\text { ستيجما } \\
\text { سنيجا } \\
\text { Sigma }\end{array}$} \\
\hline & & & 0.382221 & 2.21563 & 53 & عملية & \\
\hline \multirow[t]{2}{*}{0.423} & \multirow[t]{2}{*}{4.086} & \multirow[t]{2}{*}{125} & 0.424033 & 2.43239 & 74 & نظرية & \multirow{2}{*}{ ككل المحور } \\
\hline & & & 0.375117 & 2.13506 & 53 & عملية & \\
\hline
\end{tabular}

- يتضح من الجدول السابق أنه لا توجد أي فروق ذو دلالة إحصائيا بين استجابات عينة الدراسة بالكليات العملية وإلكليات النظرية سواء بالنسبة للمحور ككل أو الأبعاد، إذ جاعت جميع قيم (t test ) غير دالة إحصائيا عند مستوى الدلالة(ه . , •، 1 . , •)، مما يؤكد اتفاق عينة الدراسة على أن تطبيق القيادات الجامعية لأبعاد الإدارة الرشيقة جاءت بلرجة متوسطة ، وهذا يتطلب ضرورة بذل المزيد من الجها لتطويرها والارتقاء

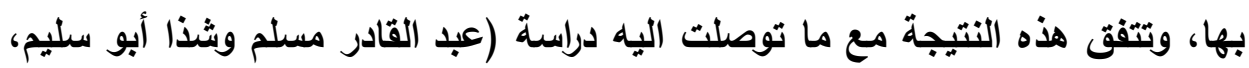

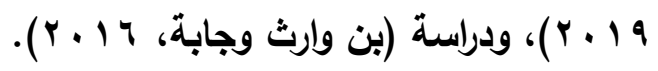




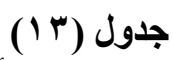

نتائج اختبار (ت) لحساب دلالة الفروق بين استجابات أفراد العينة حول ممارسة القادة الجامعيين لكلإدارة الرشيقة حسب متغير الجنس الفئس

\begin{tabular}{|c|c|c|c|c|c|c|c|}
\hline مستوى الدلاية & قيمة ت ت & الدرجة & الالحعياري & الحستوسط & العينة & \multicolumn{2}{|c|}{ الأبعاد } \\
\hline \multirow[t]{2}{*}{0.497} & \multirow[t]{2}{*}{-1.480} & \multirow[t]{2}{*}{ Iro } & 0.419383 & 2.35227 & 88 & ذكر & \multirow{2}{*}{ العظليم أماكن } \\
\hline & & & 0.400788 & 2.47009 & 39 & أنثى & \\
\hline \multirow[t]{2}{*}{0.104} & \multirow[t]{2}{*}{0.411} & \multirow[t]{2}{*}{ Iro } & 0.382368 & 2.34416 & 88 & ذكر & \multirow{2}{*}{ المستمبر } \\
\hline & & & 0.482365 & 2.31136 & 39 & أنثي & \\
\hline \multirow[t]{2}{*}{0.753} & \multirow[t]{2}{*}{-0.508} & \multirow[t]{2}{*}{ Iro } & 0.5878 & 2.214 & 88 & ذكر & \multirow{2}{*}{ الوتعددي } \\
\hline & & & 0.6130 & 2.272 & 39 & أنثي & \\
\hline \multirow[t]{2}{*}{0.229} & \multirow[t]{2}{*}{-0.691} & \multirow[t]{2}{*}{$1 Y 0$} & 0.5369 & 2.193 & 88 & ذكر & \multirow{2}{*}{ العمل القياسي } \\
\hline & & & 0.5882 & 2.267 & 39 & أنثي & \\
\hline \multirow[t]{2}{*}{0.430} & \multirow[t]{2}{*}{-0.251} & \multirow[t]{2}{*}{ IYO } & 0.423122 & 2.36526 & 88 & ذكر & \multirow{2}{*}{ ستة سيجما 6 sigma } \\
\hline & & & 0.470310 & 2.38645 & 39 & أنثي & \\
\hline \multirow[t]{2}{*}{0.650} & \multirow[t]{2}{*}{-0.575} & \multirow[t]{2}{*}{ 1ro } & 0.416848 & 2.29370 & 88 & ذكر & \multirow{2}{*}{ المحور ككل } \\
\hline & & & 0.458675 & 2.34127 & 39 & أنثي & \\
\hline
\end{tabular}

يتضح من الجدول السابق أنه لا توجد أي فروق ذات دلالة إحصائية بين استجابات

عينة الدراسة تعزي لمتغير الجنس سواء بالنسبة للمحور ككل أو الأبعاد، إذ جاعت جميع قيم ) t test) توصلت اليه دراسة (عبد القادر مسلم وشذا أبو سليم، 9 أب)، ودراسة (بن وارث وجابة،

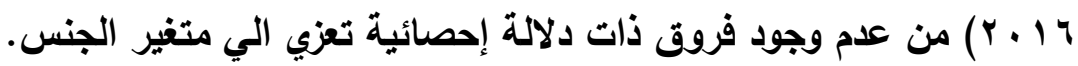




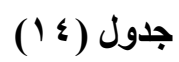

نتائج تحليل (ANOVA) لحساب دلالة الفروق بين مجموعات أفراد العينة في واقع ممارسة القادة الجامعيين للإدارة الرشيقة حسب متغير اللارجة العلمية

\begin{tabular}{|c|c|c|c|c|c|c|}
\hline مستوى الدلاية & قالمسيمةبة & متوسط المربعات & الحرجية & المربعوات & & الأبعاد \\
\hline \multirow[t]{3}{*}{0.131} & \multirow[t]{3}{*}{2.064} & 0.351 & 2 & 0.702 & المجموعات & \multirow{3}{*}{ تنظيم أماكن } \\
\hline & & 0.170 & 124 & 21.079 & المجموعات & \\
\hline & & & 126 & 21.781 & المجموع & \\
\hline \multirow[t]{3}{*}{0.222} & \multirow[t]{3}{*}{1.521} & 0.259 & 2 & 0.517 & المجموعات & \multirow{3}{*}{ التحستمين } \\
\hline & & 0.170 & 124 & 21.074 & المجموعات & \\
\hline & & & 126 & 21.591 & المجموع & \\
\hline \multirow[t]{3}{*}{0.326} & \multirow[t]{3}{*}{1.130} & 0.398 & 2 & 0.795 & المجموعات & \multirow{3}{*}{ العمل القياسي } \\
\hline & & 0.352 & 124 & 43.639 & المجموعات & \\
\hline & & & 126 & 44.434 & المجموع & \\
\hline \multirow[t]{3}{*}{0.844} & \multirow[t]{3}{*}{0.170} & 0.053 & 2 & 0.105 & المجموعات & \multirow{3}{*}{ العاملين متعددي } \\
\hline & & 0.309 & 124 & 38.263 & المجموعات & \\
\hline & & & 126 & 38.369 & المجموع & \\
\hline \multirow[t]{3}{*}{0.319} & \multirow[t]{3}{*}{1.155} & 0.219 & 2 & 0.439 & المجموعات & \multirow{3}{*}{ ستة سيجما 6 sigma } \\
\hline & & 0.190 & 124 & 23.555 & المجموعات & \\
\hline & & & 126 & 23.993 & المجموع & \\
\hline \multirow[t]{3}{*}{0.390} & \multirow[t]{3}{*}{0.949} & 0.175 & 2 & 0.349 & المجموعات & \multirow{3}{*}{ المحور ككل } \\
\hline & & 0.184 & 124 & 22.824 & المجموعات & \\
\hline & & & 126 & 23.173 & المجموع & \\
\hline
\end{tabular}

- - وتثير النتائج الإحصائية بالجدول السابق إلى انه لا توجد فروق ذات دلالة إحصائية في درجة ممارسة القادة الجامعيين للإدارة الرشيقة للمحور ككل تعزى إلى متغير الارجة الإسل العلمية، إذ كانت قيمة (F) دالة عند مستوى (0.949)، كذلك تبين انه لا توجد فروق ذات دلالة إحصائية في درجة ممارسة القيادات الجامعية للإدارة الرشيقة بمجالات (تنظيم أماكن العمل-التحسين المستمر -العمل القياسي-العاملين متعددي الوظائف-سته 
سيجما)تعزي للارجة العلمية حيث تراوحت قيمة F بين (0.170- 2.064) وكاتت قيمة دلالاتها الاحصائية تزيد عن مستوى الدلاية ه ....مما يدل على عدم وجود فروق في لئي درجات ممارسة القيادة التشاركية بالمجالات ثُعزى للارجة العلمية. - يتضح من الجداول السابقة رقم r I و ا و و \& ا أنه لا يوجد فروق ذات دلالة إحصائية لارجة ممارسة القيادات الجامعية لأبعاد الإدارة الرشيقة تعزي الي متغيرات (نوع الكلية والجنس والدرجة العلمية) وتتفق هذه النتيجة مع ما توصلت اليه دراسة (عبد القادر

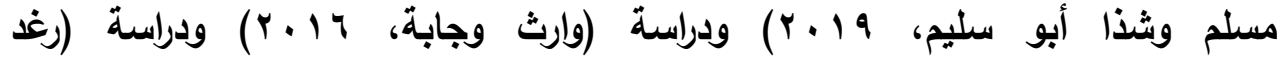
جاسم، Y 1 • Y ) من عدم وجود فروق ذات دلالة إحصائية تعزي الي متغيرات الدراسة. (†/؟) السؤال الخامس: -هل توجد فروق ذات دلالة إحصائية حول درجة ممارسة القادة الجامعيين لفاعلية الأداء الوظيفي من وجهه نظر أعضاء هيئة التدريس بجامعة الوادي الجديد وفقا لمتغيرات الدراسة؟ للإجابة علي هذا السؤال تم تطبيق اختبار (t- test) لمعرفة الفروق بين مجموعات العينة حسب متفير نوعية الكلية والجنس واختبار(ANOVA) لمعرفة الفروق بين استجابات أفراد العينة حسب متغير الارجة العلمية، ويوضح ذلك الجداول التالية : جدول (10)

نتائج اختبار (ت) لحساب دلالة الفروق بين استجابات أفراد العينة حول فاعلية الإداء الوظيفي حسب متغير نوع الكلية

\begin{tabular}{|c|c|c|c|c|c|c|c|}
\hline الدلالة & قيمة ت ت & لدرية & الالحعراف & الحستوسطي & العينة & & الأبعاد \\
\hline \multirow[t]{2}{*}{0.944} & \multirow[t]{2}{*}{-0.071} & \multirow[t]{2}{*}{125} & 0.321526 & 2.51229 & 74 & نظرية & \multirow{2}{*}{ القيادة الاكاديمية } \\
\hline & & & 0.307138 & 2.51630 & 53 & عملية & \\
\hline \multirow[t]{2}{*}{0.001} & \multirow[t]{2}{*}{3.430} & \multirow[t]{2}{*}{125} & 0.282192 & 2.60248 & 74 & نظرية & \multirow{2}{*}{ القيادة الإدارية } \\
\hline & & & 0.259622 & 2.43396 & 53 & عملية & \\
\hline \multirow[t]{2}{*}{0.070} & \multirow[t]{2}{*}{1.752} & \multirow[t]{2}{*}{125} & 0.286596 & 2.55738 & 74 & نظرية & \multirow{2}{*}{ المحور ككل } \\
\hline & & & 0.219698 & 2.47513 & 53 & عملية & \\
\hline
\end{tabular}

- - يتضح من الجدول السابق أنه لا توجد أي فروق ذو دلالة إحصائيا بين استجابات عينة

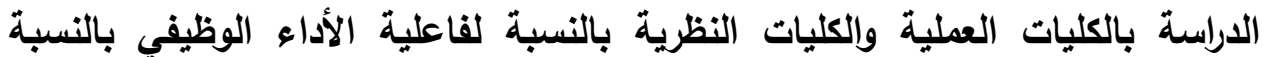
للمحور ككل وكذلك لمجال القيادات الاكاديمية، لان مستوي الالالة أكبر من ه..... 
- - بالنسبة لمجال القيادات الإدارية فتوجد فروق ذات دلالة إحصائية عند مستوي الدلالة ا.... لصالح الكليات النظرية، اذ تري عينة الدراسة ان فاعلية الأداء الوظيفي بالكليات النظرية أفضل من الكليات العملية. - تختلف هذه الدراسة مع ما توصلت اليه دراسة (فريدة الاندونسي، 19 ــ) ودراسة

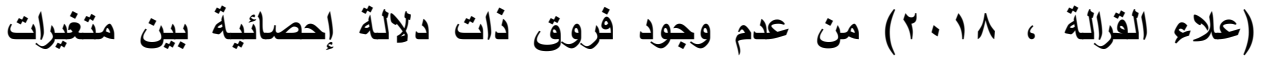

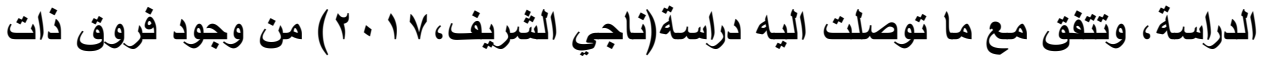
دلالة إحصائية بين متغيرات الدراسة تعزي لمتفير نوع الكلية. - تعزو الدراسة ذلك لان الكليات النظرية تهتم بالجاتب الإنساني والعلاقات الاجتماعية

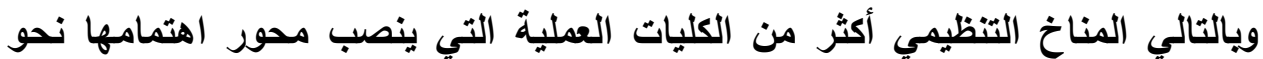
النتائج العملية.

جدول (17)

نتائج اختبار (ت) لحساب دلالة الفروق بين استجابات أفراد العينة حول فاعلية الإداء الوظيفي

\begin{tabular}{|c|c|c|c|c|c|c|c|}
\hline مستوى الدلاية & قيمة ت & الدرجة & الالتعراف & الحستوسطي & العينة & \multicolumn{2}{|c|}{ الأبعاد } \\
\hline \multirow[t]{2}{*}{0.413} & \multirow[t]{2}{*}{0.805} & \multirow[t]{2}{*}{125} & 0.321942 & 2.52893 & 88 & ذكر & \multirow{2}{*}{ الاكاديمية } \\
\hline & & & 0.297845 & 2.48019 & 39 & أنثي & \\
\hline \multirow[t]{2}{*}{0.478} & \multirow[t]{2}{*}{-0.559} & \multirow[t]{2}{*}{125} & 0.288876 & 2.52273 & 88 & ذكر & \multirow[b]{2}{*}{ الإدارية } \\
\hline & & & 0.27707 & 2.55342 & 39 & أنثي & \\
\hline \multirow[t]{2}{*}{0.314} & \multirow[t]{2}{*}{0.178} & \multirow[t]{2}{*}{125} & 0.268650 & 2.52583 & 88 & ذكر & \multirow{2}{*}{ المحور ككل } \\
\hline & & & 0.253065 & 2.51680 & 39 & أنثي & \\
\hline
\end{tabular}

- يتضح من الجدول السابق أنه لا توجد أي فروق ذو دلالة إحصائيا بين استجابات

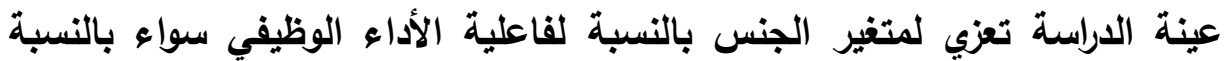
للمحور ككل أو الأبعاد، إذ جاهت جميع قيم (t test) غير دالة إحصائيا عند مستوى الدلالة - - تتفق هذه النتيجة مع ما توصلت اليه دراسة (علاء الدين الاليمي، 1 ـ ـ ) من عدم وجود فروق ذات دلالة إحصائية تعزي لمتغير الجنس. - وتعزو الدراسة ذللك الي تثابه ظروف العمل بالجامعة بالنسبة للأكور أو الاناث من حيث المكان والبيئة المحيطة والمناخ التنظيمي. 


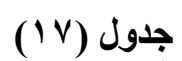

نتائج تحليل (ANOVA) لحساب دلالة الفروق بين مجموعات أفراد العينة لفاعلية الأداء

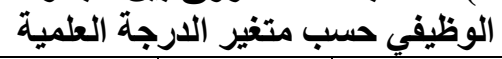

\begin{tabular}{|c|c|c|c|c|c|c|}
\hline مستوى & المحسوبة & المربعات & الرجرية & المجبعات & & الأبعاد \\
\hline \multirow[t]{3}{*}{0.857} & \multirow[t]{3}{*}{0.155} & 0.015 & 2 & 0.031 & المجموعات & \multirow{3}{*}{ الاكياديمية } \\
\hline & & 0.100 & 124 & 12.422 & المجموعات & \\
\hline & & & 126 & 12.453 & المجموع & \\
\hline \multirow[t]{3}{*}{0.101} & \multirow[t]{3}{*}{2.339} & 0.185 & 2 & 0.371 & المحمو عات & \multirow{3}{*}{ الإدارية } \\
\hline & & 0.079 & 124 & 9.824 & المجموعات & \\
\hline & & & 126 & 10.195 & المجموع & \\
\hline \multirow[t]{3}{*}{0.356} & \multirow[t]{3}{*}{1.041} & 0.072 & 2 & 0.144 & المجموعات & \multirow{3}{*}{ المحور ككل } \\
\hline & & 0.069 & 124 & 8.571 & المجموعات & \\
\hline & & & 126 & 8.715 & المجموع & \\
\hline
\end{tabular}

- يتبين من الجدول السابق أنه لا توجد فروق ذات دلالة إحصائية عند مستوى الدلالة ه > o الدرجة العلمية حيث بلغت قيمة اختبار F=1.041وكاتت دلالتها الإحصائية أعلى من مستوى الالالة ه . . .مما يدل على عدم وجود فروق بين متوسطات تقدير عينة الاراسة تُعزى للارجة العلمية. - تثفق هذه النتيجة مع ما توصلت اليه دراسة (Fleming,2010) ودراسة (Hallinger,2010) ودراسة (Yum Hamis \& ljad,2009) من عدم وجود فروق ذات دلالة إحصائية تعزي للارجة العلمية. - متعزو الدراسة ذلك الي ان جميع أعضاء هيئة التدريس باختلاف درجاتهم الاكاديمية ياركون المناخ التنظيمي المحيط بهم . (†/ه) السؤال السادس: - هل توجد علاقة ارتباط موجبة ذات دلالة إحصائية بين " درجة ممارسة الإدارة الرشيقة وفاعلية الأداء الوظيفي لدي القادة الجامعيين بجامعة الوادي الجديد من وجهه نظر أعضاء هيئة التدريس وفقا لمتفيرات الدراسة؟ 
للإجابة عن هذا السؤال تم حساب معامل الارتباط لبيرسون بين درجة ممارسة القيادة

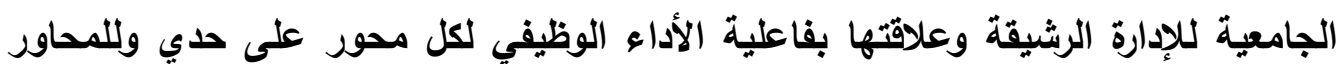

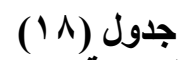

العلاقة بين أبعاد الإدارة الرشيقة ومحاور فاعلية الأداء الوظيفي

\begin{tabular}{|c|c|c|c|c|}
\hline \multicolumn{2}{|c|}{ القيادة الإدارية } & \multicolumn{2}{|c|}{ القيادة الاكاديمية } & \multirow[t]{2}{*}{ المجال } \\
\hline مستوي الدلالة & معامل الارتباط & مستوي الدلالة & معامل الارتباط & \\
\hline 0.000 & $0.546 * *$ & 0.000 & $0.400 * *$ & تنظيم أماكن العمل \\
\hline 0.000 & $0.637 * *$ & 0.000 & $0.507 * *$ & التحسين المستمر \\
\hline 0.000 & $0.661 * *$ & 0.000 & $0.472 * *$ & العمل القياسي \\
\hline 0.000 & $0.639 * *$ & 0.000 & $0.430 * *$ & الوظائفين متعدد \\
\hline 0.000 & $0.604 * *$ & 0.000 & $0.547 * *$ & ستخة سيجما 6 \\
\hline 0.000 & $0.699 * *$ & 0.000 & $0.528 * *$ & المحور ككل \\
\hline
\end{tabular}

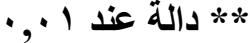

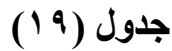

العلاقة بين الإدارة الرشيقة وفاعلية الأداء الوظيفي

\begin{tabular}{|c|c|c|}
\hline \multicolumn{2}{|c|}{ فاعلية الأداء الوظيفي } & \multirow[t]{2}{*}{ المجال (القيادة الرشيقة) } \\
\hline مستوّي الدلالة & معامل الارتباط & \\
\hline 0.000 & $0.534 * *$ & تنظيم أماكن العمل \\
\hline 0.000 & $0.647 * *$ & التحسين المستمر \\
\hline 0.000 & $0.640 * *$ & العمل القياسي \\
\hline 0.000 & $0.602 * *$ & العاملين متعدد الوظائف \\
\hline 0.000 & $0.654 * *$ & ستة سيجما 6 sigma \\
\hline 0.000 & $0.694 * *$ & المحور ككل(القيادة الرشيقة) \\
\hline
\end{tabular}

- - يتضح من الجدولين السابقين أن هناك علاقة ارتباطيه موجبة بين تقديرات درجات

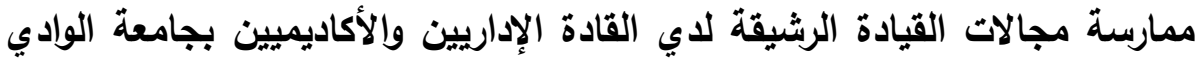
الجديد كما يراها أعضاء هيئة التدريس ويين درجات تقديرهم لدرجة فاعلية الأداء

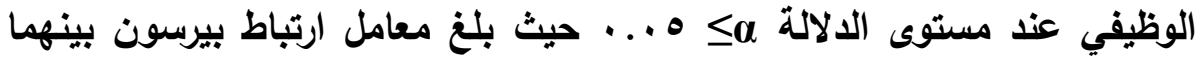

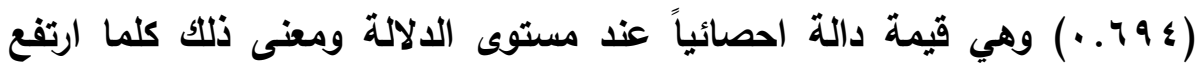
مستوى ممارسة القيادة الرشيقة كلما زادت فاعلية الأداء الوظيفي. - تتفق هذه النتيجة مع ما توصلت اليه دراسة (رغد جاسم، 17 ـ ب) من وجود علاقة إيجابية بين أدوات الإدارة الرشيقة وممارسات الموارد البشرية، كما تتفق مع ما داء 
توصلت اليه دراسة (عبد القادر مسلم وشذا أبو سليم، 9 ( ب) من وجود علاقة ارتباط موجبة بين ابعاد الإدارة الرشيقة والابداع.

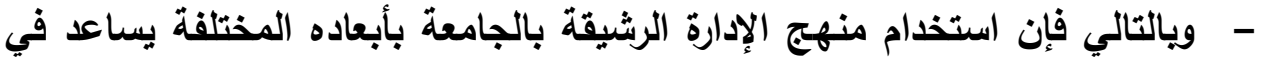
زيادة فاعلية الأداء الوظيفي للقيادات العاملة بالجامعة.

النتـائج

توصلت الاراسة الي مجموعة من النتائج تمثلت في محورين نظري وتطبيقي كما يلي:

النتائج النظرية

ا- الإدارة الرشيقة هي ثقافة مؤسسية تحتاجها المؤسسات بمختلف أنواعها ومنها الجامعات.

r- الإدارة الرشيقة ليست وليدة الساعة وإنما تعود جذورها الي القرن العشرين بفضل شركة TOYOTA.

r- اهم عنصرين تقوم عليهما ثقافة الإدارة الرشيقة في أي مؤسسة هما احترام الأشخاص والتحسين المستمر .

ع - من اجل تحقيق التحسين المستمر والفعال لأي مؤسسة ومن بينها الجامعات ويالتالي تحقيق مبادئ الإدارة الرشيقة ينبغي الاهتمام من قبل جميع القيادات وعلى مختلف

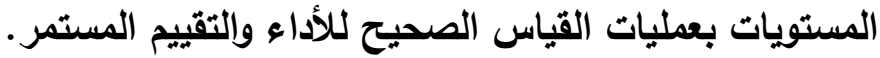
ه- ان أسلوب الإدارة الرشيقة ومن خلال الاليات والأدوات التي تستخدمها تعطي لأي مؤسسة تطبق بها ومن بينها الجامعات حلولا جذرية تقلل الي حد كبير من نسبة الهدر بها.

צ- لتحقيق فاعلية الأداء الوظيفي ينبغي الاهتمام ببعض الأمور من قبل الجامعة تتمثل في (وضوح القواعد والأنظمة التي تحكم العمل-توفير قاعدة بيانات ومعلومات دقيقة تيسر العمل-التأكيا على الالتزام والانضباط الإداري والتظيمي-مشاركة العاملين في عمليات اتخاذ القرار-التخلص من ضغوط العمل وتوفير المناخ التحفيزي للعمل-توزيع المكافآت بشكل عادل-إقامة دورات تدريبية بشكل متواصل وحسب احتياجات العمل 
V يوجد نماذج عديدة لقياس الأداء الوظيفي منها ذات الهـف الواحد ومنها ما هو متعدد الأهداف وكل نموذج مدعوم بنظرية خاصة. 1 - تعدد نماذج قياس الأداء الوظيفي يتيح لكل جامعة مرونة في اختيار أفضل المؤشرات التي تتناسب وطبيعة نشاط كل كلية من كلياتها.

\section{النتخائج التطبيقية}

9- - اكدت نتائج الدراسة الميدانية ان درجة ممارسة القادة الإداريين والأكاديميين لأبعاد الإدارة الرشيقة بجامعة الوادي الجديد جاعت بدرجة متوسطة من وجهة نظر عينة

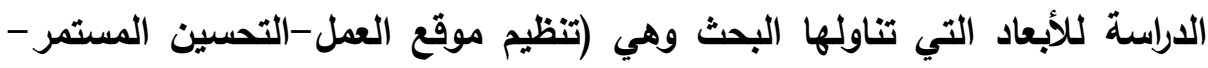
العمل القياسي -العاملين متعددي الوظائف-ستة سيجما).

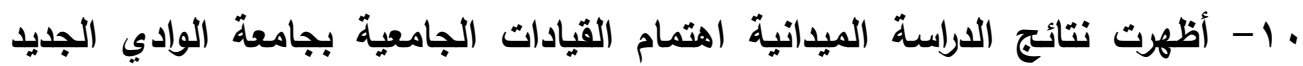
بتحقيق فاعلية الأداء الوظيفي بارجة مرتفعة. 1 ا - من خلال علاقة الارتباط الموجبة بين عناصر القيادة الرشيقة اتضح انها تلعب دورا مهما في تحقيق فاعلية الأداء الوظيفي. r أدوات الإدارة الرشيقة التي حظيت باهتمام اقل من قبل جامعة الوادي الجديد هي التحسين المستمر ، والعاملين متعددي الوظائف، والعمل القياسي. rا - أدوات الإدارة الرشيقة التي حظيت باهتمام أكبر من قبل جامعة الوادي الجديد هي تنظيم أماكن العمل وستة سيجما. ع ا- عدم وجود فروق ذات دلالة إحصائية في درجة ممارسة القيادات الجامعية للإدارة الرشيقة تعزي لمتغير نوع الكلية والجنس والدرجة العلمية. ه ا - عدم وجود فروق ذات دلالة إحصائية في درجة فاعلية الأداء الوظيفي لاي القيادات الجامعية تعزي لمتغيري الجنس واللرجة العلمية ولكن توجد فروق ذات دلالة إحصائية تعزي الي متفير نوع الكلية لصالح الكليات النظرية.

التوصيـات : في ضوء ما توصلت اليه الدراسة من نتائج يمكن القول بأنه لن تتمكن أية جامعة من مواكبة مستجدات العصر والمتغيرات السريعة في عالم التقتية والمعلومات والعولمة ومن الأداء المتوازن وتحقيق أهداف النمو والتتافسية إلا بالتخلص من (الإدارة الثقيلة) ومشكلاتها البيروقراطية وعوائقها التنظيمية والإجرائية وغيرها مما تعانيه من ترهل 
وفساد، والتحول إلى مبادئ (الإدارة الرشيقة) بمفاهيمها الحديثة وأساليبها المتطورة وشفافيتها المطلة، ونظرتها الشمولية التي تمكن من استيعاب المتغيرات الجديدة والإسهام

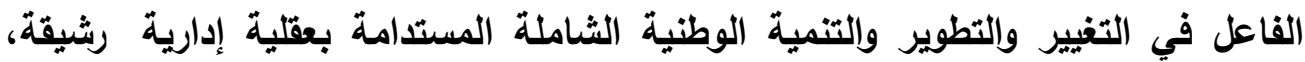
وفي ضوء ذلك توصي الاراسة الحالية بما يلي: ا. انشاء لجنة متخصصة على مستوي كل جامعة ترغب في تطبيق هذا الأسلوب الإداري الحديث مع تهيئتها لتطبيق هذه الفلسفة والاشراف على عملية تدريب العاملين على تنفيذ مبادئها وطرق إزالة الهـر بالعمليات المختلفة داخل الجامعة. r. التغيير الجذري لثقافة القيادات والعاملين بالجامعة وتوجيهها نحو ثقافة العامل الياباني التي تهتم ب(التسييز الايمقراطي للأمور-تشجيع روح المبادرة بين العاملين-العمل الجماعي-اعتماد مبدأ المغامرة في العمل والبعد عن الأساليب التقليدية الروتينية في الإدارة-محارية الروتين). r. اعتماد أساليب تقويم ومراجعة مستمرة لكافة العمليات التي تقوم بها الجامعة ويمختلف التهاتل المستويات بما يسهم في رفع مستوي فاعلية الأداء الوظيفي والتحسين المستمر للأداء.

ء. السماح بلرجة من الحكم الذاتي والاستقلالية والتمكين لاي العاملين بالجامعة على المستويين الإداري والأكاديمي وعدم التشكيك بقداتهم وكفاءاتهم مما يشجعهم على بناء ثقة متبادلة في العلاقات داخل الجامعة. ه. توفير نظام معلومات شامل وفعال ويسيط ومتاح لكافة العاملين بالجامعة وحثهم على تبادل ومشاركة المعلومات بما يخدم مصلحة العمل وعدم عرقلتها. 7. تعزيز العمل الجماعي وروح الفريق وتقديم الدعم والمساعدة من قبل القيادات الجامعية لتحقيق ذلك. V. تطوير إمكانيات العاملين بالجامعة من خلال إقامة برامج تدريبية متنوعة تمس كل المجالات والتخصصات ومنحهم فرص عادلة ومتعددة للحصول على التاريب اللازم. ^. وضع معايير قياسية للأداء واطلاع جميع العاملين عليها وذلك لكافة العمليات داخل الجامعة. 
9. إعادة النظر في اخلاقيات العمل داخل الجامعة مثل (المصداقية-الثقة-الوصول للعمل في الوقت المحدد- إنتاج المطلوب- التوقف عن الثكوى والتذمر - العمل ضمن الظروف الصعبة- تنفيذ العمل بجودة عالية...الخ)، ودعم الإدارات العليا لذلك بمنح الموظفين الذين يمتلكون أخلاقيات عمل عالية مناصب أعلى، ومسؤوليات أكبر. • 1 . تشجيع العاملين داخل الجامعة على التقييم الذاتي وإيجاد حلول إبداعية وفعالة للمشكلات ودعمهم ماديا ومعنويا.

11 ـ. العمل على نشر ثقافة تقليل الهار في الموارد بين العاملين بالجامعة. r ا. التوظيف بالجامعة علي أساس الحاجات الحقيقية كما ونوعا ويما يتناسب وطبيعة النشاط. r 1. . على كل جامعة ترغب في تطبيق مبادئ الإدارة الرشيقة الا تستعجل ظهور النتائج لان ذلك من أكبر معوقات تطبيق معايير الإدارة الرشيقة. ع ا. تضمين روية ورسالة وأهداف الجامعة تطوير القيادات الجامعية من خلال التدريب على أساليب إدارية وقيادية حديثة وناجحة مثل الإدارة الرشيقة. ه ا. ضرورة عقد مؤتمرات وندوات للتعريف بهذا الأسلوب الإداري الحديث ومحاكاة التجارب

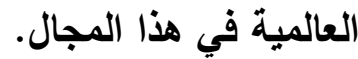
7 ا ـ تدريس ابعاد ومبادئ الإدارة الرشيقة ضمن المقررات الدراسية الخاصة بقسم الإدارة التريوية بكلية التربية وما يناظرها من الكليات الأخرى. IV المهارات الإدارية المختلفة للعاملين داخل الجامعة وخاصة القيادات بما يؤدي الي تحسين جودة العمل. 11. اجراء العديد من الاراسات التي تحدد مواصفات الخريج المطلوب بسوق العمل وريطها بالمقررات الاراسية داخل الجامعة. 19. اجراء مزيد من الاراسات المستقبلية التي تربط بين القيادة الرشيقة وغيرها من المتغيرات الأخرى مثل البيئة الإبداعية والميزة التنافسية للتعليم الجامعي. 


\section{المراجع}

أولاً: المراجع العربية:

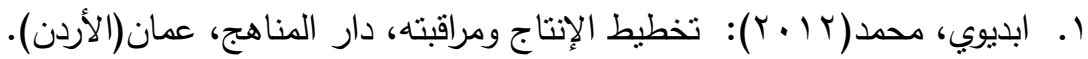

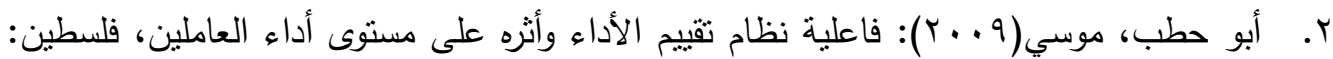

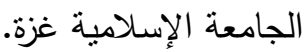

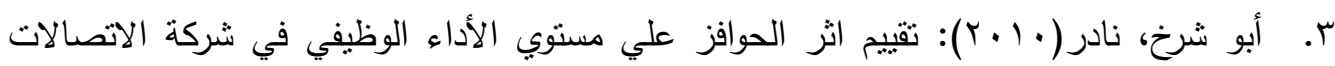
الفلسطينية من وجهة نظر العاملين، رسالة ماجستير غير منشورة، كلية الاقتصاد والعلوم الإدارية،

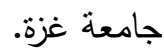

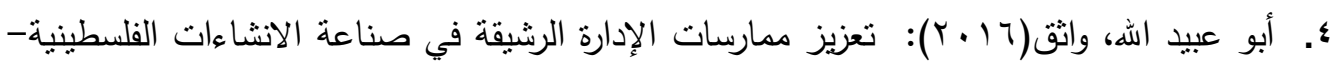

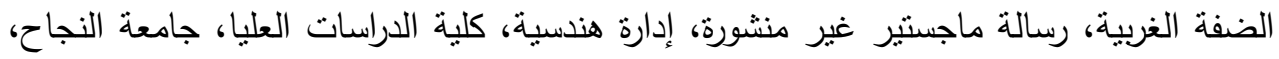
فلسطين. •. أبو معمر ، وصفيه(9 . . ץ): درجة ممارسة القيادات الإدارية بالجامعات الفلسطينية بمحافظات غزة لتقويض السلطة وسبل تفعيلها، رسالة ماجستير غير منشورة، كلية التربية، الجامعة الإسلامية، غزة.

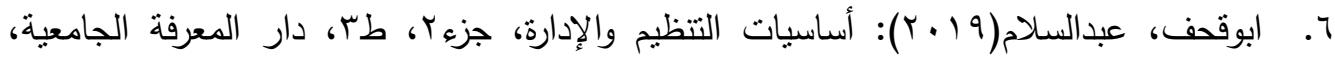

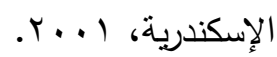
V. ال سعود، سعود(1 . . ץ): الإدارة العامة في المملكة العربية السعودية، مكتبة الملك فهر الوطنية،

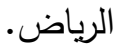

^. الاندونوسي، فريدة(9 (ب): المناخ التنظيمي وعلاقته بفاعلية الأداء الوظيفي لدي الموظفات

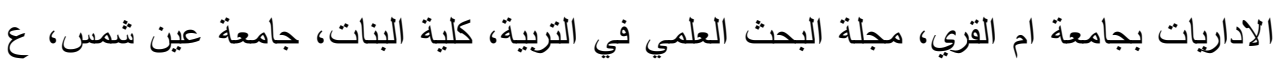

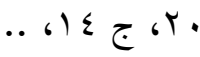
9. الاندونوسي، فريدة(9 (ب):المناخ التتظيمي وعلاقته بفاعلية الأداء الوظيفي لدي الموظفات

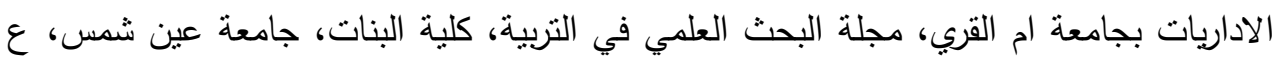

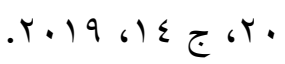

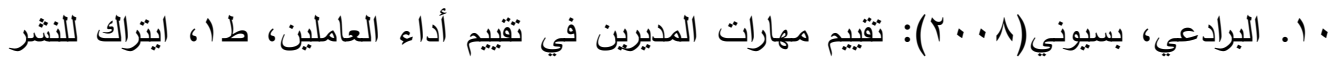
والتوزيع، مصر ·

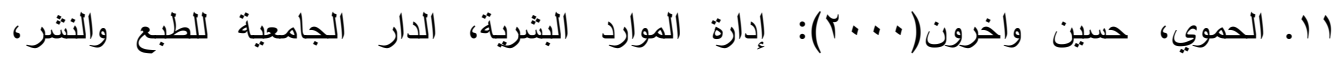
الإسكندرية. 


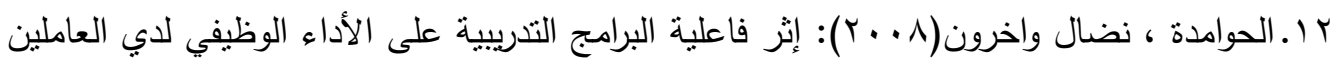

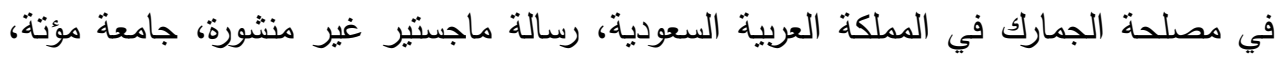

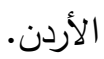

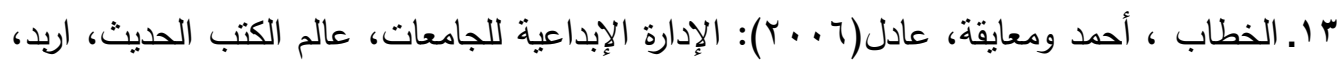

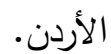

ـ ا. الاليمي،خالد(9 (ب)): محددات استخدام العاملين في المؤسسات الإعلامية الأردنية للتسويق

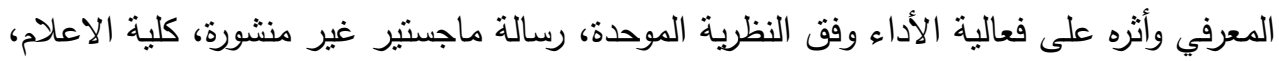

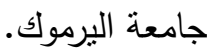

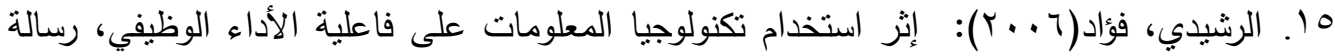
ماجستير غير منشورة، كلية التجارة، جامعة عين شمس،.

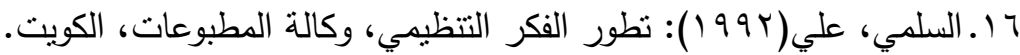

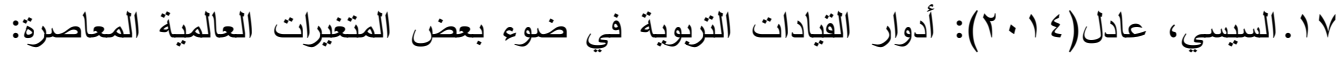

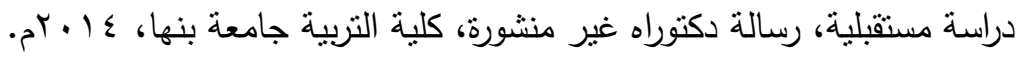

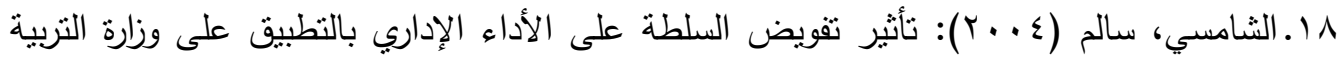
والتعليم بسلطنة عمان، رسالة ماجستير غير منشورة، أكاديمية السادات للعلوم الإدارية، القاهرة.

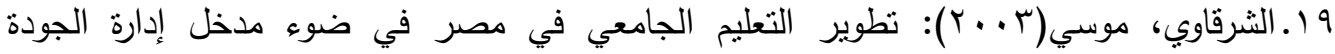
الثشاملة، مجلة كلية التربية بالإسماعيلية، العدد؟.

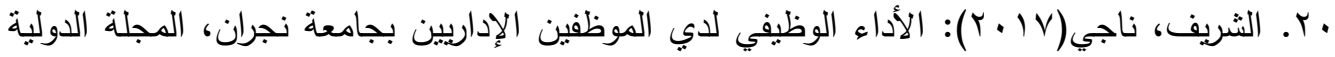
التربوية المتخصصة، مجلد 7، عددم.

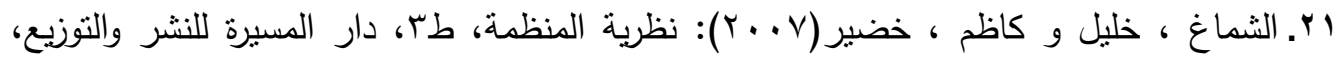
الأردن.

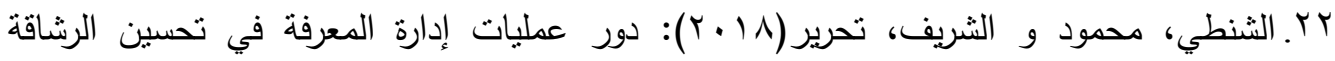

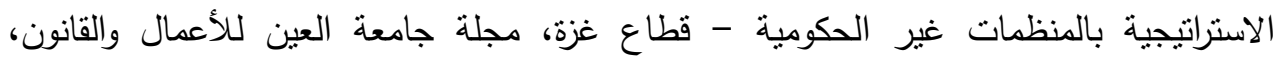

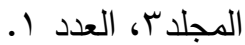

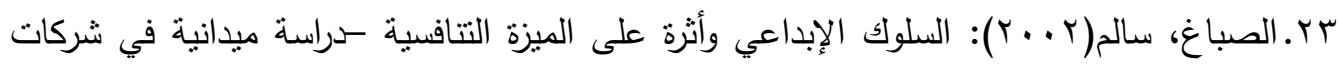
الصناعات الغذائية الأردنية، مجلة البصائر، الدجلد ا ال ، العدد .0.

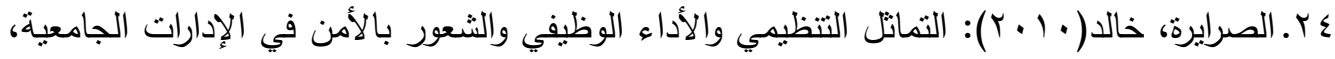
دار كنوز المعرفة العلمية للنشر والتوزيع، عمان، الأردن. 


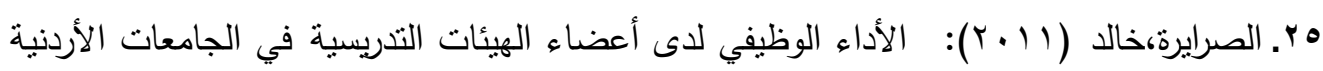

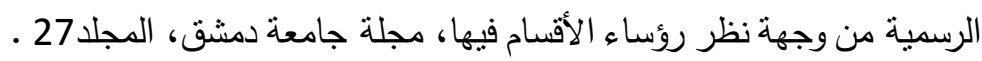

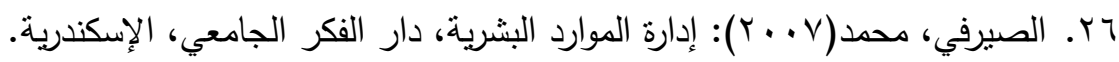

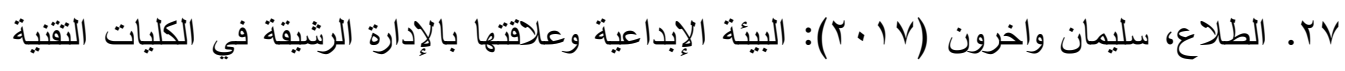

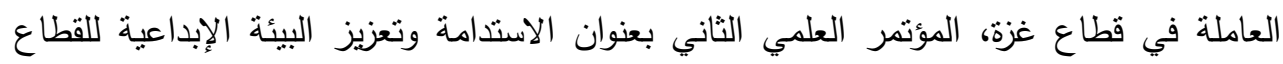

$$
\text { التقني، مرجع سابق. }
$$

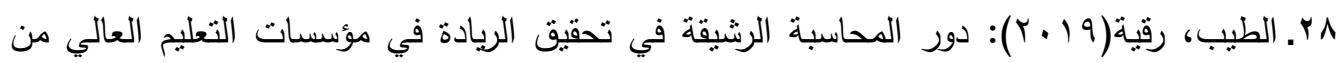

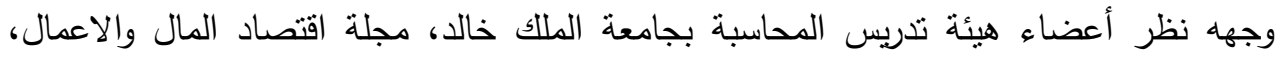

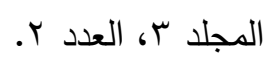

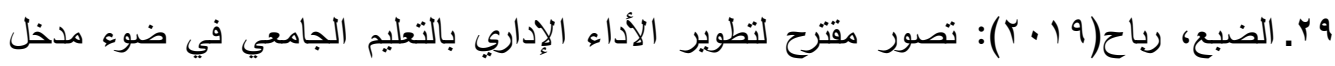

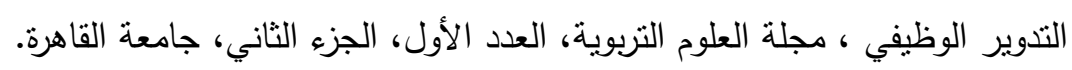

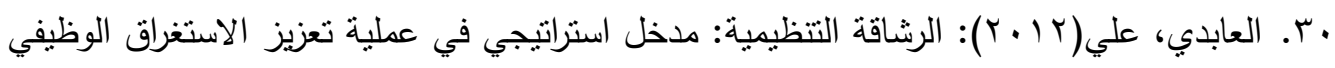
للعاملين: دراسة تجريبية لعينة من شركات القطاع الصناعي في وزارة الصناعة والمعادن، مجلة الصنائ

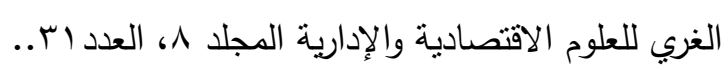

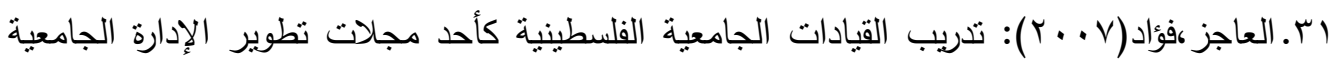

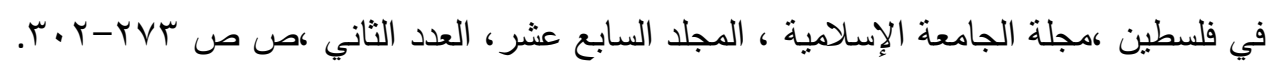

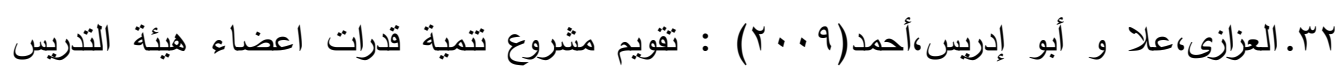

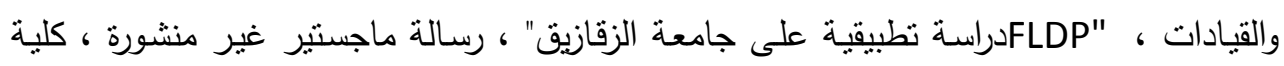
التجارة ،جامعة الزقازيق.

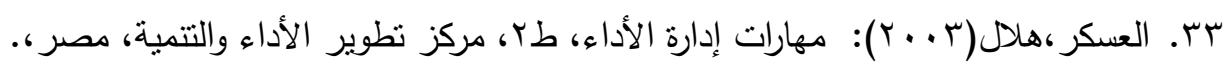

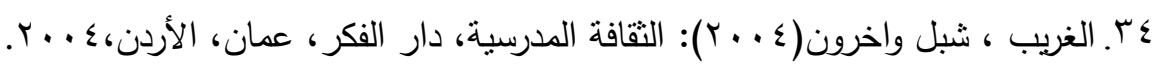

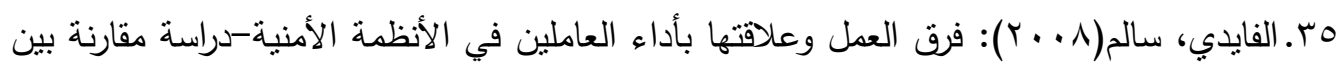

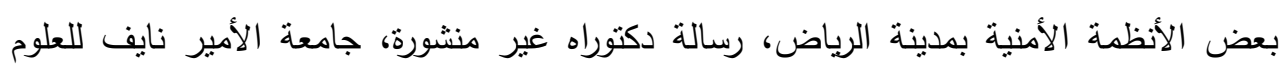
الامنية، المملكة العربية السعودية.

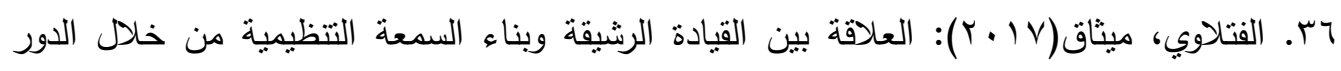

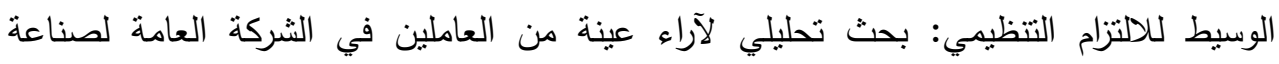

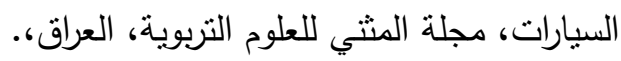




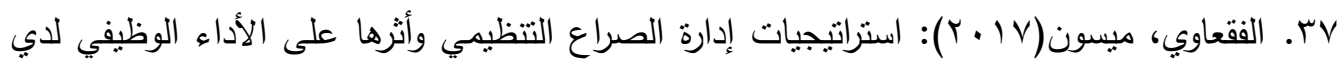
العاملين في المنظمات الاهلية الفلسطينية في قطاع غزة، رسالة ماجستير غير منشورة، كلية الئية الاقتصاد والعلوم الإدارية، جامعة الازهر، غزة.

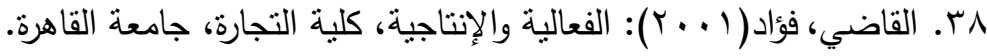

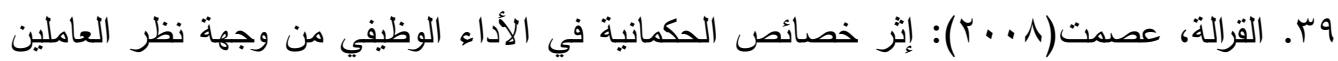
في وزارة الداخلية الأردنية، رسالة ماجستير غير منشورة، جامعة مؤته، الكرك، الأردن.

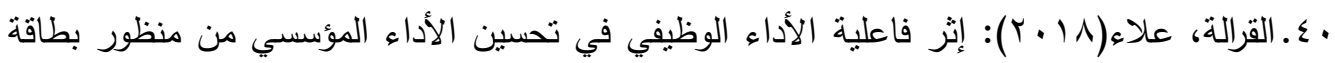

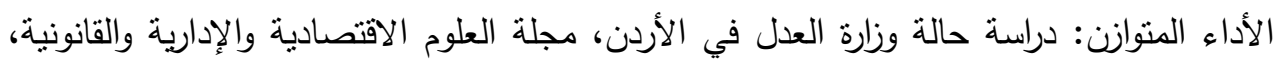

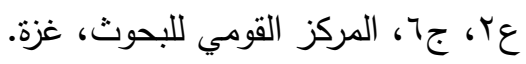

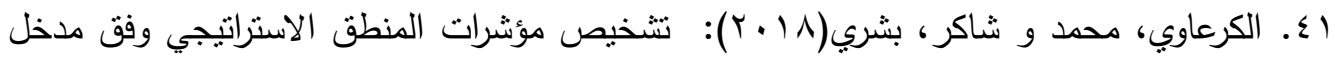

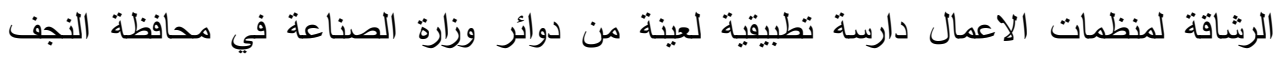
الاشرف، مجلة كلية الإدارة والاقتصاد للاراسات الاقتصادية والإدارية والمالية، المجلد • (، العدد؟.

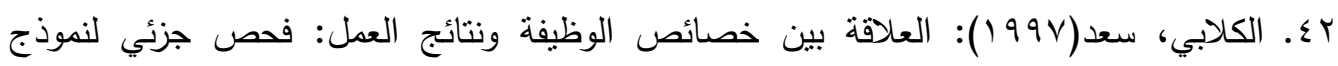

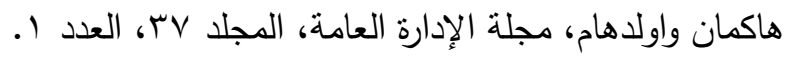
بـ ألمجم الوسيط، نسخة الكترونية https://www.almaany.com/appendix.php?language=arabic\&category=\%D8\%A7\%D9 \%84\%D9\%85\%D8\%B9\%D8\%AC\%D9\%85+\%D8\%A7\%D9\%84\%D9\%88\%D8\%B3\%D9\%8A \%D8\%B7\&lang name=\%D8\%B9\%D8\%B1\%D8\%A8\%D9\%8A

$$
\text { ؛ ؛ المنظمة العربية للعلوم الإدارية (جامعة الدول العربية)، }
$$

https://www.arado.org/Content.aspx?s2=1070

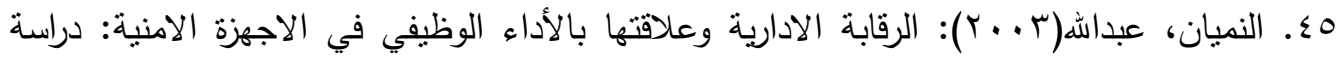

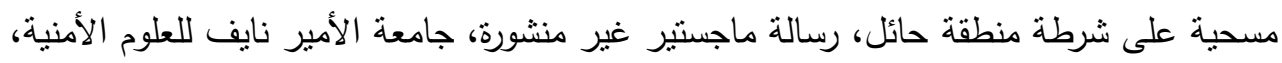

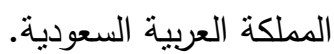

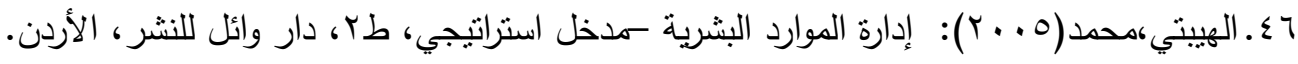

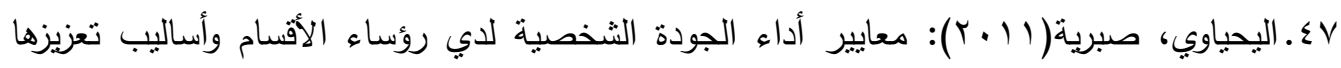

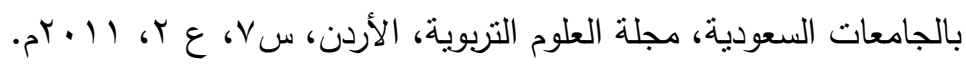

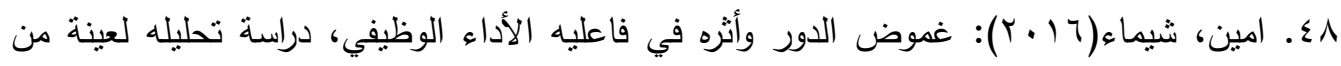

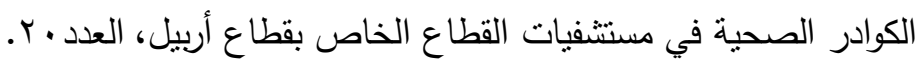




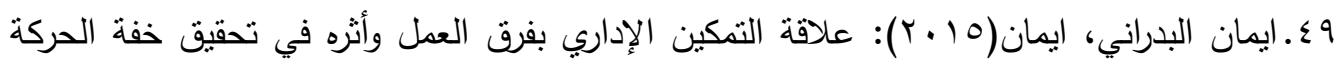
الاستراتيجية -دراسة ميدانية على عدد من مستشفيات محافظة أربيل، مجلة جامعة الانبار للعلوم

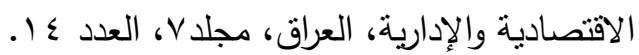

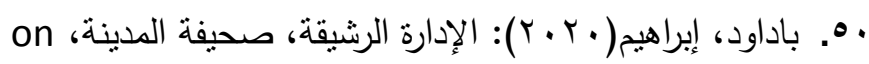
https://www.almadina.com/article/468394/\%D9\%83\%D8\%AA\%D8\%A7\%D8\%A8/\%D 8\%A7\%D9\%84\%D8\%A5\%D8\%AF\%D8\%A7\%D8\%B1\%D8\%A9\%D8\%A7\%D9\%84\%D8\%B1\%D8\%B4\%D9\%8A\%D9\%82\%D8\%A9 1.بدوي ، احمد و مصطفي، محمد(ع191)): معجم مصطلحات القوي العاملة، مؤسسة شباب الجامعة، الإسكندرية.

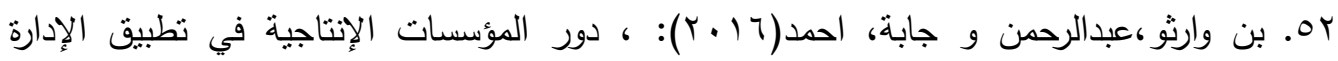
الرشيقة: دراسة ميدانية على المؤسسات الصيدلانية الجزائرية، جامعة جابي مختار عنابة، محلة

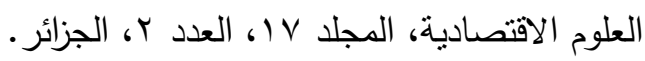

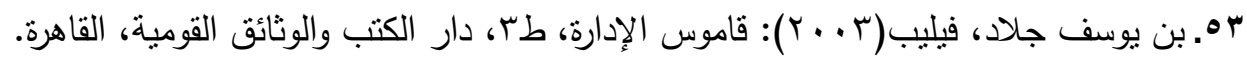

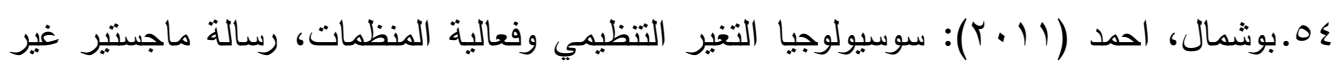
منشورة، جامعة قاصدي مرباح، الجزائر.

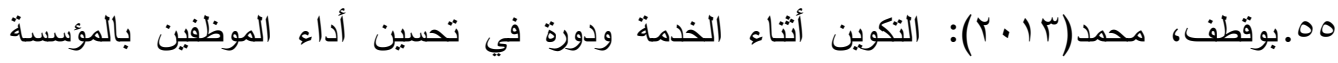
الجامعية، رسالة ماجستير غير منشورة، جامعة محمد خيضر بسكرة، الجزائر.

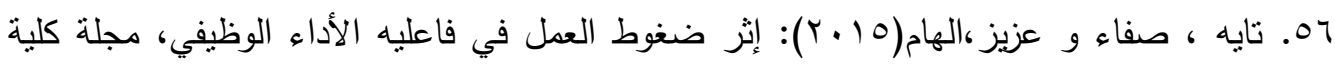
الدراسات الإنسانية الجامعة، العدد الرابع.

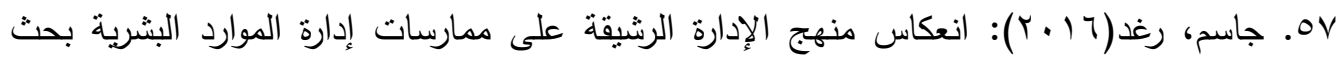

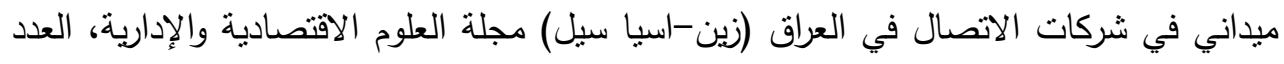

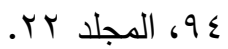
01. ه جبران، مسعود(Y (99 ) ): معجم الرائد، دار العلم للملايين، لبنان.

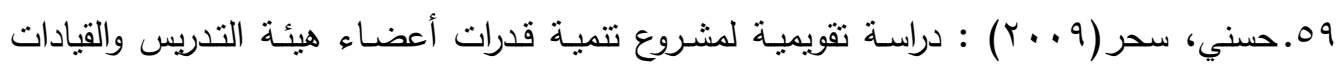
بالجامعات المصرية في ضوء بعض الخبرات العالمية" ، رسالة ماجستير غير منشورة، ، كلية كلية التربية ، جامعة بنها.

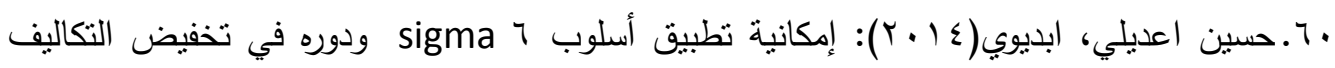
وتدعيم المقدرة التتافسية، جامعة الزرقاء، الأردن. 


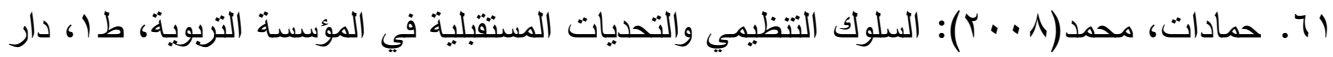

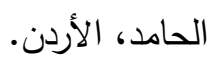

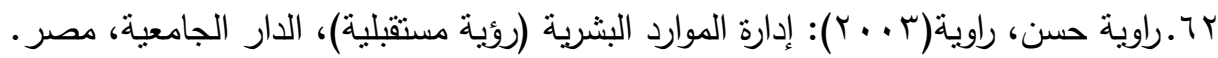

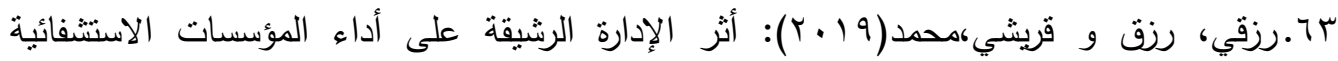
العمومية (دراسة حالة المؤسسة الاستثفائية المتخصصة في التوليد وأمراض النساء وطب الأبس الأطفال بسكرة) ، رسالة ماجستير غير منشورة، كلية العلوم الاقتصادية والتجارية وعلوم التيسير ، الجزائر .

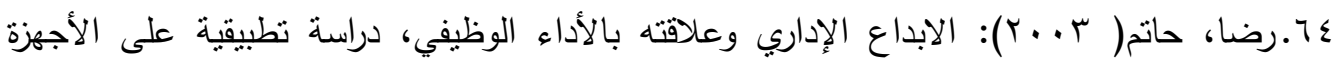
الأمنية بمطار الملك عبد العزيز بجدة، رسالة ماجستير غير منشورة، جامعة الأمير نايف للعلوم الأمنية، المملكة العربية السعودية.

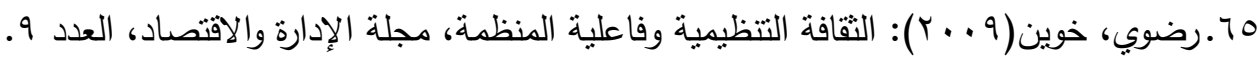

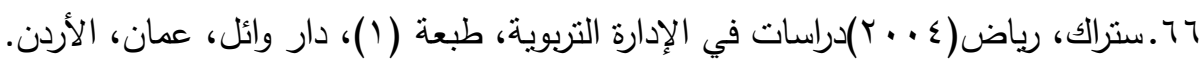

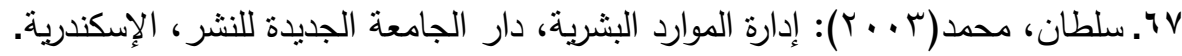

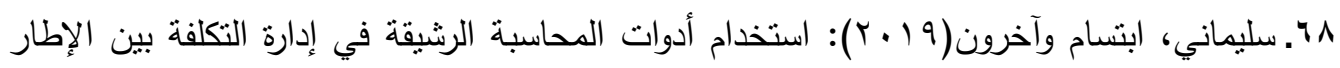

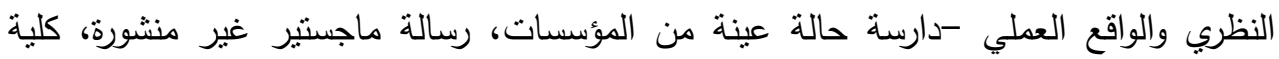
الاقتصاد والتجارة وإدارة الاعمال، جامعة الوادي، الجزائر.

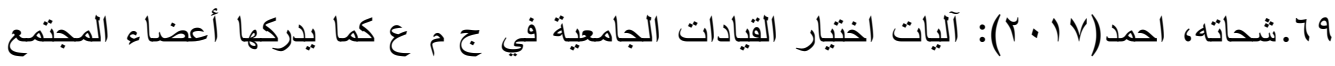
الجامعي في ضوء خبرات بعض المجتمعات الأخرى، رسالة ماجستير غير منشورة، معهد البحوث والدراسات العربية.

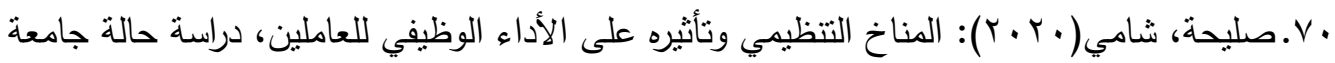

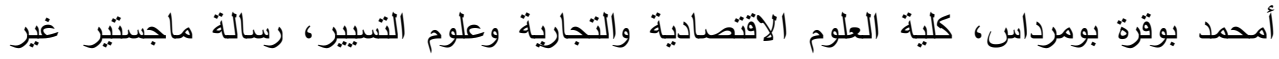

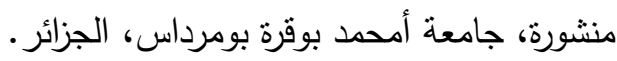

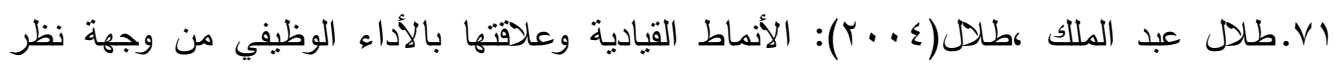
العاملين بإمارة مكة المكرمة، رسالة ماجستير غير منشورة، جامعة نايف العربية للعلوم الأمنية،

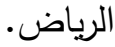

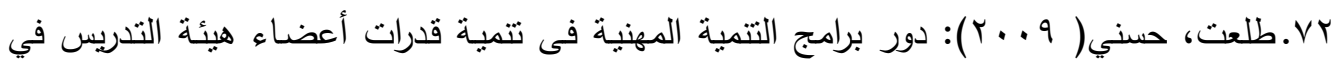

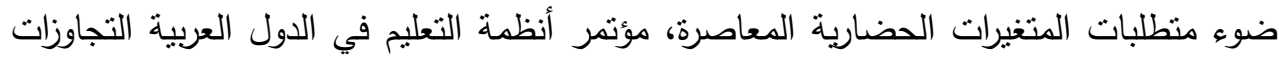
والامل، 0-7 مايو ، كلية التربية، جامعة الزقازيق. 


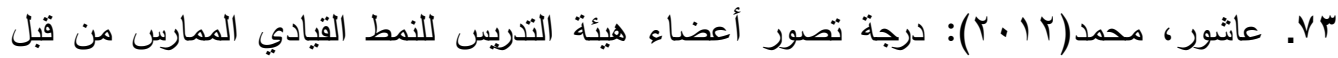

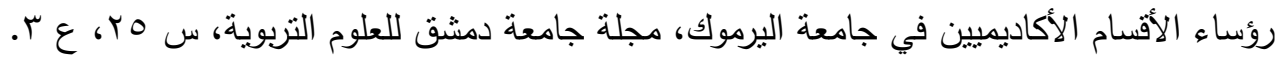
http://gss.mpa.edu.ps/article/1259/\%D8\%A7\%D9\%84\%D8\%A5\%D8\%AF\%D8\%A7\%D8 \%B1\%D8\%A9- \%D8\%A7\%D9\%84\%D8\%B1\%D8\%B4\%D9\%8A\%D9\%82\%D8\%A9

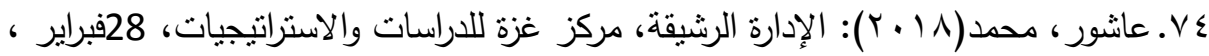

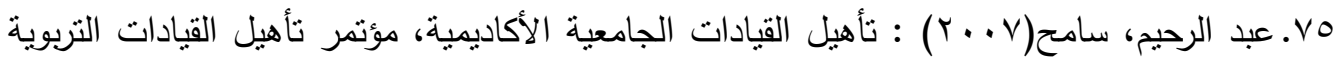

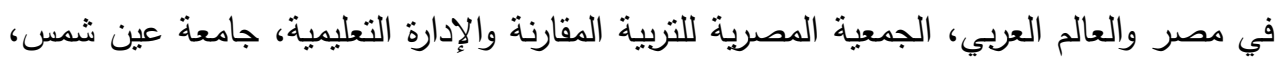

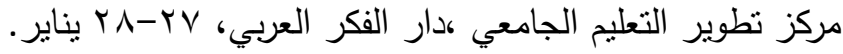

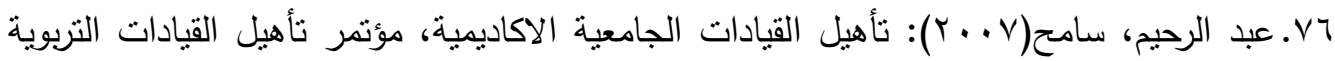

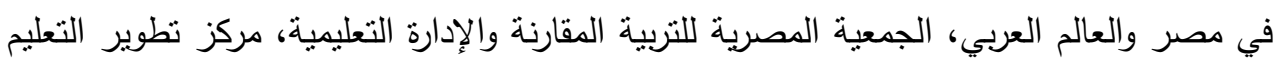

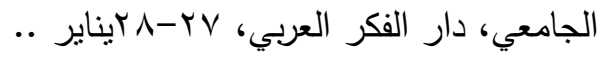

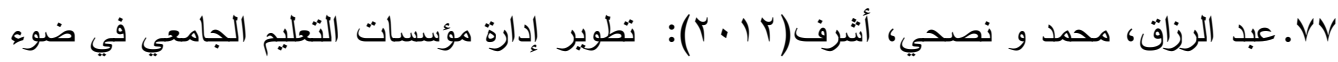
أسلوب حلقات الجودة، المؤتمر العربي الدولي الثاني لضمان الجودة، الجامعة الخليجية بالبحرين،

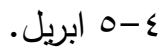

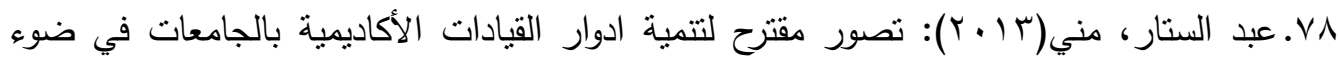
مدخل القيادة التحويلية، رسالة ماجستير غبر منشورة، كلبة التربية، جامعة بني سويف.

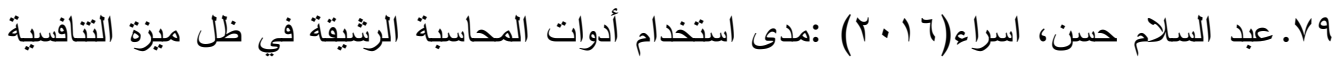
في ظل الجودة الثاملة، رسالة ماجستير غير منشورة، جامعة الازهر ، غزة، فلسطين.

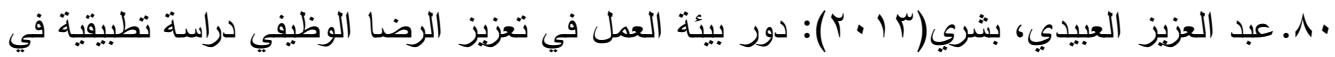

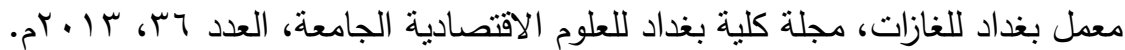

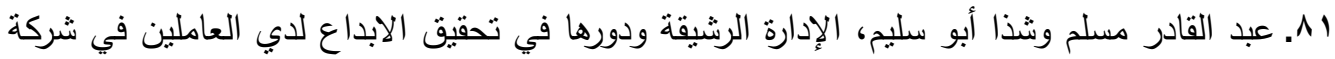
جوال بمحافظات غزة، المجلة الدولية للبحوث الاكاديمية، المجلد ج، العدد الأول.

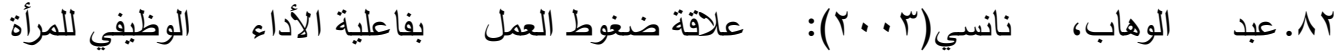
العاملة :دراسة تطبيقية على كليات جامعات القاهرة الكبرى"، رسالة ماجستير غير منشورة، بمكتبة كلية التجارة، جامعة عين شمس. r^. عبدالعال، عنتر (9 ( †): متطلبات تكنولوجيا المعلومات لتحقيق الرشاقة الاستراتيجية بالجامعات المصرية جامعة سوهاج نموذجا، المجلة التربوية بسوهاج، العدد التاسع والخمسون . 


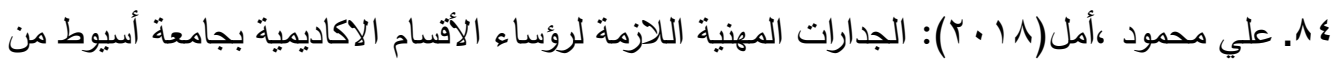
وجهه نظر أعضاء هيئة التدريس، المجلة التربوية بكلية التربية جامعة سوهاج، العدد

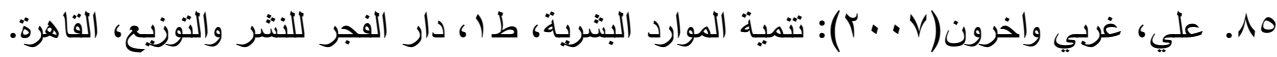

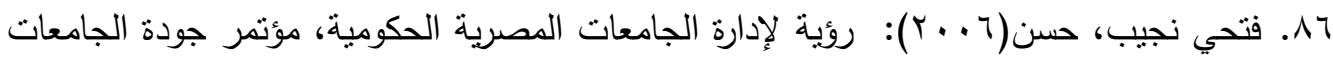
ومتطلبات الترخيص والاعتماد الجامعي، المنظمة العربية للتربية والثقافة والعلوم، الثارقة (الامارات

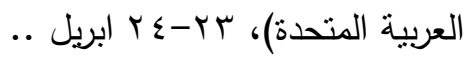
AV. فرانيس، ديف ومايك، رودكوك(990) (190): ترجمة عبد الرحمن أحمد هيجان، القيم التنظيمية، الإدارة العامة للبحوث، السعودية.

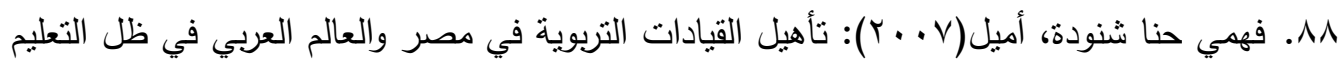

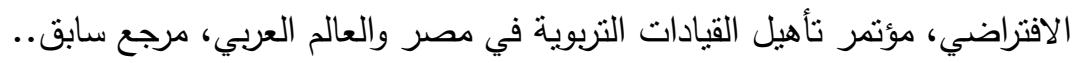

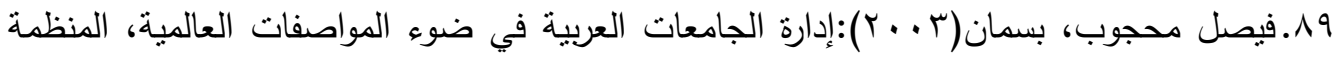
العربية للتربية والثقافة والعلوم، جامعة الدول العربية.

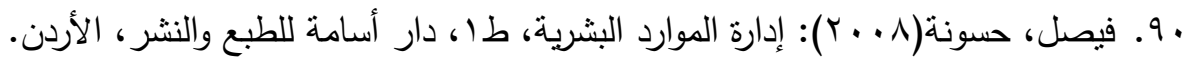

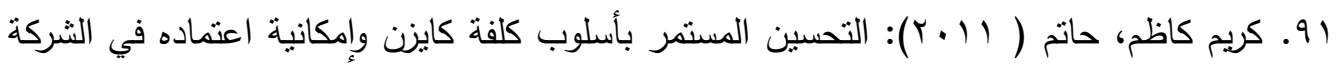
العامة لصناعة الإطارات في النجف، مجلة مركز دراسات الكوفة، العدد آ ب.

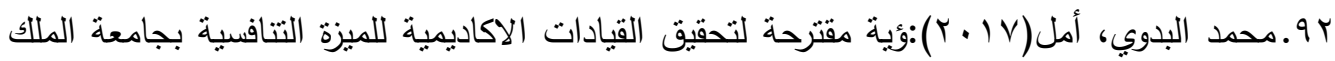

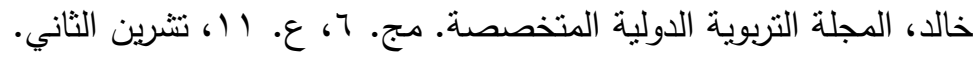

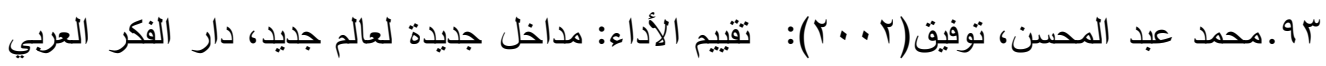
والنهضة العربية، بيروت.

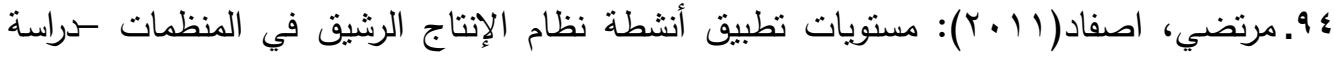

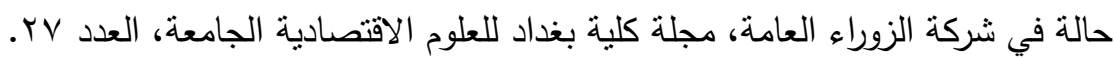

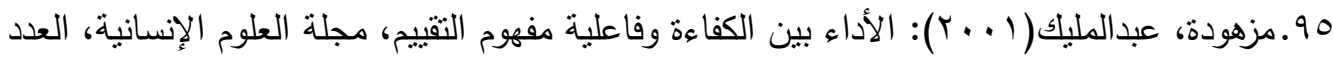
) 97 . 97

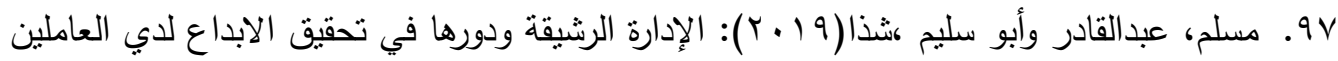

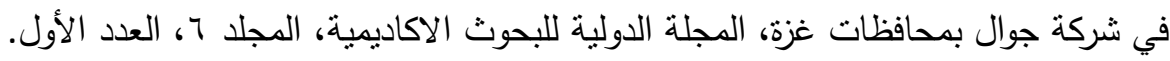
19. معجم المصطلحات الإدارية(V . . Y): المنظمة العربية للتمية الإدارية، القاهرة. 
9 9.مغاوري، هالة(7 (ب): الرشاقة التظظيمية مدخل لتحسين القدرة المؤسسية في التعليم الجامعي

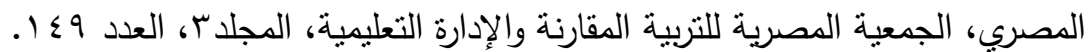

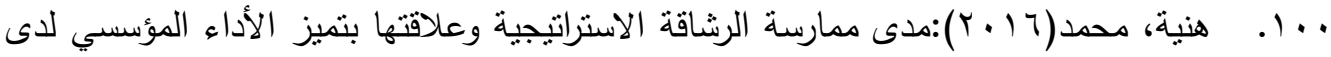
قطاع الصناعات الغذائية في قطاع غزة، رسالة ماجستير غير منشورة، كلية التجارة، الجامعة الإسلامية بغزة، فلسطين.

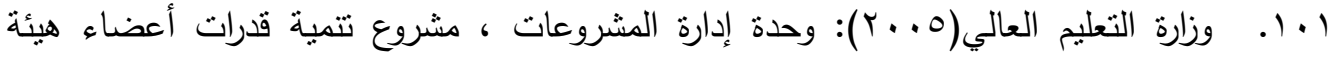

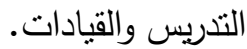

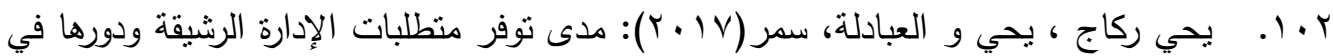
تتمية الموارد البشرية في وزارة التربية والتعليم العالي بغزة، المؤتمر العلمي الثاني بعنوان الاستدامـة وتعزيـز البيئـة الإبداعيـة للتعليـم التقني، كلية فلسطين التقنية، فلسطين.

\section{ثانياً : المراجع الأجنبية:}

103. Agrahari, R. S. , Dangle, P.A. \& Chandratre, K.V(2015): Implementation Of 5S Methodology In The Small Scale Industry: A Case Study, International Journal of Scientific \& Technology Research, Vol.(4), No.(4).

104. Anne-Caroline ,Golard(2015): Respect des personness et justice organisationnelle dans une organisation implémentant le Lean Management: le cas du CHU Dinant Godinne, UCL Namur, en vue de l'obtention du titre d'ingénieur de gestion, Louvain school of management, Université catholique de Louvain, Prom: de Nanteuil, Matthieu.

105. Audran, Arthur(2011): Strategic agility: a winning phenotype in turbulent environments (Unpublished Master Thesis), Politecnico, Di Milano, Italy.

106. Badurdeen et Gregory(2012): The softer side of Lean: analyzing corporate culture can point the way to necessary change: industrial engineer, Human Resource Management International Digest, vol.20, No 6.

107. Banuelas, R., and Antony, 1 (2002): Key ingredients for the effective implementation of Six Sigma program, Measuring Business Excellence, Vol.(6), No.(4).

108. Barac, Nada. Goran, Milovanovié Aleksandra, Andjelkovié(2010): Lean production and six sigma qualité in lean supply chain management. revue : economics and organisations. vol 7, $\mathrm{n}^{\circ} 3$.

109. Batman, Zeithamat(1994):Management, Function And strategy, Homewood, IL : rwin, 2nd ed. 
110. Beauvallet, Godefroy. Houy, Thomas(2009): adoption des pratiques de gestionlean: casdes entreprises industrielles francaises, revue francaise de gestion.

111. Becker, James C(2001): The Important of individual performance from the perspective of Gnome and ongoing atonal performance Effectiveness" small Group Research, Vol. 32.

112. Bell, Steve(2006): Lean Enterprise system Using IT for Continuous Improvement, John \& Sons Inc, New Jersey, USA.

113. Bouville, Gregor(2010): les effets de la lean production sur la santé au travail et l'absentéisme : les resultats d'une etude de cas rétrospéctive dans une entreprise de maintenance ferroviaire, actes du colloque organisation, gestion productive et santé au travail, association francaise de sosiologie, université de rouen. France - Rouen .

114. Business

Dictionary, on http://www.businessdictionary.com/definition/strategic -agility.html

115. Cardon et Bribiescas(2019): Respect for people: the forgotten principle in lean manufacturing implementation, European scientific journal, vol.11, No.13. En ligne. http://eujournal.org/index.php/esj/article/viewFile/5635/5461

116. Damrath, Felix(2015):Increasing competitiveness of service companies: developing conceptual models for implementing Lean Management in service companies, Thesis of Business Administration.

117. Dombrowski, U. \& Mielke, T(2013): Lean Leadership-Fundamental principles and their application, Procedia CIRP, Vol. 7.

118. Dove, $R(2001)$ : Response ability: The language, structure and culture of agile enterprise. USA: John Wiley and Sons.

119. Elmiliani, M(1998): Lean Behavior, Management Decision, 36 (9).

120. Encyclopedia Americana, on

https://ar.wikipedia.org/wiki/\%D8\%A7\%D9\%84\%D9\%85\%D9\%88\%D8\%B3 \%D9\%88\%D8\%B9\%D8\%A9 \%D8\%A7\%D9\%84\%D8\%A3\%D9\%85\%D8\%B1\% D9\%8A\%D9\%83\%D9\%8A\%D8\%A9

121. Erande, A., Verma, A(2008): Measuring Agility of Organization: A Comprehensive Agility Measurement Tool (CAMT). International Journal of Applied Management and Technology, 6(3).

122. Eshrat Karami and Sara Fanati Rashidi(2015): Measuring \& evaluating agility in supply CHAIN using fuzzy hierarchical analysis , Indian Journal of Fundamental and Applied Life Sciences, Vol.5 (S1).

123. Fleming, Christopher(2010):Faculty Expectation for college Presidents Jop Performance, The Journal of Higher Education, 81 (3). 
124. Glover, Wiljeana Jackson(2010): Critical Success Factors for Sustaining Kaizen Event Outcomes, Master thesis in Industrial and Systems Engineering, Virginia Polytechnic University.

125. Hallinger, Philip(2010): Using Faculty Evaluation to Improve Teaching Quality, Case study of Higher Education in Southwest Asia, Evaluation and Accountability, 22 (4).

126. Hormozi, A.S(2001):Agile Manufacturing: the next Logical Step Benchmarking an International Journal, 8(2).

127. Hueiju, Yu \& Fang, Wenchang(2009): Relative impacts from product quality, service quality, and experience quality on customer perceived value and intention to shop for the coffee shop market, Total Quality Management, 20(11).

128. James, Womak. Daniel, Jones (2009):système lean : penser l'entreprise au plus juste, pearson éducation, paris.

129. Khoshsima, Gh(2003): An Introduction into Organizational Agility, Tadbir Journal, No. 134.

130. Kinsey, S(2010): Quiet leadership: how to create positive change without the noise and negativity, journal of extension,vol. 48 ,No.5.

131. Krichbaum, Brian D(2008): Standardized Work: The Power of Consistency, White paper, Process Coaching Inc.

132. Kupfer, $J(2004)$ : when waiting is weightless: the virtue of patience. the journal of value inquiry, vol.41.

133. Larry, Ritzmam. et autres(2004): Management des operatios : principes et applications, 2eme edition, Person education. France - Paris .

134. Lean production, Free resources \&fresh perspectives, on https://www.leanproduction.com/

135. Ligungblom, Mia(2012): A Comparative Study Between Developmental Leadership and Lean Leadership - Similarities and Differences, Management and Production Engineering Review, 3 (4).

136. Liker.,(2012): Le modèle Toyota: 14 principes qui feront la réussite de votre entreprise, Paris: Pearson France.

137. Michalaska, J. , \& Szewieczek, D(2007): Study of 6s Concept and its Effect on Industry, , International Journal of Modern Engineering Research, Vol.( 24), No.( 2).

138. Mineo, $\mathrm{D}(2014)$ :The importance of trust in leadership research management review, 20 (1).

139. Narasimhan $\mathrm{R}(2006)$ : Disentangling learners and agility: an empirical investigation. Journal of Operations Management, 24(5).

140. Niccole ,Curatolo(2014): Proposition d'une méthode Lean pour l'amélioration des processus métiers: application au processus de prise 
en charge médicamenteuse à l'hôpital, thèse pour obtenir le grade de docteur, Spécialité 'Génie Industriel', Ecole nationale supérieure d'arts et métiers - ENSAM.

141. Nicholas, John(2010): Lean Production for Competitive Advantage: A Comprehensive Guide to Lean Methodologies and Management Practices, Taylor and Francis Group, productivity press.

142. Nicoulas, Houy. Thomas, Houy(2009): outils reporting structurés et pratiques d'amélioration, revue francaise de gestion, $\mathrm{n}^{\circ} 196$.

143. Nylund , Jaakko(2013): Improving Processes Through Lean Management, Thesis of Business Administration, Helsinki Metropolia.

144. Nylund, Jaakko., Improving Processes Through Lean -Management, Thesis of Business Administration, Helsinki Metropolia,2013,p.7.

145. Nylund, Jaakko(2013): Improving Processes Through Lean Management, Thesis of Business Administration, Helsinki Metropolia.

146. Ojha, $\mathrm{D}(2008)$ : Impact of Strategic agility on competitive capabilities and financial performance, unpublished $\mathrm{PhD}$ Thesis). Clemson University, USA.

147. Olivier, Fontanill. Eric, Chassende-Baroz. Carles, De Cheffontaines. Olivier, F Rémy(2010): Pratique de lean: reduire les pertes en conception production et industrialisation. Dunod. France- paris.

148. Philippe, Arnaud. Jean, Renaud (2009): guide de la gestion industrielle: principles, méthodes et outils, afnor. France - la plaine saint denis. 19. www.maqalaty.com

149. Puvanasvaran, A., Megat, M., Tang, S. Muhamad, M., \& Homouda, A(2012): Lean, behavior in implementing lean process management. Journal of Applied Sciences Research, 5(8).

150. Robert E. Morgan, Kelly Page(2008 August,): Managing business transformation to deliver strategic agility, Volume 17, Issue 5-6 .

151. Shaikh \& Khalifeh(2014): Impact of Lean Thinking and Practices on Architectural/System Architectures Level Innovation in Swedish Manufacturing Industry, Engineering, thesis.

152. Sherehiy, B(2008): Relationship between agility strategy work organization and workforce agility. Unpublished Doctor Thesis, University of Louisville, USA.

153. Siljanen, Mikael(2010): An Employee Perspective to Performance Measurement and Management: A Public Sector Case Study, Lappeenranta University of Technology, Russia.

154. Slack, Nigel, Chambers, Stuart, \&Johnston, Robert(2004): Operations Management, 4PthP ed, Prentice - Hall. 
155. Sparrow, Paul \&Otaye, Lilian(2014): Lean management and HR function capability: the role of HR architecture and the location of intellectual capital, The International Journal of Human Resource Management, Vol. (25), No. (21).

156. Toyota, 75 years of history through data, automotive business, Production Engineering, Logistics and Purchasing, Toyota Production System, En ligne,

http://www.toyotaglobal.com/company/history_of_toyota/75years/data/ automotive_business/production/system/index.html, consulté le 20 février 2019.

157. Vera, D. \& Rodriguez-Lopez, A(2004): Strategic Virtues: Humility as a source of competitive advantage organizational dynamics, 33(4).

158. Yu, M, Hamis \& M. Ijad(2009): The Balanced Scored board for Measuring Academic Staff Performance Excellence. Higher Education, 57. 